\title{
Cell-penetrating peptide-enhanced delivery of heat shock proteins in models of neurodegeneration
}

\author{
Dissertation \\ zur Erlangung des Doktorgrades \\ der Mathematischen-Naturwissenschaftlichen Fakultäten \\ der Georg-August-Universität Göttingen
}

vorgelegt von

Florian Nagel

aus Schwerin

Göttingen 2008 
D7

Referent: Prof. Dr. Rüdiger Hardeland

Korreferent: Prof. Dr. Ralf Heinrich

Tag der mündlichen Prüfung: 30.04.2008 
Dedicated to my Parents 


\section{CONTENTS}

ABBREVIATIONS

$1 \quad$ INTRODUCTION 3

1.1 Apoptosis is a double-edged sword: the decision for life or death 3

1.2 Parkinson's disease (PD) - a concomitant phenomenon of an ageing society 6

1.2.1 PD Pathology: The progressive loss of dopaminergic neurons and a-synuclein "toxicity" 6

1.2.2 Etiology of PD: Where does it come from?

$\begin{array}{lll}1.3 & \text { Model systems to explore various aspects of PD } & 8\end{array}$

1.3.1 MPTP provides one model for PD 9

1.3.2 6-OHDA causes degeneration of the nigrostriatal system 10

$1.4 \quad$ "Established" and novel therapies for PD 11

1.4.1 Current therapeutic strategies 11

1.4.2 Neuroprotective gene therapy - achievements and perspectives 12

$\begin{array}{lll}1.5 & \text { The Trojan horse approach - a therapeutic strategy } & 14\end{array}$

1.5.1 The HIV-transactivator of transcription 15

1.5.2 The Tat uptake mechanism: How to cross biological membranes? 16

1.6 Heat shock proteins (Hsps): endogenous modulators of apoptotic cell death 19

1.6.1 The heat shock protein 70 (Hsp70) - the best studied stress response protein 20

1.6.2 Tat-mediated Hsp70 delivery in models of neurodegeneration 21

$\begin{array}{lll}1.7 & \text { Objectives } & 22\end{array}$

2 MATERIALS AND METHODS 23

$2.1 \quad$ Cloning and expression of the Tat-Hsp70 construct 23

2.2 Purification of Tat fusion proteins $\quad 23$

2.2.1 Improved purification protocol for recombinant Tat-Hsp70 24

$\begin{array}{lll}2.3 & \text { Cell culture models } & 27\end{array}$

2.3.1 SH-SY5Y human neuroblastoma cells 28

$\begin{array}{ll}\text { 2.3.2 Rat nigrostriatal CSM14.1 cells } & 29\end{array}$

$\begin{array}{lll}2.3 .3 & \text { Rat primary dopaminergic midbrain neurons } & 29\end{array}$

2.4 Cell transduction by Tat-Hsp70 in vitro 30

2.4.1 Western blot analysis $\quad 30$

2.4.2 Immunocytochemistry 31

$\begin{array}{ll}2.4 .3 & \text { Live Imaging in vitro } \\ & 31\end{array}$

$\begin{array}{lll}2.5 & \text { Fluorescence-based folding assay } & 32\end{array}$

$\begin{array}{lll}2.6 & \text { In vitro cell death assays } & \mathbf{3 4}\end{array}$

2.6.1 Application of Tat-Hsp70 and 6-OHDA cell death induction in SH-SY5Y cells 34 
2.6.2 Primary dopaminergic midbrain neurons and $\mathrm{MPP}^{+}$toxicity

2.7 Immunohistochemistry to demonstrate delivery of recombinant protein across the blood-brain barrier into the midbrain and retina

$2.8 \quad$ MPTP and Tat-Hsp70 treatment of mice 36

2.8.1 Mouse treatment and TH-immunostaining 36

$\begin{array}{llr}2.8 .2 & \text { Neurochemical analysis } & 37\end{array}$

$\begin{array}{lll}2.8 .3 & \text { MPTP metabolism } & 38\end{array}$

$\begin{array}{lll}2.8 .4 & \text { Nissl-staining } & 38\end{array}$

$\begin{array}{ll}2.8 .5 & 39 \\ 2.8 .6 & \text { Stereology }\end{array}$

2.8.6 The retina as a model for the death of dopaminergic neurons 39

2.9 Chemicals, media, buffers, solutions and antibodies 40

$\begin{array}{lll}2.9 .1 & \text { List of chemicals } & 40\end{array}$

\begin{tabular}{ll}
2.9 .2 & List of media \\
\hline
\end{tabular}

$\begin{array}{ll}\text { 2.9.3 List of buffer and solutions } & 41\end{array}$

$\begin{array}{lll}2.9 .4 & \text { Table of antibodies } & 43\end{array}$

$\begin{array}{llr}2.10 & \text { Statistics } & 44\end{array}$

$\begin{array}{lll}3 & \text { RESULTS } & 45\end{array}$

3.1 Efficient transduction of SH-SY5Y cells with Tat-Hsp70 45

3.2 Tat-Hsp70 isolated under native conditions displays the highest intracellular chaperone activity

3.3 Native purified Tat-Hsp70 is protective against different toxic stimuli 55

3.3.1 Only native isolated Tat-Hsp70 protects SH-SY5Y cells against 6-OHDA induced cell death in vitro

3.3.2 Tat-Hsp70 protects dopaminergic midbrain neurons against $\mathrm{MPP}^{+}$toxicity

3.4 Systemically applied Tat-Hsp70 co-localizes with dopaminergic neurons in the substantia nigra pars compacta and with TH-positive amacrine cells in the mouse retina

3.5 Tat-Hsp70 protects dopaminergic neurons in the SNpc against systemic application of MPTP

3.6 Intraperitoneal and intraocular injections of MPTP or 6-OHDA fail to cause degeneration of dopaminergic amacrine interneurons in the mouse retina

4 DISCUSSION

4.1 The molecular mechanism behind the CPP-mediated cargo uptake

4.2 Transduction efficiency and functionality of Tat fusion proteins is influenced by the purification procedure 
4.3 Tat-Hsp70 protects dopaminergic neurons in vitro and in vivo

4.4 Dopaminergic amacrine interneurons in the mouse retina are resistant against parkinsonian toxins

4.5 Future CPP application - a combination of efficiency and specificity

5 SUMMARY

6 ACKNOWLEDGEMENTS

7 REFERENCES

8 PUBLICATIONS

9 CURRICULUM VITAE 


\section{ABBREVIATIONS}

AAV

AD

AIF

ATP

Bax

BBB

$\mathrm{Bcl}-\mathrm{X}_{\mathrm{L}}$

Bcl-2

BSA

CDNA

cdYFP

CMF

CPPs

DIV

DOPAC

DA

DAB

DAPI

ECFP

FCS

FITC

GDNF

$\mathrm{H}_{2} \mathrm{O}_{2}$

$\mathrm{HA}$

HEPES

HIV

Hsp70

HPLC

HVA

$\operatorname{lgG}-H R P$

i.o.

i.p.
Adeno-associated virus

Alzheimer's disease

Apoptosis inducing factor

Adenosine triphosphate

Bcl-2-associated $X$ protein

Blood-brain barrier

long isoform of $\mathrm{B}$-cell lymphoma $\mathrm{x}$ protein

B-cell lymphoma 2 protein

Bovine serum albumin

Copy DNA

Chaperone-dependent yellow fluorescent protein

Calcium-magnesium-free

Cell penetrating peptides

Days in vitro

3,4-Dihydroxyphenylacetic acid

Dopaminergic

3,3'-Diaminobenzidine

4',6-Diamidino-2-phenylindole

Enhanced cyan fluorescent protein

Fetal calf serum

Fluorescein-5-isothiocyanate

Glial cell line-derived neurotrophic factor

Hydrogen peroxide

Hemagglutinin

4-2-Hydroxyethyl-1-piperazineethanesulfonic acid

Human immunodeficiency virus

Heat shock protein 70

High performance liquid chromatography

Homovanillic acid

Immune globulin horseradish peroxidase

Intraocular

Intraperitoneal 


\begin{tabular}{|c|c|}
\hline JNK & C-jun-N-terminal kinases \\
\hline NGS & Normal goat serum \\
\hline MAO-B & Monoamine oxidase-B \\
\hline $\mathrm{MPP}^{+}$ & 1-Methyl-4-phenylpyridinium \\
\hline MPTP & 1-Methyl-4-phenyl-1,2,3,6-tetrahydropyridine \\
\hline $\mathrm{NaHCO}_{3}$ & Sodium hydrogen carbonate \\
\hline NTA & Nitrilotriacetic-acid \\
\hline PAA & Polyacrylamide \\
\hline PBS & Phosphate-buffered saline \\
\hline PD & Parkinson's disease \\
\hline PDF & Probability density function \\
\hline RVG & Rabies virus glycoprotein \\
\hline SDS & Sodium dodecyl sulfate \\
\hline siRNA & Small interfering RNA \\
\hline SN & Substantia nigra \\
\hline $\mathrm{SNpc}$ & Substantia nigra pars compacta \\
\hline Tat & Trans-activator of transcription \\
\hline TED & Tris-carboxymethyl-ethylene-diamine \\
\hline $\mathrm{TH}$ & Tyrosine hydroxylase \\
\hline TNF & Tumor necrosis factor \\
\hline WST-1 & Water-soluble tetrazolium salt-1 \\
\hline XIAP & X-chromosome-linked inhibitor of apoptosis protein \\
\hline $6-O H D A$ & 6-Hydroxydopamine hydrochloride \\
\hline 3 & 3 Prime \\
\hline $5^{\prime}$ & 5 Prime \\
\hline$\mu$ & Mean \\
\hline$\sigma$ & Standard deviation \\
\hline
\end{tabular}




\section{INTRODUCTION}

\subsection{Apoptosis is a double-edged sword: the decision for life or death}

The term "apoptosis" is derived from the Greek expression for "falling off" and describes an evolutionarily conserved form of cell death, first described by Kerr and colleagues (Kerr et al., 1972). Morphologically, apoptosis can be characterized by condensation and fragmentation of chromatin, compaction of cytoplasmic organelles, a decrease in cell volume and alterations in the plasma membrane, resulting in phagocytosis of apoptotic cells (Schulz, 2006). In contrast to necrosis, which is mediated by external factors and in which cells lyse either after irreversible injury or secondary local inflammatory responses of the tissue, apoptosis occurs without provoking an inflammatory reaction and damage of surrounding tissue (Kerr et al., 1972).

Apoptosis can be triggered either from the intrinsic pathway, or from the extrinsic pathway, depending on the cell type and the external apoptotic stimuli (Chen and Wang, 2002). The extrinsic pathway is mediated by binding of surface membrane receptors to "death activators" such as Fas-ligand and tumor necrosis factor (TNF) (Figure 1). These trigger signaling cascades with downstream activation of autocatalytic cleavage of caspases. Initiator caspases such as caspase-8 trigger the activation of downstream effector caspases such as caspase 3 (Scaffidi et al., 1998; Petak and Houghton, 2001). The intrinsic apoptosis pathway is a mitochondriainvolving signaling and can be induced by DNA damage, heat shock, oxidative stress and high $\mathrm{Ca}^{2+}$ concentrations (Kaufmann and Earnshaw, 2000) and trigger the activation of a variety of pro-apoptotic molecules. Upon receiving the stress signal, the pro-apoptotic members of the Bcl-2-protein family, such as Bcl-2 homologous antagonist (Bak), Bcl-2-associated X protein (Bax) and BH3-only proteins (e.g., Bid) translocate to the outer mitochondrial membrane, where they induce pore formation (Hague and Paraskeva, 2004), releasing cytochrome $\mathrm{c}$ into the cytoplasm (Figure 1). Enhanced mitochondrial permeabilization-mediated cytochrome $c$ release is also triggered by permeability transition pore complex formation (Green and Kroemer, 2004). Central to mitochondria-based apoptosis is the assembly of the apoptosome. This occurs when in presence of ATP, procaspase-9 oligomerizes with released 
cytocrome $\mathrm{c}$ and the adaptor molecule apoptotic protease-activating factor 1 (Apaf1), causing the activation of initiator caspase-9 (Budihardjo et al., 1999; Chen and Wang, 2002; Yenari et al., 2005). Activated Caspase-9 then leads to activation of various effector caspases including caspase-3 (Yenari et al., 2005). However, the extrinsic and intrinsic apoptotic pathways are not mutually exclusive; rather, there is cross-talk between the two. For instance, Bid, a pro-apoptotic member of the Bcl-2 family, can be cleaved by caspase- 8 . The truncated Bid translocates to mitochondria and leads to the release of cytochrome $\mathrm{c}$ into the cytosol and triggers caspase activation (Petak and Houghton, 2001; Weishaupt et al., 2003; MacFarlane and Williams, 2004). Besides cell death executed by caspases, recent evidence indicates that apoptosis can also occur in complete absence of caspase activation (Lorenzo and Susin, 2007). Models for caspase-independent apoptosis consider apoptosisinducing factor (AIF) as a mitochondrial effector of apoptotic cell death (Susin et al., 1999).

Apoptosis is essential for successful embryonic development and maintains normal cellular homeostasis in adult organisms. It allows a cell to self-degrade to eliminate unwanted or dysfunctional cells of the body. For example, apoptosis acts as a homoeostatic mechanism for controlling cell populations and protects the organism against genotoxic or virally infected cells (Shub, 1994). Local apoptosis plays a role in embryonic development, such as the formation of interdigital clefts and involution of phylogenetic vestiges (Kerr et al., 1972). However, perturbation of cellular homeostasis can be a primary pathological event resulting in disease. On the one hand, insufficient apoptosis is known to be associated with the development of various types of cancer and autoimmunity (Soubrane et al., 2000; MacFarlane and Williams, 2004). On the other hand, neurodegenerative diseases such as spinocerebral ataxias, Huntington's chorea and Alzheimer's disease (AD) are characterized by excessive apoptosis. For Parkinson's disease (PD), molecular apoptotic markers were detected in brain tissue of PD patients (Hartmann et al., 2000,2001 ) and in animal paradigms of PD (Tatton and Kish 1997; Eberhardt et al., 2000), suggesting a major role of apoptosis. 


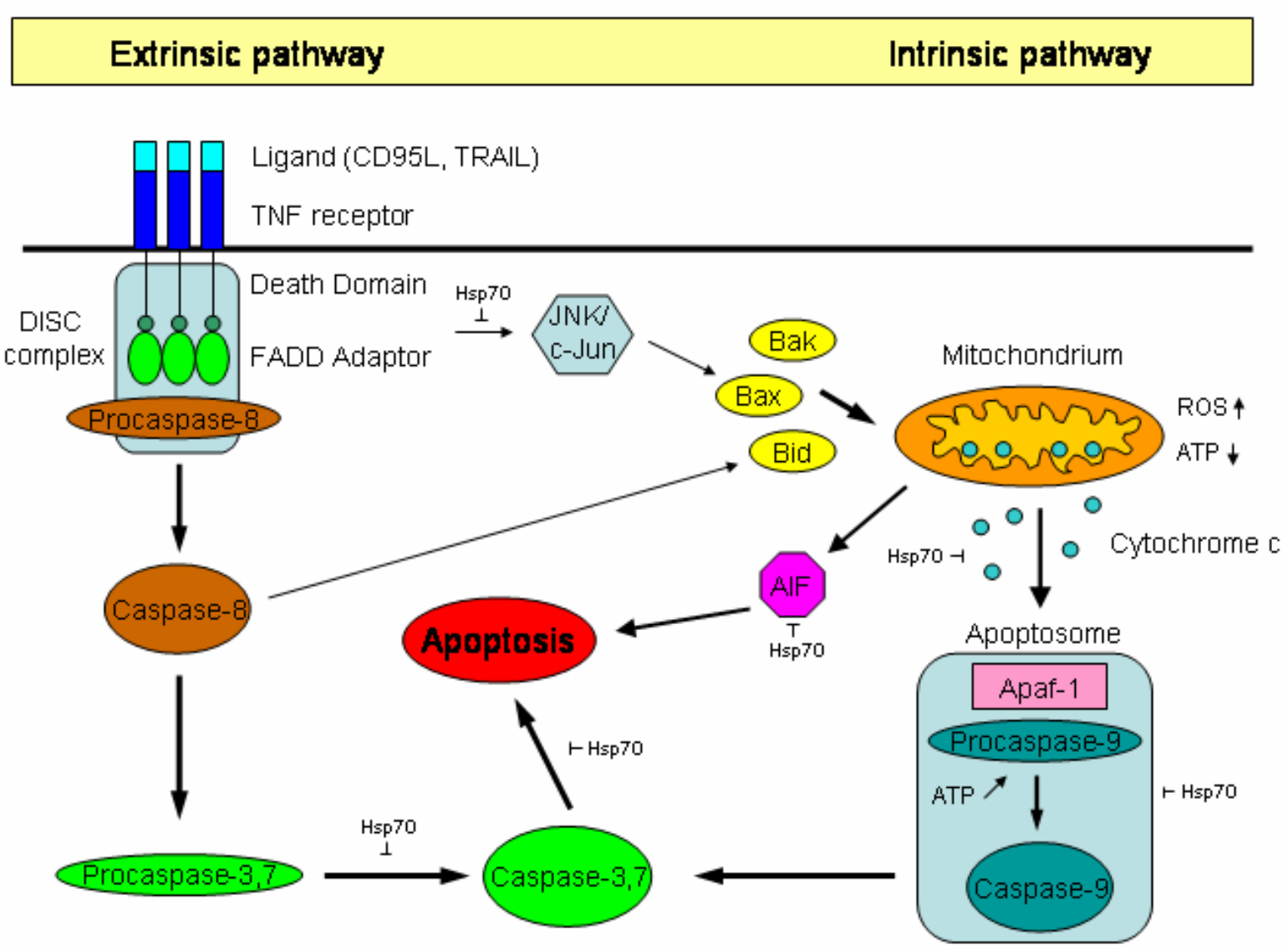

Figure 1. An illustration of the major apoptotic pathways, namely via death receptor activation (extrinsic) and by stress induced stimuli (intrinsic).

Cell surface death receptors of the tumour necrosis factor (TNF) receptor family triggered by CD95 and TNF-related apoptosis-inducing ligand (TRAIL), results in rapid activation of the initiator caspase 8 after procaspase-8 recruitment to a trimerized receptor-ligand complex (DISC) through the adaptor molecule Fas-associated death domain protein (FADD). The intrinsic pathway is induced by endogenous signals and results in perturbation of mitochondria. The translocation of pro-apoptotic members of the $\mathrm{Bcl}-2$ family (Bid, Bax, Bad) promotes the release of cytochrome $\mathrm{c}$ from the intermitochondrial membrane space. Cytochrome $\mathrm{c}$ binds to apoptotic protease-activating factor 1 (Apaf-1) and forms the Apaf-1-pro-caspase 9 apoptosome complex, and causes the activation of initiator caspase-9. The activated initiator caspases 8 and 9 then activate the effector caspases 3 and 7 , which are responsible for the cleavage of important cellular substrates. Caspase mediated substrate cleavage results in the classical biochemical and morphological changes of apoptosis. Other apoptotic molecules like the flavoprotein AIF are also released from the mitochondria along with cytochrome $\mathrm{c}$. The anti-apoptotic functions of Hsp70 are indicated. Hsp70 blocks cytochrome c release from mitochondria and interferes with Apaf-1 to prevent recruitment of pro-caspase- 9 into the apoptosome. It has been shown that Hsp70 inhibits caspase-3 both immediately upstream and downstream of caspase- 3 activation. Furthermore it binds to AIF and inhibits AlF-induced chromatin condensation. It has also been proposed that Hsp70 acts in earlier steps, for instance by preventing JNK activation (modified from Garrido et al., 2001; Gabai et al., 2002; MacFarlane and Williams, 2004 and Yenari et al., 2005). 


\subsection{Parkinson's disease (PD) - a concomitant phenomenon of an ageing society}

Parkinson's disease (PD) was first recognized and documented in "An Essay on the Shaking Palsy" by the British physician James Parkinson in 1817. Today, PD is the second most frequent neurodegenerative disorder of the central nervous system after Alzheimer's disease (Riederer et al., 1990), affecting 1-2\% of the human population (Giasson et al., 2000). PD usually occurs in middle age, typically beginning around age 60 and the likelihood of contracting the disease increases with age. This is a general feature of most neurodegenerative diseases. Therefore PD becomes more relevant in an ageing society (Schelling, 2000). The major clinical and pharmacological abnormalities of PD are tremor, muscle rigidity, slowness of voluntary movement (bradykinesia) and posturnal instability (Jackson-Lewis and Przedborski, 2007). Other symptoms are olfactory dysfunction (Herting et al., 2007) and adverse effects in the visual system (Bodis-Wollner and Tagliati, 1993). All these abnormalities in PD patients correlate with the progressive impairment of dopaminergic neurons.

\subsubsection{PD Pathology: The progressive loss of dopaminergic neurons and a-synuclein "toxicity"}

PD pathology encompasses a number of brain areas such as the ventral tegmental area (VTA), noradrenergic locus coeruleus, serotonergic raphe nuclei of reticular formation, cholinergic nuclei and anterior olfactory structures (Braak et al., 2000; Braak et al., 2006) as well as the visual system (Bodis-Wollner and Tagliati, 1993). However, the nigrostriatal pathway has been consistently identified as the most severely damaged in PD (Dauer and Przedborski, 2003) and is characterized by the loss of dopaminergic (DA) neurons in the substantia nigra pars compacta (SNpc), the depletion of striatal dopamine, and the presence of intraneuronal proteinaceous cytoplasmatic inclusions, termed "Lewy bodies" (Schulz and Falkenburger, 2004). The major component of these aggregates is $\alpha$-synuclein. Normal $\alpha$-synuclein is an abundant, 140 amino acid long, highly soluble neuronal cytoplasmic protein, and is predominantly localized to presynaptic terminals in the central nervous system, 
where it is associated with synaptic vesicles. Abnormal $\alpha$-synuclein disrupts cellular function leading to DA neurodegeneration, and has been intensively studied. Transgenic mice expressing human A53T mutated a-synuclein develop severe mitochondrial pathology (Stichel et al., 2007), suggesting a crucial role of a-synuclein in modulating mitochondrial functions in PD. This further suggests a-synuclein as a modulator in oxidative damage, since a-synuclein null mutant mice are resistant against MPTP toxicity (Dauer et al., 2002), while DA neurons in the SNpc are more vulnerable to mitochondrial dysfunction following MPTP application in human a-synuclein transgenic mice (Song et al., 2004). Conformationally modified a-synuclein is converted into pathological oligomers and higher-order aggregates that fibrillize and deposit into Lewy bodies and Lewy neurites in affected neurons of the PD brain (Lee and Trojanowski, 2006). Whether the oligomers or the accumulation of fibrillar deposits are the toxic species remains under debate. Nevertheless, there is strong evidence implicating increased expression of $\alpha$-synuclein and pathologically altered forms of this protein in the pathogenesis of both familial and idiopathic PD (Lee and Trojanowski, 2006).

\subsubsection{Etiology of PD: Where does it come from?}

Despite the early description of PD features, the cause underlying the death of nigrostriatal DA neurons is not well understood (Dauer and Przedborski, 2003). For a minority of PD cases (approximately 5\%), a number of specific gene mutations were identified and revealed novel proteins that may induce $P D$ as a result of neurodegeneration. Five genes linked to rare familiar forms of $P D$ have been identified, namely PARK2, PINK1, DJ-1, LRRK2 and SNCA, of which the mutations in the gene encoding for a-synuclein (SNCA) have been studied most extensively. (for a-synuclein; see sections 1.2.1, 1.4.2 and 4.3). In addition, possible susceptibility genes (ATP13A2, UCH-L1 and HTRA2) have been identified, that may increase the risk of developing PD. The precise relationship of these genes to the more common idiopathic illness is uncertain; however the typical and extremely consistent phenotype of both idiopathic and familial PD suggests that one common molecular mechanism may underlie PD (Thomas and Beal, 2007).

Among the different cell death pathways (apoptosis, necrosis, autophagy), apoptosis has been implicated as one of the important mechanisms leading to neuronal death 
in PD (Tatton and Kish, 1997; Eberhardt et al. 2000; Hartmann et al., 2000, 2001), whereas intrinsic signals target the mitochondrial membrane. A biochemical hallmark of PD is a reduced activity of complex I of the electron transport chain (Schulz and Beal, 1994), leading to ATP depletion and formation of reactive oxygen species (see also section 1.1, 1.3.1 and 1.3.2), which damage DA neurons. Evidence of increased oxidative stress was found in postmortem PD brains as reported by Andersen (2004). Furthermore, a reduced activity of complex I was found in the brains of idiopathic PD patients (Schapira et al., 1995). Since the major forms of parkinsonism are idiopathic, external factors influencing progression must be examined to support the idea of a complex disease with multiple etiological factors involved in disease pathogenesis (Thomas and Beal, 2007). The disease may result from neurotoxins, pesticides like rotenone and paraquat, or drugs (MPTP or 6-OHDA, details in section 1.3), head trauma, or other medical disorders. However, none of the models using toxins such as rotenone or 6-OHDA to induce DA cell death reproduce all PD features. Therefore, the development of appropriate model systems for further evaluation of the precise molecular mechanisms are required for a better understanding of PD pathology and to establish treatment strategies.

\subsection{Model systems to explore various aspects of PD}

Over the years, a variety of models have been established to initiate neurodegeneration in DA neurons (Bove et al., 2005). Since $\alpha$-synuclein is known to be the major component of protein aggregations in the brains of PD patients, research groups focused on the development of a-synuclein transgenic mouse models. Overexpression of wild-type or mutant $\alpha$-synuclein leads to a synucleinopathy. However - at least in mice - evidence for reliably induced DA cell death was weak for many years (Schulz, 2006). Therefore, toxins like 6-hydroxydopamine (6-OHDA), rotenone, paraquate, 1-methyl-4-phenyl-1,2,3,6tetrahydropyridine (MPTP) or methamphetamine were used to mimic PD features. In our day, these models are widely used to study molecular details of various diseasemodifying pathways (Schober, 2004) and to improve our understanding of the etiology of PD and other neurodegenerative diseases. 


\subsubsection{MPTP provides one model for PD}

So far, none of all the validated toxin models faithfully reproduce PD (Jackson-Lewis and Przedborski, 2007). However, among these, the model provided by MPTP application has at least three advantages over all other toxic models (Przedborski and Vila, 2003). First, MPTP induces a syndrome in humans and monkeys indistinguishable from PD. Second, systemical application of MPTP produces a reproducible and irreversible lesion of the nigrostriatal dopaminergic pathway. Third, even though safety measures are important, its use is not technically challenging. Neither surgery nor particular equipment is required (Jackson-Lewis and Przedborski, 2007).

The neurotoxin MPTP was recognized in 1982 when young drug addicts developed a profound parkinsonian syndrome after intravenous injection of meperidine analogs. The meperidine analogs were contaminated with MPTP, a byproduct of meperidine chemical synthesis (Langston et al., 1983). In the last three decades, the complex pharmacology and key steps in MPTP-mediated neurotoxicity have been identified. Lipophilic MPTP rapidly passes the blood-brain barrier (BBB) and cellular membranes. In astrocytes, monoamine oxidase B converts MPTP into 1-methyl-4-phenyl-pyridinium ion $\left(\mathrm{MPP}^{+}\right)$, the active toxic metabolite (Ransom et al., 1987) (Figure 2). $\mathrm{MPP}^{+}$is taken up into DA neurons by their dopamine transporters (DAT) (Mayer et al., 1986), inhibiting mitochondrial complex I (Tipton and Singer, 1993). It promotes ATP depletion and generation of reactive oxygen species (ROS) (Rossetti et al., 1988). These initial intrinsic events lead to a variety of cellular perturbations including the induction of death signals, which can activate apoptotic pathways (Przedborski et al., 2004, see section 1.1 and Figure 1), such as the activation of p53 (Trimmer et al., 1996; Duan et al., 2002) and JNK/c-jun (Saporito et al., 2000; Xia et al., 2001), leading to Bax induction (Ghahremani et al., 2002; Lei et al., 2002), cytochrome c release and caspase activation (Dodel et al., 1998; Yang et al., 1998). Bax-mediated neurodegeneration of DA neurons in vivo was reported by Vila et al. (2001). Furthermore, DNA damage stimulates poly-(ADP-ribose) polymerase (PARP) activity, which triggers the translocation of the caspaseindependent AIF (Przedborski et al., 2004). Besides these intrinsic pathways, neuronal cell death is also extrinsically meditated. MPTP or MPP ${ }^{+}$treatment induce cytocrome c release and neuronal cell death in vitro (Viswanath et al., 2001; 
Gonzalez et al., 2004) and in vivo in the substantia nigra (Viswanath et al., 2001) via rise in caspase 8 activity. Inhibition of these different pathways may serve as a therapeutic target (Schulz et al., 1999; see section 1.4.2). Another widely used toxin in models for PD is 6-OHDA, which induces symptoms similar to MPTP (see next section).

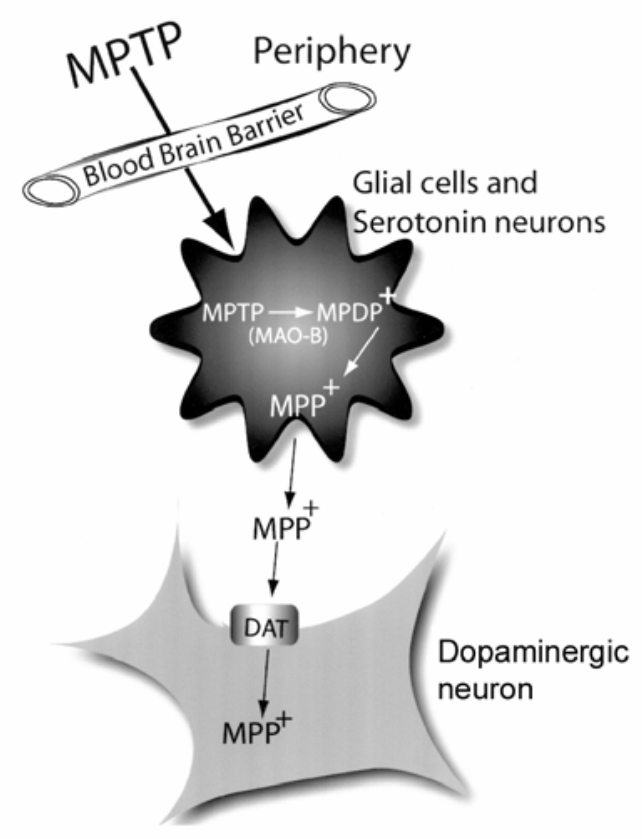

Figure 2. The 1-methyl-4-phenyl-1,2,3,6-tetrahydropyridine (MPTP) metabolism.

After systemic application MPTP crosses the blood-brain barrier (BBB). Inside the glia cells of the brain, MPTP is converted into MPP ${ }^{+}$via monoamine oxidase $\mathrm{B} . \mathrm{MPP}^{+}$is released from these cells into the extracellular space and is taken up into dopaminergic neurons by the dopamine transporter (DAT) (reproduced from Przedborski and Vila, 2003).

\subsubsection{6-OHDA causes degeneration of the nigrostriatal system}

6-OHDA is a hydroxylated analogue of the natural neurotransmitter dopamine (Blum et al., 2001). It was originally isolated by Senoh and Witkop (1959) and Sehoh et al. (1959) and its biological effects were first demonstrated by Porter et al. (1963), who showed that 6-OHDA induces efficient noradrenaline depletion in sympathetic nerves to the heart. Today, 6-OHDA represents a commonly used neurotoxin in degeneration models of DA neurons, including the nigrostriatal system (Blum et al., 2001) and has been found to be accumulated in patients suffering from PD (Andrew et al., 1993). 6-OHDA-induced toxicity is selective for DA neurons, due to the preferential uptake of 6-OHDA by the DAT. 6-OHDA accumulates in the cytosol and 
induces cell death through free radical formation and respiratory inhibition of the mitochondrial complex I, similar to MPTP-mediated cell death (Schober, 2004). It has been shown that 6-OHDA treatment inhibits enzyme activity of striatal glutathione and superoxide dismutase in rat brains, which normally counteract damaging effects of oxidative stress. 6-OHDA-mediated mitochondrial ATP depletion causes increased expression of death signals, as discussed for the MPTP model. Both toxic mechanisms are not necessarily linked, but appear to act synergistically during neuronal degeneration (Schober, 2004).

In contrast to MPTP, systemically administered 6-OHDA fails to cross the BBB. Thus, it has to be injected stereotactically into the brain. When infused into the substantia nigra (SN), 6-OHDA causes an anterograde, or, after injection into the striatum, a retrograde degeneration of the whole nigrostriatal system (Kirik et al., 1998; O'Neill et al., 2004,). The 6-OHDA model does not mimic all pathological and clinical features of human PD; it represents a widely used model with selective cell death of DA neurons and preservation of non-DA neurons, but lacks the formation of cytoplasmatic inclusions (Lewy Bodies) (Schober, 2004). The 6-OHDA and MPTP models are widely used and have provided evidence about the molecular mechanisms causing neurodegeneration. However, this knowledge has rarely been translated into novel therapies for PD.

\section{4 "Established" and novel therapies for PD}

\subsubsection{Current therapeutic strategies}

The disease pattern of PD develops slowly and the first clinical abnormalities initially occur in PD patients when $60-85 \%$ of the DA neurons in the SNpc are degenerated (Schapira et al., 1995). Reliable early diagnosis like testing olfactory dysfunction is still elusive (Herting et al., 2007). To date no causal therapy of PD exists, however medications or surgery can provide relief from the symptoms. Levodopa (L-DOPA) is a widely used form of treatment. L-DOPA is transformed into dopamine in DA neurons by L-aromatic amino acid decarboxylase (Playfer, 1997). However, only $5 \%$ of L-DOPA enters the DA neurons. The remaining L-DOPA is metabolized elsewhere, causing a variety of side effects. A disadvantage of L-DOPA treatment is the reduction of endogenous L-DOPA formation. The dopa decarboxylase inhibitors 
carbidopa and benserazide help to prevent the metabolism of L-DOPA before it reaches the DA neurons and are given as combination preparations of carbidopa/levodopa (sinemet) and benserazide/levodopa (madopar). L-DOPA is an important substrate of catechol-o-methyl transferase (COMT). Therefore, COMT inhibitors (entacapone) save L-DOPA from COMT and prolong the action of L-DOPA. Together with the carbidopa/levodopa treatment this "triple therapy" becomes a standard in the treatment of PD (Pahwa, 2006). Another way to stimulate DA receptors is the use of dopamine antagonists (e.g. bromocriptine, pergolide), which are moderately effective in reducing the fluctuation of motor symptoms. As the dopamine metabolism is impaired in PD patients, one other pharmaceutical therapy for PD blocks dopamine breakdown, mediated by monoamine oxidase-B (MAO-B). MAO-B inhibitors (selegiline, rasagiline) reduce the symptoms of PD patients. When drug therapy becomes insufficient after some years, surgical treatments, in particular deep brain stimulation, are an option for patients refractory to pharmaceutical therapy (Pahwa, 2006). However, none of the currently available treatments has been proven to slow the progression of PD.

\subsubsection{Neuroprotective gene therapy - achievements and perspectives}

Neurodegenerative diseases are characterized by excessive apoptosis. Most pro-apoptotic signals converge on the breakdown of the mitochondrial membrane potential, followed by release of cytochrome $c$ and ATP depletion (Figure 1). Thus, several studies focused on the maintenance of mitochondrial integrity by overexpression of anti-apoptotic proteins or by inhibition of pro-apoptotic molecules using pharmacological inhibitors. For instance, overexpression of a dominant inhibitor of caspase-1 (Klevenyi et al., 1999) or caspase inhibition via overexpressed Bcl-2 (Yang et al., 1998) protects DA neurons against MPTP neurotoxicity. In order to prevent neurodegeneration of retinal ganglion cells, Malik et al. (2005) performed injections of an adeno-associated virus (AAV) expressing the long isoform of B-cell lymphoma $\mathrm{x}$ protein $(\mathrm{Bcl}-\mathrm{X} \mathrm{L})$ to protect retinal ganglion cells after optic nerve transection. Other candidates to delay neurodegeneration are neurotrophic factors. Lentiviral mediated application of glial cell line-derived neurotrophic factor (GDNF, Ericson et al., 2005), neurturin (NTN, Fjord-Larsen et al., 2005) and the conserved dopamine neurotrophic factor (CDNF, Lindholm et al., 2007) have been shown to 
protect the nigrostriatal pathway in vivo. The strategy to inhibit the apoptotic pathway proved to be efficient, although in long-term studies substantial neuronal cell loss was still observed (Malik et al., 2005). To improve long term neuroprotection S. Kügler's group in our lab performed a combination of mitochondrial protection and neurotrophic support via co-expression of $\mathrm{Bcl}-\mathrm{X}_{\mathrm{L}}$ and GDNF in two different in vivo nerve lesion paradigms (the combination of GDNF and XIAP application is discussed in section 4.3). They showed that the efficacy of this combination approach significantly differed depending on post-lesion time. Bcl- $\mathrm{X}_{\mathrm{L}}$ expression was more important for neuronal survival in the early phase after lesion, whereas GDNF expression was neuroprotective in the advanced state of neurodegeneration. Furthermore, $\mathrm{Bcl}-\mathrm{x}_{\mathrm{L}}$ expression was not sufficient to finally inhibit degeneration of deafferentiated midbrain neurons. Long-lasting GDNF-mediated neuroprotection depended on $\mathrm{Bcl}-\mathrm{x}_{\mathrm{L}}$ co-expression in the traumatic lesion paradigm, but was independent of Bcl- $x_{L}$ in the 6-OHDA lesion model (Shevtsova et al., 2006).

A growing body of evidence suggests that cell death in PD might be triggered by fibrillar $\alpha$-synuclein inclusions (see Lewy bodies in section 1.2.1 and 1.2.2). Thus, several $\alpha$-synuclein animal models have been generated in flies, worms, and mice to further support the view that pathological a-synuclein is linked to the mechanisms of neurodegeneration and to targeting a-synuclein-mediated neurodegeneration for PD drug screening (Lee and Trojanowski, 2006). An attractive target for drug development is the inhibition of a-synuclein aggregation. Interestingly, dopamine has been found to inhibit a-synuclein fibrillization, whereas the inhibitory activity of dopamine depends on its oxidation (Norris et al., 2005). Moreover, the treatment of transgenic a-synuclein-expressing flies with the drug geldanamycin (Auluck et al., 2005) or by transgene expression of Hsp70 (Auluck et al., 2002) protects DA neurons against $\alpha$-synuclein toxicity through extended chaperone activity (more about Hsp70 in section 1.6.1; the role of $\alpha$-synuclein will be further discussed in section 4.3).

However, the major impediment to accomplish clinical trials of therapies for PD is the lack of biomarkers for early diagnosis and to monitor patient's response to new drug applications (Lee and Trojanowski, 2006). The realization of this PD drug discovery goal as well as the development of an improved therapeutic strategy to arrest and reverse the progression of PD would revolutionize PD treatment. 


\subsection{The Trojan horse approach - a therapeutic strategy}

On the one hand, drugs need to be sufficiently polar to be soluble in water and to easily distribute in the organism. On the other hand, such substances need to be hydrophobic enough to cross the lipid bilayer of biological membranes. Many drugs do not fulfill those physical properties and have thus failed to make it into clinical trials (Dietz and Bähr, 2004). To bypass these problems, drugs need to be extensively modified. To deliver therapeutic proteins across the blood-brain barrier (BBB) provides an additional challenge (Lo et al., 2001). Already established methods like electroporation, chemical transfection or microinjection have the disadvantage of damaging cell membranes and do not allow sufficient control of the amount of delivered protein (Dietz and Bähr, 2004).

By the mid 1960s there was growing evidence that polybasic proteins such as polyornithin and poly-lysine enhance protein uptake (Ryser, 1967; Ryser, 1968), but it needed two and half decades more until the first cargo transduction by so called "protein transduction domains" using the homeodomain of Antennapedia (Antp) was achieved in 1992 (Perez et al., 1992). Since then, a variety of "protein transduction domains", also called "cell penetrating peptides" (CPPs), like derivatives from the herpes simplex virus type 1 (HSV-1) VP22, transportan, polyarginine, penetratin and the human immunodeficient virus (HIV)-transactivator of transcription (Tat) have been used to mediate cargo translocation across biological membrane (Dietz and Bähr, 2004; Fischer et al., 2005). CPPs have been applied successfully in models of neurodegenerative diseases, such as autoimmune encephalomyelitis, AD, PD (Borsello and Forloni, 2007; Dietz et al., 2008), stroke (Dietz et al., 2002; Kilic et al., 2003) and inflammation (Gratton et al., 2003; Hotchkiss et al., 2006; Letoha et al. 2006). A potential benefit of using CPP fusion proteins is the efficient and fast translocation across biological membranes, including the ability to transfect primary non-dividing cells (Jones et al., 2005). Furthermore, no immunological responses to CPP fusion protein treatment are known. Thus, the non-invasive application of CPPlinked therapeutic reagents is a promising alternative approach for the delivery of proteins to their target area, as indicated by research of the last 15 years (Dietz and Bähr, 2005). 


\subsubsection{The HIV-transactivator of transcription}

The 101 amino acid transcriptional activator of transcription (Tat) of HIV-1 is necessary for the replication of the virus. Tat facilitates HIV diffusion within the infected organism (Izmailova et al., 2003) and causes the death of uninfected bystander T-cells (Yang et al., 2003). The protein consists of five domains. Domain four contains the basic sequence RKKRRQRRR (Jeang et al., 1999). This short cationic domain (Tat ${ }_{49-57}$ ) is essential for its transduction.

In 1988, the HIV-Tat protein was used to mediate cargo transport across biological membranes for the first time. Two research groups independently found that Tat can cross cellular membranes, accumulates in the nucleus and transactivates genes within the cells (Frankel and Pabo, 1988; Green and Loewenstein, 1988). Since then, the Tat basic domain has been the focus of many laboratories. S. F. Dowdy was the first to generate a bacterial expression vector that allowed the purification of recombinant proteins with an in-frame Tat (Tat ${ }_{49-57}$ ) fusion (Nagahara et al., 1998). One year later, a novel approach to deliver proteins throughout the body and across the BBB was published (Schwarze et al., 1999). A Tat-fluorophore conjugate was detected in the brain 20 min after intraperitoneal (i.p.) injection. Tat-mediated delivery of the $120 \mathrm{kDa}$ beta-galactosidase protein was less efficient: The protein was detectable in different tissues including the brain after 4 to 8 hours (Schwarze et al., 1999). Previous studies examined mice brains 20 min after intravenous application of Tat-beta-galactosidase and found cell transduction in kidney, liver and spleen, but not in the brain (Fawell et al., 1994). This suggests that the Tat transduction potential, especially to enter the BBB, depends on the cargo size and perhaps other factors (Details about the transduction process will be discussed in sections 1.5.2 and 4.1). The Dowdy lab further reported that additional 50 different proteins could be transduced by this approach (Schwarze et al., 1999), although the corresponding data were never shown in detail.

Tat-mediated transduction allows the application of anti-apoptotic cargoes in order to inhibit apoptosis in neurodegenerative diseases. A Tat-Bcl- $\mathrm{X}_{\mathrm{L}}$ fusion protein has been demonstrated to transduce a pancreatic cell line in vitro (Embury et al., 2001). Cultured neurons such as cerebellar granule neurons treated with Tat-Bcl- $\mathrm{X}_{\mathrm{L}}$ were more resistant against potassium and serum deprivation-induced apoptosis (Dietz et al., 2002) and primary cortical neurons showed an improved survival after 
staurosporine-induced cell death (Cao et al., 2002). Further in vitro studies reported neuroprotection of a modified Tat-Bcl-2 construct in PC12 cells and primary neurons (Soane and Fiskum 2005). The effect of Tat- $\alpha$-synuclein is ambiguous, showing protection of PC12 cells against apoptosis at low concentrations and toxicity at higher concentrations (Albani et al., 2004). On the one hand, this result confirms the view that $\alpha$-synuclein supports neuronal survival (including Hsp70 activation; Albani et al., 2004), while it also has a major role in PD disease development (see sections 1.2.1 and 1.2.2). In vivo application of Tat fusion proteins is also promising, as demonstrated (1) by Tat-Bcl-XL-mediated neuroprotection of DA neurons in the substantia nigra after i.p. injection of MPTP (Dietz et al., 2008), (2) after nerve trauma (Dietz et al., 2002), (3) in a model of multiple sclerosis (Diem et al., 2005), or (4) by neuroprotection against neonatal hypoxic-ischemic brain injury via inhibition of caspases and AIF (Yin et al., 2006). In ischemia therapy, Tat-XIAP, Tat-Bcl- $\mathrm{X}_{\mathrm{L}}$ and Tat-GDNF reduce infarct size after cerebral artery occlusion (Cao et al., 2002; Kilic et al., 2002; Kilic et al., 2003; Guegan et al., 2006). The application of Tat-Hsp70 in this model is in progress (Doeppner et al., in preparation).

\subsubsection{The Tat uptake mechanism: How to cross biological membranes?}

Biological membranes present semi-permeable barriers, which allow small molecules to pass. However they are impermeable for molecules greater than $500 \mathrm{Da}$, which include many anti-apoptotic proteins like XIAP; GDNF, Bcl- $x_{L}$ and Hsp70. The ability of cell-penetrating peptides (CPPs) like the basic domain of Tat to cross biological membranes and to deliver macromolecular cargoes allows to construct therapeutic CPP fusion proteins. The current understanding of the mechanism of CPP transduction has already enhanced transduction efficiency and led to the development of some therapeutic approaches. The Tat domain has been shown to deliver large active proteins into cells in vitro and in vivo (Schwarze et al., 1999; Guegan et al. 2006; Dietz et al., 2008; Nagel et al., 2008). Recent reports identify macropinocytosis, a specialized form of endocytosis, as the major cellular entry for Tat fusion proteins and have created a new paradigm in the study of these peptides (Gump and Dowdy, 2007). The current model of the Tat-mediated transduction process suggested by Dowdy is a multiple process involving Tat binding to the cell surface, formation of the macropinosomes and endosomal escape into the 
cytoplasm. Initially, the positively charged arginine residues of the Tat domain electrostatically interact with the negatively charged cell surface (for influence of protein purification on transduction efficiency see below and section 4.2). Substitution of these residues reduces transduction efficiency (Wender et al., 2000). Arginine cations stabilize the guanidino groups and are involved in the formation of bidentate hydrogen bonds with sulfate, phosphate or carboxylate anions (Rothbard et al., 2004). It remains to be discussed in which proportion, the arginine guanidino groups are also responsible for macropinocytosis. A large body of evidence suggests that Tat and other CPPs bind to sulfated glycans like heparan sulfate. These negatively charged sulfate glycans serve as binding pool for highly basic Tat and also facilitate its interaction with the membrane. In glycan-deficient cells, less transduction was observed using fluorescent labeled proteins (Tyagi et al., 2001; Console et al., 2003). The idea of Tat-glycan interaction is supported by publications showing that hydrogen bonds between Tat and sulfates increase the hydrophobicity of the peptide, which could facilitate its interaction with the membrane (Rothbard et al., 2004). As sulfate glycans are commonly present on the cellular surface, the transduction appears to be largely independent of the cell type. Whether Tat-glycane bonds further induce the formation of macropinosomes has not been fully explored. In macropinocytosis, circular ruffles cover large extracellular particles in the surrounding medium (Jones, 2007). Actin-disrupting agents such as cytochalasin A or amiloride inhibit this form of endocytosis and thus Tat fusion protein uptake, suggesting first, a major role of actin in the formation of macropinosomes (Hacker et al., 1997) and second, that macropinocytosis is responsible for the Tat uptake (Wadia et al., 2004; Kaplan et al., 2005). The application of Tat fusion protein induced uptake of neutral dextran into cells indicates a fluid phase endocytosis (Wadia et al., 2004). Furthermore, the active small GTPase Rac is necessary for actin rearrangement, macropinocytosis and Tat transduction (Jones, 2007; Nakase et al., 2007).

Recent attempts focusing on the delivery of protein conjugates by the Tat sequence resulted in contradictory conclusions. Reports claim that the uptake occurs through lipid raft-dependent endocytosis (Richard et al., 2003; Fischer et al., 2005; Foerg et al., 2005;) involving either macropinocytosis (Wadia et al., 2004) or a calveolae pathway (Ferrari et al., 2003; Fittipaldi et al., 2003), whereas to some degree also clathrin-mediated endocytotis occurs (Saalik et al., 2004; Vendeville et al., 2004; Figure 3). Although Duchardt et al., (2007) reported that the Tat peptide and other 
CPPs simultaneously use three endocytic pathways: macropinocytosis, clathrinmediated endocytosis and caveolae/lipid-raft-mediated endocytosis, S. Dowdy's work suggests that only macropinocytosis is involved in the Tat uptake (Gump and Dowdy, 2007). Some of the contradictions about the CPP membrane penetration may be explained by different transduction pathways that are not mutually exclusive. Which proportion of the compounds are trafficked by which pathway may depend on the cargo properties (size, charge), the type of CPP employed, the cells to be transduced, the culture conditions, or the details of the in vivo application (Dietz and Bähr, 2005). Whether efficient membrane penetration is the rate limiting step in the delivery of proteins to their target intracellular compartments is further discussed in sections 4.1 and 4.2. In the same sections, I also consider how the development of improved transduction properties for many CPP fusion proteins opens new therapeutic strategies (see section 4.3 and 4.5) .

Besides the dispute about the CPP-mediated internalization process, questions about the influence of recombinant protein purification on transduction efficiency and intracellular functionality remained. The pioneering purification of recombinant Tat fusion proteins by Dowdy and coworkers was carried out under denaturing conditions (Vocero-Akbani et al., 2000; Becker-Hapak et al., 2001; Vocero-Akbani et al., 2001). It was assumed that denatured proteins may transduce more efficiently into cells than correctly folded proteins. Once inside the cell, transduced denatured proteins would be correctly folded by chaperones (Vocero-Akbani et al., 2000; Vocero-Akbani et al., 2001). Most of the following publications retained the initially recommended protein purification procedure (Dietz et al. 2002; Kilic et al., 2002; Wheeler et al., 2003; Diem et al., 2005; Dietz et al., 2006a/b; Guegan et al., 2006; Hotchkiss et al., 2006). The denaturant (urea) was removed in one rapid step, preventing folding of the protein into its native conformation (Nagahara et al., 1998). On the other hand, a few reports were published utilizing CPP fusion proteins isolated in their native conformation (Schwarze et al., 1999; Schwarze et al., 2000; Zhou et al., 2006), which were biologically active inside transduced cells as well. Thus, the use and subsequent fast removal of a denaturant like urea during protein purification may not be the most auspicious method for every type of protein and application (see sections 3.1, 3.2, 3.3.1 and 4.2). In this study, we have examined the transducibility and activity of Tatfused heat shock protein 70 (Hsp70) isolated under denaturing or non-denaturing conditions (about Hsp70: see section 1.6,). 


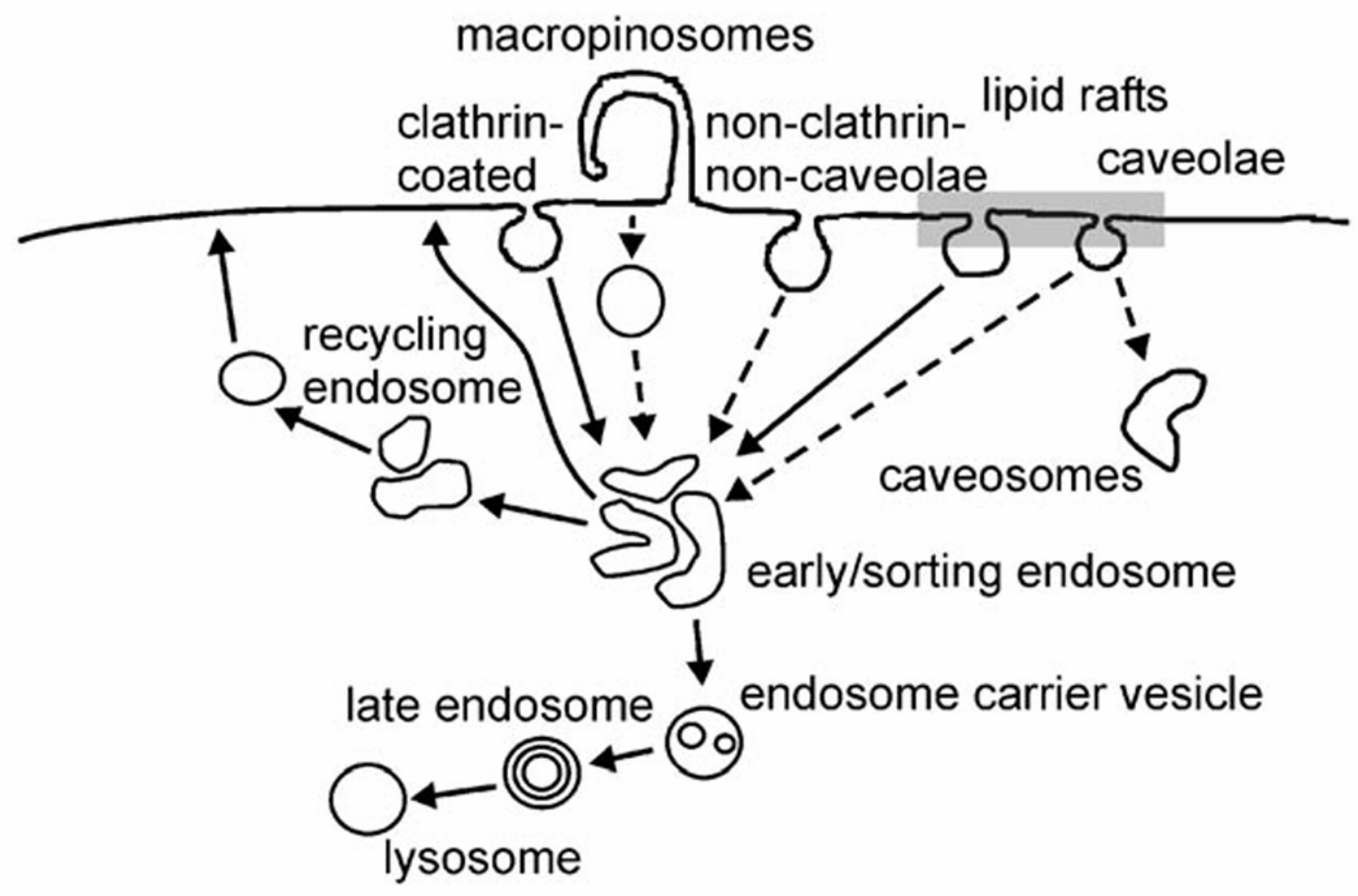

Figure 3. Proposed uptake mechanisms for cell-penetrating peptides (CPPs).

Cellular entry by endocytosis. Cellular uptake of CPPs by clathrin-coated vesicles, macropinocytosis and lipid rafts/caveolae are shown. Dotted lines indicate pathways which are still under discussion (reproduced from Fischer et al., 2005).

\subsection{Heat shock proteins (Hsps): endogenous modulators of apoptotic cell death}

Heat shock proteins (Hsps) were first discovered in 1962 (Ritossa, 1962) as a set of highly conserved proteins in all organisms from bacteria to mammals. In mammals, they have been classified into four families according to their size: Hsp90, Hsp70, Hsp60 and small Hsps.

Expression of Hsps can be induced by different kinds of stress such as heat shock, UV light, heavy metals, oxidative stress (Garrido et al., 2001; Kelly and Yenari, 2002; Wheeler et al., 2003; Giffard and Yenari, 2004), and in a variety of pathologic states, including cerebral ischemia, neurodegenerative diseases, epilepsy, and trauma (Yenary et al., 1998; Giffard et al., 2004; Dong et al., 2005; Truettner et al., 2007). Most of the Hsps have strong cytoprotective effects and behave as molecular chaperones for other cellular proteins (Garrido et al., 2001). Some of the important 
house keeping functions attributed to molecular chaperones are (1) import of proteins into cellular compartments; (2) folding of proteins in the cytosol, endoplasmatic reticulum and mitochondria; (3) degradation of unstable proteins; (4) dissolution of protein complexes; (5) prevention of protein aggregation; (6) control of regulatory proteins and; (7) refolding of misfolded proteins (Bukau and Horwich, 1998). Chaperone specificity is defined by the structure of the chaperone, and the size and localization of the protein to be chaperoned (Garrido et al., 2001). However, they are also involved in antigen presentation, steroid receptor function, intracellular trafficking, nuclear receptor binding, and apoptosis (Giffard and Yenari, 2004).

Hsps differ among each other in their role in regulating apoptosis, with pro-apoptotic function being reported for Hsp10 and Hsp60 (Garrido et al., 2001) on the one hand, and anti-apoptotic function being reported for Hsp27 and Hsp70 on the other hand (Klucken et al., 2004; Dong et al., 2005; Gorman et al., 2005; Shen et al., 2005; Nagel et al., 2008).

\subsubsection{The heat shock protein 70 (Hsp70) - the best studied stress response protein}

The heat shock protein $70(\mathrm{Hsp} 70)$ is the best studied chaperone. Hsp70 promotes protein folding to the native state, refolding of misfolded and aggregated proteins and prevents the protein aggregation, which is a hallmark of many neurodegenerative diseases (Mayer and Bukau, 2005). Besides its chaperone function, Hsp70 is known to be a potent anti-apoptotic and anti-inflammatory protein (Yenari et al., 2005) and has been studied in many models of neurodegenerative diseases such as PD, AD, ALS and other related insults (e.g. ischemia) (Garrido et al., 2001; Dong et al., 2005; Galazka et al., 2006). Hsp70 appears to have effects at several different steps in the apoptotic cascade (Figure 1). In the extrinsic apoptotic pathway, upstream of mitochondrial damage, Hsp70 specifically interferes with the Bid-dependent apoptotic pathway via inhibition of TNF or heat shock mediated JNK activation in vitro (Park et al., 2001; Gabai et al., 2002). The intrinsic apoptotic pathway can be blocked by Hsp70 via interference at multiple sites. It increases B-cell lymphoma 2 protein (Bcl2) expression (Kelly et al., 2002) and can inhibit cytochrome c release (Beere et al., 2000; Creagh et al., 2000). The interference of Hsp70 with Apaf-1 prevents the recruitment of procaspase-9 into the apoptosome (Beere et al., 2000; Saleh et al., 
2000). Downstream in the apoptotic cascade, Hsp70 is furthermore able to inhibit caspase-3 (Mosser at al., 1997). Moreover, Hsp70 antagonizes in a caspaseindependent pathway by interfering with AIF (Susin et al., 1999; Ravagnan et al., 2001). An additional apoptosis regulatory protein interacting with Hsp70 is the Bcl-2associated athanogene 1 (Bag-1; Liman et al., 2005). It has been reported to function as co-chaperone of Hsp70, simultaneously regulating the activity of $\mathrm{Bcl}-2$ and Rafkinase (Song et al., 2001). However, it is not strictly essential for the chaperone activity of Hsp70 (Gässler et al., 2001).

Induction of Hsp70 expression allows cells to endure a harmful environment for a certain time. In cases where the endogenous Hsp70 level might be insufficient to protect cells against specific stress stimuli, the delivery of recombinant Hsp70 might be beneficial.

\subsubsection{Tat-mediated Hsp70 delivery in models of neurodegeneration}

To apply recombinant Hsp70 as therapeutic reagent, a vector is required for its delivery, because Hsp70 is too large to freely pass biological membranes or the BBB. As described in section 1.5.1, one of the most commonly used CPPs is a derivative of the basic domain of the Trans-activator of transcription (Tat ${ }_{49-57}$ ) from HIV, where effective transduction and functionality of delivered cargoes like the anti-apoptotic Bcl-X $\mathrm{X}_{\mathrm{L}}$ have been well demonstrated in vitro and in vivo (Schwarze et al., 1999; Dietz et al., 2002; Guégan et al., 2006; Dietz et al., 2006a/b; Hotchkiss et al., 2006; Yin et al., 2006; Dietz et al., 2008). Therefore, the Tat domain seems to be a promising vector for its delivery (Wheeler et al., 2003; Lai et al., 2005). Only two studies using the Tat approach for recombinant Hsp70 delivery have been already reported. Wheeler et al. (2003) treated HSF -/- cells with Tat-Hsp70 and detected that Tatmediated delivery of Hsp70 confers cytoprotection against thermal stress and hyperoxia in vitro. Tat-Hsp70 was also protective on primary neurons after induction of exitotoxicity and nitrosative stress (Lai et al., 2005). In both studies, an efficient cell transduction by Tat-Hsp70 was detected and showed an effective way to increase biologically active Hsp70 inside the cells in vitro. However, the determination of TatHsp70 effectiveness in neuroprotection in vivo is missing so far. Furthermore, all these studies used Tat fusion proteins purified under denaturing conditions, which is 
the current dogma to be the best method for Tat fusion protein purification. This claim has not been examined in detail.

\subsection{Objectives}

The goal of our study was to investigate the therapeutic potential of Tat-Hsp70 in models of neurodegeneration, especially of PD. To address this question, we generated a fusion protein between the basic 11-amino acid domain of Tat (CPP) and Hsp70 to deliver recombinant Hsp70 across cellular membranes and the bloodbrain barrier. We examined the influence of the purification procedure on the functionality of CPP fusion proteins, which had not been systematically investigated before. Our challenge was to identify a purification protocol that rendered the highest functionality of Tat-Hsp70. This study might provide a first step towards developing general rules for the most auspicious purification strategy for other CPP fusion proteins.

Although many studies of Tat fusion protein application in different models of neurodegeneration exist (Dietz et al. 2002; Hotchkiss et al, 2006; Yin et al., 2006; Dietz et al., 2008), currently there are no publications about the in vivo application of Tat-Hsp70 in those models. Therefore, we addressed the question whether TatHsp70 protects DA neurons in in vivo models of PD.

DA neurons are also present in the retina, and visual impairments in PD patients have been reported (Bodis-Wollner, 1990; Bodis-Wollner, 2003). However, publications quantifying MPTP-induced TH-positive amacrine cell death in the retina are rare and the results are not consistent. Furthermore most approaches such as the depletion of glutathione, which induces apoptosis in the mouse retina in vivo (Roh et al., 2007), or NMDA-induced exitotoxicity (Fischer et al., 1998; Fischer at al., 2004), do not specifically degenerate DA neurons, but rather induce general degeneration, independent of cell type. That prompted me to test whether DA amacrine interneurons in the retina are vulnerable against parkinsonian toxins and render reproducible models to study specific degeneration in amacrine cells of the retina. 


\section{MATERIALS AND METHODS}

\subsection{Cloning and expression of the Tat-Hsp70 construct}

To create an expression vector for the Tat-Hsp70 fusion protein, rat $h s p 70.1$ cDNA was cloned into the pTat-hemagglutinin (HA) expression vector (kindly provided by $\mathrm{S}$. F. Dowdy, University of California in San Diego, USA). pTat-HA is derived from pRSET Tм B (Invitrogen $\mathrm{GmbH}$, Karlsruhe, Germany). We amplified the Hsp70.1 coding sequence by polymerase chain reaction of the corresponding region of Hsp70.1 rat cDNA-containing plasmid (kindly provided by K. Lisowska, Centre of Oncology, Gliwice, Poland) with the sense primer 5'- CAG TAG GTA CCG CCA AGA AAA CAG CGA TCG GC-3' and the antisense primer 5'- GCA GCG AAT TCC TAA TCC ACC TCC TCG ATG GT -3'. Purified fragments were cloned into the KpnI/EcoRI sites of the pTat-HA and the pRSET $^{\text {TM }} \mathrm{B}$ expression vector (Invitrogen $\mathrm{GmbH}$, Karlsruhe, Germany). The resulting expression cassette includes a sequence encoding six histidine residues, the 11-amino acid transduction domain (YGRKKRRQRRR) of the Tat protein (5' of the polylinker, under the control of a T7 promoter), a hemagglutinin (HA) tag (YPYDVPDYA) and the Hsp70 sequence (Figure 4). The constructs were verified by DNA sequence analysis.

\subsection{Purification of Tat fusion proteins}

Tat-Hsp70, Tat-HA and Hsp70 were expressed in Escherichia coli strain BL21 (DE3)pLysS (Novagen, Madison, WI, USA) and isolated in their native conformation (in $10 \mathrm{mM}$ Tris $\mathrm{pH} 10,20 \%$ glycerol, $274 \mathrm{mM} \mathrm{NaCl}, 0.1 \%$ Pluronic, $0.02 \%$ Tween-80 buffer) (Dietz and Bähr, 2007) or under denaturing conditions in binding buffer (8 M urea, $100 \mathrm{mM} \mathrm{NaCl}, 20 \mathrm{mM}$ Hepes, pH 8.0, $5 \mathrm{mM}$ imidazole) as reported previously (Vocero-Akbani et al., 2000; Becker-Hapak et al., 2001; Vocero-Akbani et al., 2001; Dietz and Bähr, 2007). Transformation and testing of different Escherichia coli clones is described in detail in Dietz and Bähr (2007). Cell debris was removed by centrifugation and the cell extracts were purified by metal-affinity chromatography using either Ni-tris-carboxymethyl-ethylene-diamine (TED) for purification under native conditions or Ni-nitrilotriacetic-acid (NTA) (Macherey-Nagel, Düren, Germany) for denaturing protocols (Figure 4). Protino ${ }^{\circledR} \mathrm{Ni}$ resin (Macherey-Nagel, Düren, 
Germany) was used for the native purification of the Tat-HA control protein. Protein was eluted by stepwise addition of binding buffer containing increasing concentrations of imidazole (0.1-5 M, lane 1-5 of Figure 5. A, 6. A and lane 1-6 of Figure 7. A) and collection of $2 \mathrm{ml}$ fractions. The column eluate was purified from imidazole and urea (in case of none native purification) either by gel filtration (Sephadex ${ }^{\mathrm{TM}}$ G-50 M, GE Healthcare, Munich, Germany) in order to rapidly desalt the Tat-Hsp70 fusion protein, or by dialysis (Spectra/Por ${ }^{\circ}$ Float A-Lyser, MWCO: 10000 or 3500 , Spectrum laboratories) against 5 changes of a 250 fold buffer solution $(274 \mathrm{mM} \mathrm{NaCl}, 20 \mathrm{mM}$ Hepes, $\mathrm{pH} 8.0$ or $10 \mathrm{mM}$ Tris pH10, $20 \%$ glycerol, $0.1 \%$ Pluronic, $0.02 \%$ Tween- 80 buffer) for slowly removing imidazole and denaturant. A detailed protocol for Tat-Hsp70 purification for the different conditions is given below (see section 2.2.1). We confirmed identity of proteins by Western blotting (see section 2.4.1). Anti-HA antibodies were purchased from Covance Inc. (NJ, USA). Protein purity was assessed via Coomassie (Coomassie Brilliant Blue, MERCK, Germany) stained polyacrylamide (PAA)-gels. The protein concentration was quantified by comparison with protein standards, loaded on Coomassie-stained PAA gels (Figure 5 - Figure 7). This procedure rendered 3 different preparations each for both Tat-Hsp70 and Hsp70, which we tested for transduction efficiency, chaperone activity and neuroprotection.

\subsubsection{Improved purification protocol for recombinant Tat-Hsp70}

\subsubsection{Gene expression}

We inoculated $200 \mathrm{ml} \mathrm{LB}$-medium with a glycerol stock of the clone over night. ampicillin (1:1000, $100 \mathrm{mg} / \mathrm{ml}$ stock) and chloramphenicol (1:1000, $34 \mathrm{mg} / \mathrm{ml}$ stock) were added to select for cells carrying these resistances. The next morning, we inoculated 1/ LB-medium (with ampicillin 1:1000, no chloramphenicol) with the $200 \mathrm{ml}$ culture. At an optical density (600 nm) of $0.4-0.8$, we added $9 \mathrm{~g}$ lactose to induce the lacUV5 promotor and added 1\% ethanol (absolute 100\%). At the time of induction and each hour thereafter we took a $20 \mu \mathrm{l}$ sample, which was centrifuged for $1 \mathrm{sec}$ at full speed before supernatant was discarded and the pellet frozen at $-20^{\circ} \mathrm{C}$ for gel 
analysis. The $4 \mathrm{~h}$ induction led to high levels of protein synthesis of all cloned constructs. Therefore, cells were harvested at that time.

\subsubsection{Harvest of bacteria and nickel affinity chromatography}

We equilibrated 5-10 $\mathrm{ml} \mathrm{Ni-TED} \mathrm{in} \mathrm{a} \mathrm{polypropylene} \mathrm{gravity} \mathrm{column} \mathrm{(Ni-Resin} \mathrm{for} \mathrm{Tat-}$ HA or Ni-NTA for Tat-Hsp70 purification under denaturing conditions) with 2 bed volumes of phosphate-buffered saline (PBS) and 5 bed volumes of equilibration buffer (for purification under native conditions: in $10 \mathrm{mM}$ Tris $\mathrm{pH} 10,20 \%$ glycerol, $274 \mathrm{mM} \mathrm{NaCl}, 0.1 \%$ Pluronic, $0.02 \%$ Tween-80 buffer, or buffer $\mathrm{z}$ in case of purification under denaturing conditions). We harvested bacteria by centrifugation at $3,300 \mathrm{rcf}$ for $10 \mathrm{~min}$ at $4^{\circ} \mathrm{C}$, before bacteria were washed once with ice-cold PBS and transferred to a $50 \mathrm{ml}$ screw-cap tube to repeat the centrifugation step (3,300 rcf, 10 $\left.\min , 4^{\circ} \mathrm{C}\right)$. The bacterial pellet was resuspended in equilibration buffer for native purification protocols (for denaturing conditions in GuHCl-buffer).

Protease inhibitor (1.5\% of P8465, Lot $112 \mathrm{~K} 4018$, Sigma) and DNase $(0.5 \mathrm{mg} / 1 \mathrm{ml})$ were added into solution to reduce interaction of the positively charged Tat domain and the negatively charged DNA. For purification under native conditions, lysosyme $(0.5 \mathrm{mg} / \mathrm{ml})$ was added for chemical lysis of bacteria. We performed sonication of the pellets (60-90 sec, 100\%) until clumps were completely dissolved and then stored the tubes on ice for $10 \mathrm{~min}$. After centrifugation at $16,400 \mathrm{rcf}$ for $6 \mathrm{~min}$ at $4^{\circ} \mathrm{C}$ we collected the supernatant. Sonication and centrifugation were repeated 4-5 times to increase protein yield. The supernatants of each step were pooled and exposed to a high speed spin at 38,724 rcf for $20 \mathrm{~min}$ to remove all residual bacterial debris. We collected a $20 \mu \mathrm{l}$ sample of the supernatant and the pellet for later gel analysis. The supernatant was filtered through a kimwipe tissue, before the protein solution was transferred onto the column. The equilibrated Ni-TED was removed together with the protein solution and was incubated in a head-over-end shaker for $1 \mathrm{~h}$ at $4^{\circ} \mathrm{C}$, after which the protein-Ni-TED solution slurry was poured onto the column. A $20 \mu \mathrm{l}$ sample was collected ("flow-through") for SDS-gel analysis. Columns were washed with 10 bed volumes of equilibration buffer (see above) and a $20 \mu \mathrm{l}$ sample ("wash") was collected for SDS-gel analysis. For elution, increasing concentrations of imidazole ( $5 \mathrm{ml}$ of $0.1 \mathrm{M}, 0.5 \mathrm{M}, 1 \mathrm{M}$ and $2 \mathrm{ml}$ of $5 \mathrm{M}$ ) in the specified equilibration buffer were added on the column and $2 \mathrm{ml}$ fractions were collected. 1 bed volume of $1.1 \%$ acetic 
acid was used to push out all imidazole/protein still remaining in the column. Columns were regenerated with 10 bed volume of $1.1 \%$ acetic acid, $30 \%$ glycerol and distilled $\mathrm{H}_{2} \mathrm{O}$. Columns were stored with $30 \%$ ethanol at $4^{\circ} \mathrm{C}$. For SDS PAGE analysis of the sample, $20 \mu \mathrm{l} 2 \times$ SDS-loading buffer were added into the collected samples of supernatant, pellet, flow-through, wash, and $2 \mu \mathrm{l} 2 \times$ SDS buffer were added to $2 \mu \mathrm{l}$ of all Nickel fractions, before samples were heated $\left(90^{\circ} \mathrm{C}\right.$ for $5 \mathrm{~min}$ ) and loaded on an SDS gel (8-10\% PAA). In a few cases it was necessary to concentrate the protein by Amicon ${ }^{\mathrm{TM}}$ Ultra Centrifugal Filter Device (MWCO: 10.000 kDa for TatHsp70 and Hsp70, 3.500 kDa for Tat-HA).

\subsubsection{Removal of salt and imidazole}

Sephadex G-50 columns (PD-10) were equilibrated with $25 \mathrm{ml}$ buffer (20\% glycerol in PBS for denaturing purification; for native isolation see equilibration of Ni-TED in section 2.2.1.2). Later, we collected $80.5 \mathrm{ml}$ protein fractions in $1.5 \mathrm{ml}$ siliconized tubes. Protease inhibitor (4\% of P8465, Lot 112K4018, Sigma) was added into each tube, which where placed on ice. Concentrated protein solution was transferred in a volume of $2.5 \mathrm{ml}$ onto the equilibrated PD-10 column. We discarded the flow-through. For all purification protocols the same equilibration buffer was added (10 mM Tris $\mathrm{pH} 10,20 \%$ glycerol [ $50 \%$ glycerol also possible], $274 \mathrm{mM} \mathrm{NaCl}, 0.1 \%$ Pluronic, $0.02 \%$ Tween-80 buffer) in steps of $0.5 \mathrm{ml}$ onto the column, and 8 fractions were collected. All fractions were centrifuged for $2 \mathrm{~min}$ at maximum speed in a microcentrifuge to check for precipitation. $2 \mu$ of each fraction plus $2 \mu \mathrm{l} 2 \times \mathrm{SDS}$ loading buffer were run on an SDS gel, together with BSA standards to estimate protein concentration. Finally, we stored the fusion protein at $-20{ }^{\circ} \mathrm{C}$. The recombinant proteins were then ready to use. 


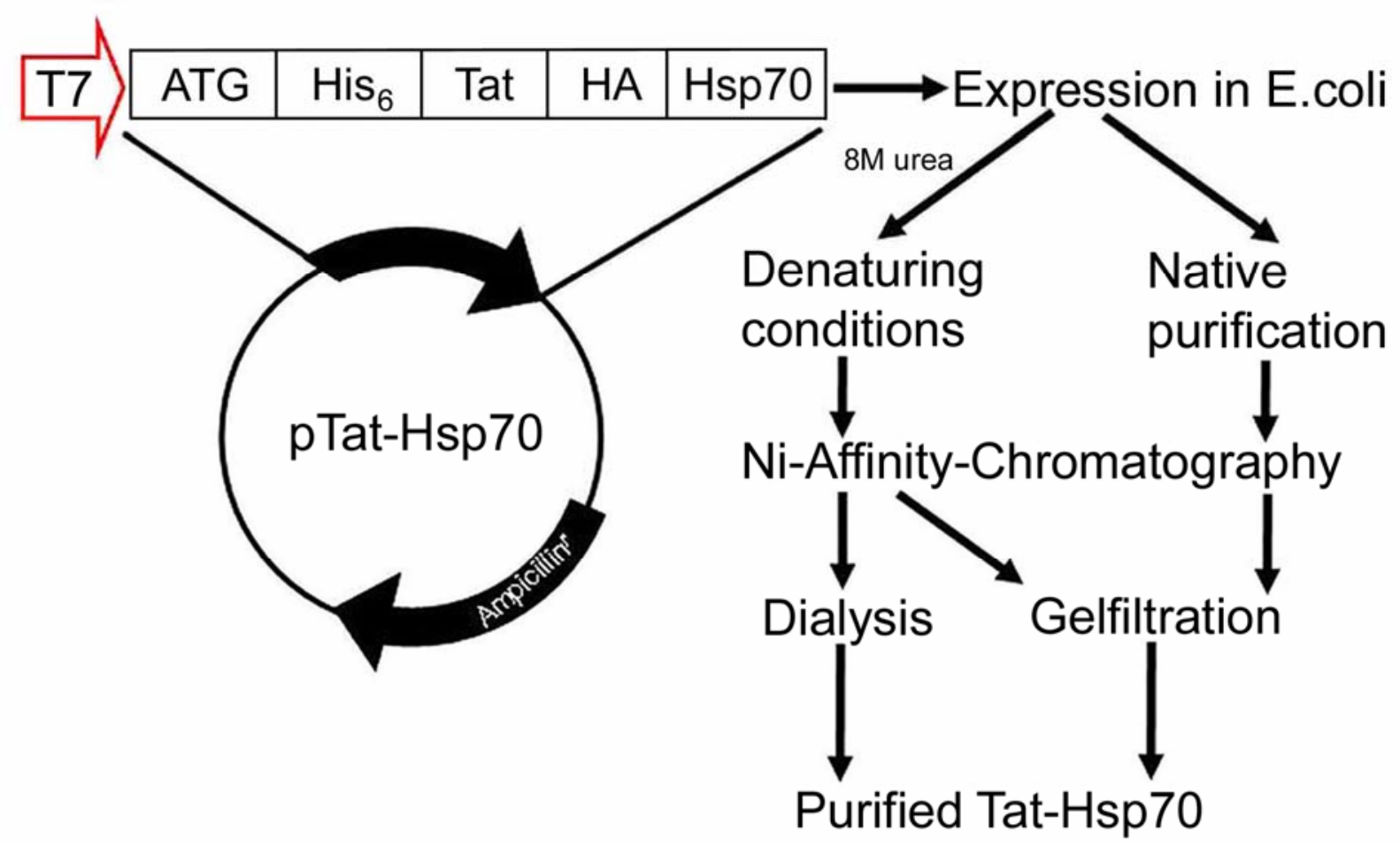

Figure 4. Synthesis and purification of Tat fusion proteins.

To create an expression vector for the Tat-Hsp70 fusion protein rat $h s p 70.1$ cDNA was cloned into the pTat-hemagglutinin (HA) expression vector. The resulting expression cassette includes a sequence encoding six histidine residues, the 11-amino acid transduction domain (YGRKKRRQRRR) of the Tat protein (5' of the polylinker, under the control of a T7 promoter), a hemagglutinin (HA) tag (YPYDVPDYA) and the Hsp70 sequence. Tat-Hsp70, Tat-HA and Hsp70 were expressed in Escherichia coli and were isolated in buffers using $8 \mathrm{M}$ urea or a not denaturing buffer. Cell debris was removed by centrifugation and the cell extracts were purified by Ni-affinity chromatography. Protein was eluted by stepwise addition of binding buffer containing increasing concentrations of imidazole. Imidazole and urea were either rapidly removed by gel filtration, or removed slowly by dialysis against a buffer containing $274 \mathrm{mM} \mathrm{NaCl}$.

\subsection{Cell culture models}

For all in vitro experiments we used two cell lines, SH-SY5Y human neuroblastoma and immortalized rat nigrostriatal CSM14.1. Additionally, primary midbrain neurons from rats (Wistar, E14) were prepared and cultured for viability assays. 


\subsubsection{SH-SY5Y human neuroblastoma cells}

SH-SY5Y cells are a third generation of human neuroblastoma cells derived from the neuroepithelom-cell line SK-N-SH. The original cell line was isolated from a woman's metastatic bone tumor in 1970 (Biedler et al., 1973). The dividing cells form clusters of cells which are reminders of their cancerous nature, but certain treatments such as retinoic acid and brain-derived neurotrophic factor (BDNF) can force the cells to dendrify and differentiate. Furthermore, these cells are characterized by expression of neurofilament and vimentin.

In our study, SH-SY5Y cells were cultured in $10 \mathrm{~cm}$ culture dishes (Greiner bio-one, Solingen; Incubator: Function line, Heraeus, Hannover, Germany), maintained in Dulbecco's modified Eagle's medium containing $15 \%$ fetal calf serum (FCS), penicillin $(100 \mathrm{U} / \mathrm{ml})$, and streptomycin $(100 \mu \mathrm{g} / \mathrm{ml})$ (Invitrogen, Karlsruhe, Germany) at $37^{\circ} \mathrm{C}$ in a humidified atmosphere of $95 \%$ air and $5 \% \mathrm{CO}_{2} . \mathrm{SH}-\mathrm{SY} 5 \mathrm{Y}$ cells were passaged (90\% confluence) every 3-4 days into a new dish. Under sterile conditions (Laminar flow, Heraguard, Heraeus, Hannover, Germany) cell culture medium was removed and neurons were washed with PBS, before $3 \mathrm{ml}$ of trypsin (1\%) were added to the cells (PAA, Cölbe, Germany). After $10 \mathrm{~min}$ of incubation, the cell suspension was transferred into tubes (Greiner bio-one, Solingen; Incubator: Function line, Heraeus, Hannover, Germany) and was centrifuged for 5 min at 390 rcf (at about $21^{\circ} \mathrm{C}$ ). The cell pellet was resuspended in $1 \mathrm{ml}$ culture medium and approximately $300 \mu \mathrm{l}$ were cultured in a new $10 \mathrm{~cm}$ dish. $10 \mu \mathrm{l}$ of the resuspended cell pellet were added into a counting chamber (Neubauer-Zählkammer, HechtAssistant, Sondheim, Germany) to determine the cell number via light microscopy.

To investigate the transduction efficiency cells were seeded into 16-well dishes (LabTek $^{\mathrm{R}}$, Chambered \#1.0 Borosilicate Coverglass System, NUNC ${ }^{\mathrm{TM}}$, Wiesbaden, Germany) with $2 \times 10^{4}$ cells $/ \mathrm{cm}^{2}$, or on $15 \mathrm{~mm}$ coverslips in 24 well dishes at a density of $6 \times 10^{4}$ cells $/ \mathrm{cm}^{2}\left(2 \times 10^{5}\right.$ cells $\left./ \mathrm{ml}\right)$. For the chaperone experiments, cells were cultured on $15 \mathrm{~mm}$ coverslips in 24-well dishes (Multiwell ${ }^{\mathrm{TM}} 24$ well, Falcon, Oxnard, CAM, USA) at a density of $1.5 \times 10^{4}$ cells $/ \mathrm{cm}^{2}\left(5 \times 10^{4}\right.$ cells $\left./ \mathrm{ml}\right)$. To perform viability assays, cells were seeded in 96-well dishes (Becton Dickinson $\mathrm{GmbH}$, Heidelberg, Germany) with $6 \times 10^{4}$ cells $/ \mathrm{cm}^{2}\left(2 \times 10^{5}\right.$ cells $\left./ \mathrm{ml}\right)$. Cells were differentiated with $10 \mu \mathrm{M}$ retinoic acid for $24 \mathrm{~h}$ (Sigma, Taufkirchen, Germany) for all experiments. 


\subsubsection{Rat nigrostriatal CSM14.1 cells}

CSM 14.1 cells are nigrostriatal rat cells, which were conditionally immortalized by a temperature sensitive SV-40-large-T-antigene (Hass and Wree, 2002), which allows temperature-dependent induction of differentiation. Furthermore, CSM 14.1 cells are neomycin resistant (Zhong et al., 1993).

In our study, we cultured CSM14.1 cells in $10 \mathrm{~cm}$ culture dishes (Greiner bio-one, Solingen; Incubator: Function line, Heraeus, Hannover, Germany) in Dulbecco's modified Eagle's medium containing 10\% fetal calf serum, penicillin (100 U/ml) and streptomycin $(100 \mu \mathrm{g} / \mathrm{ml})$ (Invitrogen, Karlsruhe, Germany) at $32^{\circ} \mathrm{C}$ in a humidified atmosphere of $95 \%$ air and $5 \% \mathrm{CO}_{2}$. Passaging of CSM14.1 cells was carried out as described for SH-SY5Y cell in section 2.2.1. Cells were seeded on $15 \mathrm{~mm}$ cover slips in 24-well dishes (Multiwell ${ }^{\mathrm{TM}} 24$ well, Falcon, USA) at a density of $1.5 \times 10^{4} \mathrm{cells} / \mathrm{cm}^{2}$ $\left(5 \times 10^{4}\right.$ cells $\left./ \mathrm{ml}\right)$. To differentiate the cells, they were transferred to $39^{\circ} \mathrm{C}$ for 14 days. During differentiation, CSM14.1 cells develop a neuronal phenotype and can be characterized as dopaminergic (DA) cells sequentially expressing DA-markers like the nuclear receptor-related 1 (Nurr1), tyrosine hydroxylase (TH) and aldehyde dehydrogenase 2 (ALDH2).

\subsubsection{Rat primary dopaminergic midbrain neurons}

Adult female pregnant rats (Wistar, provided by the animal research facility of Göttingen University Medical Center, Germany) were sacrificed by $\mathrm{CO}_{2} 14$ days after mating. The venter was cleaned with ethanol (70\%), the peritoneum was opened and the uteri were prepared and transferred into calcium-magnesium-free (CMF) medium. For further preparation of the midbrain we kept the embryos in cold CMF medium. Using a binocular microscope (Stemi 2000, Zeiss, Göttingen, Germany), mesencephalic tissue was dissected and cells prepared as described by Krieglstein et al. (1995) and Lingor et al. (2000). In brief, collected tissue pieces were centrifuged at $210 \mathrm{rcf}$ for $4 \mathrm{~min}$. The tissue pellet was then incubated in $750 \mathrm{ml}$ of trypsin $\left(0.25 \%, 15 \mathrm{~min}, 37^{\circ} \mathrm{C}\right.$; Sigma, Taufkirchen, Germany). Trypsin was inactivated by addition of $750 \mathrm{ml}$ of cold FCS and suspension was incubated with $40 \mu \mathrm{l}$ DNase for $3 \mathrm{~min}$ at about $21^{\circ} \mathrm{C}(10 \mathrm{mg} / \mathrm{ml}$, Sigma, Taufkirchen, Germany). 
Tissues were dissociated by gentle trituration using a fire-polished Pasteur pipette. Cell suspensions were centrifuged at 210 rcf for $4 \mathrm{~min}$ and resuspended in culture medium. Cells were seeded on poly-L-ornithine/laminin (Sigma, Taufkirchen, Germany)-coated 96-well plates (Becton Dickinson GmbH, Heidelberg, Germany) at a density of 175,000 cells $/ \mathrm{cm}^{2}$. Cultures were maintained at $37^{\circ} \mathrm{C}$ in a humidified atmosphere and $5 \% \mathrm{CO}_{2}$ in DMEM/F12 plus $\mathrm{N} 1$ supplements and antibiotics for 5 days. Cultured midbrain neurons contain mostly GABAergic neurons, while approximately $5 \%$ are $\mathrm{TH}$-positive neurons, which represent the DA phenotype.

\subsection{Cell transduction by Tat-Hsp70 in vitro}

\subsubsection{Western blot analysis}

To compare the transduction efficiency of different preparations of Tat-Hsp70 and Hsp70, SH-SY5Y neuroblastoma cells were treated for different time periods (30 min, $1 \mathrm{~h}, 4 \mathrm{~h}, 24 \mathrm{~h}$ ) with Tat-Hsp70 or Hsp70 (250 nM) isolated either under denaturing or native conditions. Trypsin was applied for $10 \mathrm{~min}$ to degrade not incorporated protein before cell lysates were collected in 2 x SDS-buffer (4\% SDS, 20\% glycerol, $127 \mathrm{mM}$ Tris base $\mathrm{pH}$ 6.8, $4 \mathrm{mM}$ ethylenediaminetetraacetic acid, 2\% 2-mercaptoethanol, $0.015 \%$ bromphenol blue). For examination of intracellular stability of recombinant protein, Tat-Hsp70 (250 nM) isolated under native conditions was added for different time periods on SH-SY5Y cells $(0.5 \mathrm{~h}, 1 \mathrm{~h}, 2 \mathrm{~h}, 12 \mathrm{~h}, 24 \mathrm{~h}, 48 \mathrm{~h}, 72 \mathrm{~h}, 96 \mathrm{~h})$. Cell lysates were heated $\left(5 \mathrm{~min} .95^{\circ} \mathrm{C}\right)$ and sonicated $(50 \%, 30 \mathrm{sec}$.) before electrophoresis was performed on $8 \%$ PAA gels. Proteins were subsequently transferred to nitrocellulose membranes (AppliChem $\mathrm{GmbH}$, Darmstadt, Germany) and a mouse antibody against the hemagglutinin-tag (Covance Inc., NJ, USA, 1:3000) or a goat antibody against Hsp70 (Santa Cruz Biotechnology, CA, USA, 1:500) were applied, followed by an incubation with a goat anti-mouse IgG-HRP secondary antibody (Santa Cruz Biotechnology, CA, USA, 1:3000) or a donkey antigoat IgG-HRP-conjugated secondary antibody (Santa Cruz Biotechnology, CA, USA, 1:5000). Between all steps, blots were washed with Tris-buffered saline (TBS-T) with $0.1 \%$ Tween-20. Labeled proteins were detected using the enhanced chemiluminescence-plus reagent (Amersham, Buckinghamshire, England) and exposed to photographic film. An anti-actin primary antibody (Chemicon International, 
Temecula, CA, USA, 1:5000), which cross-reacts with all known isoforms of actin, and a goat anti-mouse HRP-conjugated secondary antibody (Santa Cruz Biotechnology, CA, USA, 1:3000) were used to assess equal loading in each lane. Protein amounts were estimated using the Quantity-One software package (Bio-Rad Laboratories, Hercules, Calif, USA).

\subsubsection{Immunocytochemistry}

SH-SY5Y cells were treated with native isolated Tat-Hsp70 or Hsp70 without the Tat domain $(500 \mathrm{nM})$ and incubated for $4 \mathrm{~h}$ at $37^{\circ} \mathrm{C}$. After cell fixation with $4 \%$ paraformaldehyde $\left(20 \mathrm{~min}\right.$ at about $\left.21^{\circ} \mathrm{C}\right)$, cells were incubated with $50 \mathrm{mM}$ ammonium chloride/PBS and permeabilization in $0.2 \%$ Triton-X/PBS for $10 \mathrm{~min}$. Cells were blocked in $2 \% \mathrm{BSA} / \mathrm{PBS}\left(30 \mathrm{~min}\right.$ at about $21^{\circ} \mathrm{C}$ ) and incubated over night at $4^{\circ} \mathrm{C}$ with a mouse primary antibody against the hemagglutinin-tag (Covance Inc., NJ, USA, $1: 200$, in $2 \%$ BSA/PBS) followed by incubation with a Cy3-conjugated goat anti-mouse secondary antibody (Jackson Immuno-Research Laboratories Inc., USA) $\left(1: 500\right.$, in $2 \%$ BSA/PBS for $1 \mathrm{~h}$ at $\left.37^{\circ} \mathrm{C}\right)$. Finally, nuclear staining with 4',6-diamidino2-phenylindole (DAPI, $2 \mu \mathrm{g} / \mathrm{ml}, 5 \mathrm{~min}$ ) was performed and cells were mounted with Mowiol (EMD Bioscience, La Jolla, San Diego ,CA, USA). Labeling was visualized by fluorescence microscopy using a Zeiss Axioplan II microscope with Zeiss Axiovision Software (Zeiss, Jena, Germany) and a digital camera (AxioCam, Zeiss Jena, Germany). Between all steps cells were washed with PBS.

\subsubsection{Live Imaging in vitro}

Tat-Hsp70 and Hsp70 (3 $\mu \mathrm{g} / \mu \mathrm{l})$ purified under native conditions were dialyzed against an amine-free buffer (0.2 $\mathrm{M} \mathrm{NaHCO}_{3} \mathrm{pH} 8.3,50 \%$ glycerol, $3 \mathrm{mM}$ sodium azide). The amine-reactive compound fluorescein-5-isothiocyanate isomer (FITC, Molecular Probes, Eugene, OR, USA) was dissolved in dimethylsulfoxide (10 mg/ml) and was incubated with protein solution for $1 \mathrm{~h}$ at about $21^{\circ} \mathrm{C}$ with continuous stirring. Column chromatography (Sephadex size exclusion column, GE Healthcare, Munich, Germany) was used to purify the conjugates. The concentration of the FITC linked Tat-Hsp70 and Hsp70 was calculated as described in section 2.2. The relative 
efficiency of the labeling reaction was determined by measuring the absorbance maximum of the protein at $280 \mathrm{~nm}$ and the absorbance of the dye (FITC) at $494 \mathrm{~nm}$. The Tat-Hsp70-FITC conjugates were diluted to approximately $0.1 \mathrm{mg} / \mathrm{ml}$. The calculation of the degree of labeling was carried out as described in the Handbook of Fluorescent Probes and Research Products (www.probes.com).

$$
\begin{gathered}
A_{\text {protein }}=A_{280}-A_{\max }(C F) \\
D O L=\left(A_{\max } \times M W\right) /\left(\left[A_{\text {protein }}\right] . x \epsilon_{\text {dye }}\right)
\end{gathered}
$$

where $\mathrm{DOL}=$ degree of labeling, Correction Factor $\left(C F=A_{280 \text { free dye }} / A_{\text {max free dye; }} 0.3\right.$ for FITC), $M_{\text {Tat- }}$ $\mathrm{Hsp70}=77000 \mathrm{Da}, \mathrm{MW}_{\mathrm{Hsp} 70}=70000 \mathrm{Da}, \mathrm{MW}_{\mathrm{FITC}}=389.38, \mathrm{~A}_{\text {maxFITC }}:$ measured at $494 \mathrm{~nm}, \epsilon_{\mathrm{FITC}}=68000$ (extinction coefficient of FITC at the absorbance maximum), $1.4 \mathrm{~A}_{\text {protein }}=1 \mathrm{mg} / \mathrm{ml}$.

FITC-Tat-Hsp70 and FITC-Hsp70 (200 nM, in 50\% glycerol, $0.2 \mathrm{M} \mathrm{NaHCO}_{3}$ ) treated cells were washed with PBS before live recordings were performed by fluorescence (Zeiss, Jena, Germany) and confocal microscopy (Leica, Bensheim, Germany) $1 \mathrm{~h}$, $2 \mathrm{~h}$ or $7 \mathrm{~h}$ after protein treatment, respectively.

\subsection{Fluorescence-based folding assay}

The chaperone folding assay is an elegant technique to examine whether the method of protein purification influences the functionality of recombinant Tat fusion proteins. For determination of chaperone activity in individual cells, a mutated YFP expression vector (pcdYFP) was used as chaperone sensor (Liman et al., 2005). The foldingimpaired chaperone-dependent yellow fluorescent protein (cdYFP), which shows fluorescence recovery as folding response, was kindly provided by Christoph $P$. Dohm in our laboratory. For the enhanced cyan fluorescent protein (ECFP), we employed a site-directed mutagenesis-variant (Cerulean, ECFP/S72A/Y145AH148D, David. W. Piston, University of Vanderbilt, Nashville, Tennessee, USA) with improved characteristics regarding its fluorescence lifetime. More detailed information on constructs, transformation and protein purification have been described previously (Rizzo et al., 2004; Liman et al., 2005; see also table 1). 


\begin{tabular}{|c|c|c|}
\hline construct & Excitation & Emission \\
\hline$p c d Y F P$ & $513 \mathrm{~nm}$ & $527 \mathrm{~nm}$ \\
\hline$p E C F P$ & $435 \mathrm{~nm}$ & $475 \mathrm{~nm}$ \\
\hline
\end{tabular}

Table 1: Plasmids

Rat nigrostriatal CSM 14.1 and SH-SY5Y neuroblastoma cell lines were cultured to $70 \%$ confluence on $15 \mathrm{~mm}$ coverslips in 24-well dishes. For the quantification of the cellular foldase capacity, we transfected cells with $0.125 \mu \mathrm{g}$ of pcdYFP vector and $0.125 \mu \mathrm{g} p E C F P$ vector (BD Bioscience Clonetech) per well. To facilitate quantitative co-expression, we used magnet-assisted transfection in serum free medium according to supplier's protocol (MATra, IBA BioTAGnology, Göttingen, Germany). After 20 min incubation at $37^{\circ} \mathrm{C}$, different preparations of Tat-Hsp70 and Hsp70 $(250 \mathrm{nM})$ were added into the medium, followed by $24 \mathrm{~h}$ incubation to allow cdYFP/ECFP co-expression and cell transduction by recombinant proteins.

Cells were fixed with $4 \%$ paraformaldehyde in PBS for 30 min and mounted with Mowiol (EMD Bioscience, La Jolla, CA) on object slides for confocal microscopy (Leica, Bensheim, Germany). Detection of cdYFP and ECFP fluorescence was performed according to a previous report (Liman et al., 2005). The folding efficiency was evaluated by image arithmetic (cdYFP fluorescence/reference ECFP fluorescence) using Image J 1.32 software (http://rsb.info.nih.gov/ij/). Folding ratio histograms were prepared for 15 cells for each condition and analyzed using the lgor analysis package (IGOR Pro 5.04 (Windows '95-XP, Wave Metrics Inc., Lake Oswego, USA). The histograms were normalized to the sum area of the cells and scaled to the folding response of control cells without recombinant protein treatment (cdYFP/ECFP fluorescence ratio of 1 ). The cellular foldase activity is displayed in false-color coding where warmer colors indicate higher folding activity. For statistical analysis of the different treatments, probability density functions (PDF) were generated from the cumulative histograms of experiments on the same condition by re-normalization to unity. As the folding response in cells appears to have a nonGaussian distribution, we adopted an established analysis method (Esposito et al., 2007). For each cell, the probability of exceeding the threshold at the mean $(\mu)+2^{*}$ the standard deviation of the control distribution (the " $2 \sigma$ threshold"), i.e., the probability of obtaining higher cdYFP ratios than contained in the control, was 
obtained by integration of the normalized folding ratio histogram values exceeding the $2 \sigma$ threshold.

\subsection{In vitro cell death assays}

\subsubsection{Application of Tat-Hsp70 and 6-OHDA cell death induction in SH-SY5Y cells}

Cells were treated with recombinant protein $(250 \mathrm{nM})$ isolated as described in section 2.1. $1.5 \mathrm{~h}$ later, 6-hydroxydopamine (6-OHDA) was added to the cell culture medium at final concentrations of 40,50 or $60 \mu \mathrm{M}$. Cell viability was assessed $24 \mathrm{~h}$ after 6-OHDA treatment using the WST-1 proliferation reagent (Roche Applied Science, Mannheim, Germany). The assay is based on the cleavage of the tetrazolium salt WST-1 by succinate-tetrazolium reductase producing soluble formazan. The enzyme is part of the respiratory chain in mitochondria. This conversion only occurs in viable cells. Cells were incubated with WST-1 for $1 \mathrm{~h}$. The formed formazan dye was quantified via measurement of the absorbance (optical density) at $450 \mathrm{~nm}$ using a THERMOmax microplate reader (Tecan, Spectra Rainbow, Austria). The absorbance is proportional to the number of metabolically active cells. Values for different protein treatments were normalized against buffer control.

\subsubsection{Primary dopaminergic midbrain neurons and $\mathrm{MPP}^{+}$toxicity}

Cells were prepared as described in section 2.3.3. Only about $5 \%$ of the cultured cells $\left(\mathrm{E} 14\right.$, Wistar) are DA and thus sensitive to $\mathrm{MPP}^{+}$. The total number of cells can be used as an internal control for possible variations in cell density among experimental conditions or independent experiments. The medium was exchanged against fresh one after 1 and 3 days in vitro (DIV). On DIV 4, Tat-Hsp70, Tat-HA, Hsp70, or vehicle (50\% glycerol, $274 \mathrm{mM} \mathrm{NaCl}, 10 \mathrm{mM}$ Tris $\mathrm{pH} 10,0.1 \%$ Pluronic, $0.02 \%$ Tween-80) was applied to the culture. As an additional control, cells were kept in culture without any protein or buffer treatment. The final concentration of recombinant protein was $250 \mathrm{nM}$ each. After $2 \mathrm{~h}$ of incubation, 1-methyl-4phenylpyridinium (MPP ${ }^{+}$, Sigma, Taufkirchen, Germany) was added to the culture at 
a final concentration of $6 \mu \mathrm{M}$ for $24 \mathrm{~h}$. Immunohistochemistry was performed with an primary antibody against tyrosine hydroxylase ( $\mathrm{TH}$, Advanced Immunochemical Inc., CA, USA, 1:500) and a Cy3-coupled anti-rabbit (1:200, in 10\% NGS/PBS, Jackson ImmunoResearch Lab. Inc., USA) secondary antibody followed by nuclear-staining with DAPI ( $2 \mu \mathrm{g} / \mathrm{ml}, 5 \mathrm{~min})$. After staining, cultures were kept in PBS and numbers of TH-positive cells and DAPI-positive nuclei were counted immediately in at least 3 fields per well of the 96-well plate for each condition using a fluorescence microscope (Axiovert, Zeiss, Jena, Germany). We then calculated the fraction of TH-positive cells of the total cell number. Single digital photographed pictures (Axiovert, Zeiss, Jena, Germany) were taken with a $20 \mathrm{x}$ objective and were analyzed with Image $\mathrm{J}$ (http://rsb.info.nih.gov/ij/, free software, 1.37v, National Institutes of Health, Maryland, USA). Neurites were counted and neurite length was measured. To determine the length distribution of neurites, the untreated control condition was set to $100 \%$ for each experiment. Neurite length of Tat-Hsp70, Hsp70, Tat-HA and buffer-treated cultures (with and without $\mathrm{MPP}^{+}$application) were normalized against the control cells without any protein or buffer treatment.

\subsection{Immunohistochemistry to demonstrate delivery of recombinant protein across the blood-brain barrier into the midbrain and retina}

Adult male mice (22-30 g) purchased from Charles River Wiga (Sulzfeld, Germany) were intraperitoneally (i.p.) injected with $5 \mathrm{nmol}$ Tat-Hsp70 or Hsp70 (3 times in 24 hours) purified under native conditions. 6 hours after the final protein injection, anaesthesia, brain fixation, and immunohistochemistry were carried out according to Nagel et al. (2008). $18 \mu \mathrm{m}$ (SN) and $8 \mu \mathrm{m}$ (retina) cryosection slices were incubated with a mouse anti-Hsp70 primary antibody (Stressgen Bioreagents, BC, Canada, $1: 200$ ) and an anti-mouse-Alexa 680-conjugated secondary antibody (Molecular Probes, Eugene, OR, USA, 1:200). TH-staining is described in the next section. Slices were incubated with DAPI $(2 \mu \mathrm{g} / \mathrm{ml}$ for $1 \mathrm{~h})$ before slides were mounted with Mowiol (EMD Bioscience, La Jolla, San Diego, CA, USA). Labeling was visualized by fluorescence microscopy using a Zeiss Axioplan II microscope with Zeiss Axiovision Software (Zeiss, Jena, Germany) and a digital camera (AxioCam, Zeiss Jena, Germany). 


\subsection{MPTP and Tat-Hsp70 treatment of mice}

\subsubsection{Mouse treatment and TH-immunostaining}

Mice were treated according the German guidelines for the care and the use of laboratory animals and in accordance with the European Communities Council Directive of $24^{\text {th }}$ November 1986 (86/609/EEC).

Immediately before injection, fusion proteins were mixed with SDS to a final concentration of $0.5 \%$ to prevent protein degradation and also to block their instantaneous internalization, allowing slow diffusion and progressive release within the peritoneal cavity (Schutze-Redelmeier et al., 1996). On days 1, 2, 3, 4, 5, 7, 9 and 11 of the experiment, 14 weeks-old C57BL/6 mice (21.5-30.5 g, Charles River Wilmington, MA, USA) were i.p. injected with $5 \mathrm{nmol}$ of either Tat-Hsp70, control protein Tat-HA, dialysis buffer, or PBS, always at the same time of the day. All proteins were isolated under native conditions. On five consecutive days $(1,2,3,4,5$ of the experiment), $30 \mathrm{mg} / \mathrm{kg}$ MPTP were i.p. injected $6 \mathrm{~h}$ after protein application. In all groups, at least 5 animals were used for evaluation (PBS: $n=5$; PBS + MPTP: $n=6$; buffer + MPTP: $n=7$; Tat-HA + MPTP: $n=7$; Tat-Hsp70 + MPTP: $n=6) .14$ days after the last MPTP injection, mice were sacrificed and their brains prepared for immunostaining according to Dietz et al. (2006b). The posterior parts of the brains including the SN were cut into $50 \mu \mathrm{m}$ coronal sections. Every $3^{\text {rd }}$ section was incubated with an anti-TH antibody (Advanced Immunochemical Inc., Long Beach, CA, USA, 1:1000) and a biotinylated goat anti-rabbit secondary antibody (Jackson ImmunoResearch Laboratories, Inc., Baltimore, PA, USA, 1:200) followed by incubation with the Vectastain ${ }^{\circledR}$ ABC-Peroxidase-Kit (Vector Laboratories, Inc., Burlingame, CA, USA). The reaction was developed in 3,3'-diaminobenzidine (Sigma, Taufkirchen, Germany). Of the striatum, every $6^{\text {th }}$ section was collected for immunostaining using the Vectastain ${ }^{\circledR}$ Elite ABC-Kit (Vector Laboratories, Inc., Burlingame, CA, USA). 


\subsubsection{Immunohistochemistry protocol}

Brain slices were washed $3 \times 5 \mathrm{~min}$ in $0.1 \mathrm{M}$ TBS, before they were incubated in $10 \%$ methanol and $3 \% \mathrm{H}_{2} \mathrm{O}_{2}$ (in $0.1 \mathrm{M}$ TBS) for 5 min to block endogenous peroxidases. After $3 \times 5$ min washing in 0.1M TBS, the cortex of the slices was removed. Midbrain slices and slices of the striatum were then incubated in 5\% NGS (in $0.1 \mathrm{M}$ TBS) for $1 \mathrm{~h}$ to block unspecific antibody binding. An anti-tyrosine hydroxylase antibody (rabbit) was applied for $48 \mathrm{~h}\left(1: 1000\right.$ in $2 \% \mathrm{NGS} / 0.1 \mathrm{M}$ TBS) at $4{ }^{\circ} \mathrm{C}$, followed by washing the slices ( $3 \times 5 \mathrm{~min}$ in $0.1 \mathrm{M}$ TBS.) and incubation with an anti-rabbit-biotin antibody (1:200 in $2 \%$ NGS in $0.1 \mathrm{M} \mathrm{TBS})$ at about $21^{\circ} \mathrm{C}$ for $1 \mathrm{~h}$. The preparation of the Vectastain ${ }^{\circledR}$ ABC working solution (2 drops of reagent $A$ and $B$ per $10 \mathrm{ml}$ TBS) was carried out 45 min before its application on brain slices. Either the ABC-Kit (Vector Laboratories Inc., Burlingham, CA, USA) for incubation of midbrain slices, or the Elite-Kit for incubation of striatal slices (Vector Laboratories Inc., Burlingham, CA, USA) were applied for $1 \mathrm{~h}$ at about $21^{\circ} \mathrm{C}$. After the following washing steps $(3 \times 5 \mathrm{~min}$ in $0.1 \mathrm{M}$ TBS), all slices were incubated in $50 \mathrm{ml}$ Tris $\mathrm{GN}$ (pH 7.6) of $25 \mathrm{mg} \mathrm{DAB}, 100$ $\mu \mathrm{l}$ ammonium chloride, $150 \mu \mathrm{l}$ glucoseoxidase, $400 \mu$ glucose, either $15 \mathrm{~min}$ for midbrain slices or 20 min for the striatal slices. The DAB was inactivated with sodium hypochlorite. Slices were washed ( $3 \times 5 \mathrm{~min}$ in $0.1 \mathrm{M}$ TBS) and transferred onto gelatin-coated objective slides.

\subsubsection{Neurochemical analysis}

Striata were rapidly dissected and transferred to dry-ice, before perchloric acid $(20 \mu \mathrm{l} / \mathrm{mg}$ tissue of $0.1 \mathrm{M})$ was added to precipitate proteins. Samples were sonicated $50 \%, 10 \mathrm{sec}$ ) and centrifuged at $15.700 \mathrm{rcf}$ for $20 \mathrm{~min}$. Supernatant was collected and frozen at $-80^{\circ} \mathrm{C}$ until the concentrations of dopamine, 3,4-dihydroxyphenylacetic acid (DOPAC) and homovanillic acid (HVA) were measured by high performance liquid chromatography (HPLC) with electrochemical detection as previously described (Eberhardt et al., 2000). Catecholamine concentrations were expressed in pmol per mg of striatal tissue. 


\subsubsection{MPTP metabolism}

$\mathrm{MPP}^{+}$levels in the brain were determined by HPLC. 3 mice of each group were i.p. injected with $30 \mathrm{mg} / \mathrm{kg}$ MPTP and sacrificed $90 \mathrm{~min}$ later. Striata, midbrains and eyes were quickly dissected on ice, homogenized in $20 \mu \mathrm{l} 0.1 \mathrm{M}$ perchloric acid per mg tissue and then debris removed by high-speed centrifugation (see section 2.8.2). $20 \mu \mathrm{l}$ of the supernatant were injected onto a reverse-phase column (Nucleosil-100 C18, Knauer, Berlin, Germany) and quantified by UV absorption at $300 \mathrm{~nm}$ (UVD 340U, Dionex, Berlin, Germany) using Chromeleon 6.60 software. The mobile phase consisted of $697 / 1000 \mathrm{ml}$ acetonitrile in phosphate buffer $(\mathrm{pH} 2.5)$. The flow rate was $0.5 \mathrm{ml} / \mathrm{min}$. Values represent $\mathrm{pg} \mathrm{MPP}^{+}$per $\mathrm{mg}$ of wet tissue.

\subsubsection{Nissl-staining}

Slices were dried for $12-24 \mathrm{~h}$ at about $21^{\circ} \mathrm{C}$. Gelatin-coated slides and were incubated in $95 \%$ ethanol for $20 \mathrm{~min}$, followed by incubation in a chloroform-solution for $10 \mathrm{~min}$, before slices were dehydrated with $95 \%$ and $100 \%$ ethanol ( $2 \times 2 \mathrm{~min})$. Xylene (Roth, Karsruhe, Germany) was applied for $5 \mathrm{~min}$ and the ethanol treatment was then repeated vice versa starting with $100 \%$ ethanol for 5 and $95 \%$ ethanol for 2 times $2 \mathrm{~min}$. A short wash with distilled water (2 $\mathrm{min}$ ) was carried out before cresylviolet (thionin acetate, Sigma, Taufkirchen, Germany) staining was performed for $7 \mathrm{~min}$. After a washing step in distilled water $(3 \times 2 \mathrm{~min})$ slices were fixed in formalinacetic solution (Formalin, Sigma, Taufkirchen, Germany) and, after additional washing steps ( $3 \times 2 \mathrm{~min}), 95 \%$ ethanol was used to dehydrate slices ( $3 \times 2 \mathrm{~min})$. 100\% n-butanol (Merck, Darmstadt, Germany) and cedar wood oil (Sigma, Taufkirchen, Germany) were applied for 10 min each. The sections were clarified with xylene ( $2 \times 10 \mathrm{~min}$ ), and entellan was used to mount the sections. The striatal slices were only dehydrated with increasing concentrations of ethanol $(70 \%, 95 \%$ and $100 \%$ for $10 \mathrm{~min}$ each), followed by xylene treatment $(2 \times 10 \mathrm{~min})$. 


\subsubsection{Stereology}

The number of tyrosine hydroxylase-positive neurons in the SNpc was assessed using stereological methodology. Here, the number of TH-positive neurons in the SNpc and Nissl-positive neurons was counted from the left side of each DAB-stained and Nissl-stained section from all animals per group by using the optical dissector technique (Stereo Investigator 6.0, MicroBrightField Inc., Zeiss microscope, Jena, Germany; Dehmer et al., 2004). Counts were performed manually and blinded for treatment. We evaluated striatal fiber density by subtracting the optical density of the cortex from the striatum using Scion Image 4.0.3.2 software (Windows '95-XP, Washington D.C., Scion Corporation, Frederick, Maryland, MD, USA).

\subsubsection{The retina as a model for the death of dopaminergic neurons}

For the subacute MPTP model, retinas were prepared from the same mice that were i.p. injected for evaluation of DA neurons in SNpc. For the acute MPTP model, mice were anesthetized with diethyl ether and we performed a single intraocular (i.o.) injection of MPTP $(0.5 \mu \mathrm{l}$ of $20,10,5,2 \mu \mathrm{g} / \mu \mathrm{l})$ or PBS into the right eye $(n=4)$. In a second experiment, we i.o. injected $\mathrm{MPP}^{+}(0.5 \mu \mathrm{l}$ of 50 or $200 \mu \mathrm{g} / \mu \mathrm{l})$ or $6-$ OHDA $(0.5$ $\mu \mathrm{l}$ of 30 or $60 \mu \mathrm{g} / \mu \mathrm{l})$. Native purified Tat-Hsp70 was i.p. injected $(5 \mathrm{nmol})$ at the same time. 7 days after MPTP injection retinas were cut into $18 \mu \mathrm{m}$ sections on a cryostat. Every $3^{\text {rd }}$ section was incubated with an anti-TH antibody (Advanced Immunochemical Inc., CA, 1:1000) and a Cy3-conjugated goat anti-rabbit secondary antibody (Jackson ImmunoResearch Laboratories, Inc., 1:200). Slides were mounted with Mowiol (EMD Bioscience, La Jolla, CA). Labeling was visualized by fluorescence microscopy using a Zeiss Axioplan II microscope with Zeiss Axiovision Software (Zeiss, Jena, Germany) and a digital camera (AxioCam, Zeiss Jena, Germany). We counted every TH-stained amacrine cell and calculated the total number of TH-positive cells per retina by interpolation. Counts were performed manually and blinded for treatment. MPP ${ }^{+}$levels in the eye were determined by HPLC as described in section 2.8.3. 


\subsection{Chemicals, media, buffers, solutions and antibodies}

\subsubsection{List of chemicals}

AppliChem: chloroform, glycine, imidazole, LB medium (powder), LB agar (powder), milk powder, PBS (1x Dulbecco's, powder), sodium dodecylsulfate (SDS), Tris.

Bio-Rad Laboratories: rainbow marker.

Calbiochem AG: Mowiol.

Fluka: chloral hydrate, p-coumaric acid.

GE-Healthcare: Sephadex G-50 columns (PD-10)

GeReSo GmbH: 99\% ethanol.

Gibco: B27 supplement, DMEM, DMEM: F12 (1:1), OptiMEM.

IBA BioTAGnology: Magnetic Assistant Transfection (MATra).

Mackerey Nagel: Ni-Resin, Ni-TED.

MERCK: n-Butanol, Coomassie Brilliant Blue, hydrogen peroxide, $\mathrm{NaHCO}_{3}$, ammonium chloride.

Molecular Probes: FITC.

PAA Laboratories GmbH: FCS, NGS, penicillin, streptomycin.

Quiagen: Ni-NTA, QIAGEN Plasmid Maxi Kit.

$\underline{\text { Riedel-de Haën }}{ }^{\circledR}$ : ethanol absolute.

Roche: DNase I, WST-1.

Roth: ampicillin, BSA, chloramphenicol, diethylether, $\mathrm{D}(+)$-sucrose, entellan, ethylenediaminetetraacetic acid, glacial acetic acid, glucose, glycerol, Hepes, hydrochloric acid, methanol, $\mathrm{NaCl}$, sodium hypochlorite, paraformaldehyde, Triton-X, urea, xylene

Sakura: Tissue-Tek ${ }^{\circledR}$.

Serva: bromphenol blue sodium salt (BPB), tetramethylethylendiamine.

Sigma: cedar wood oil, glucoseoxidase, DAB, DAPI, dimethylsulfoxide, formaldehyde, lactose, laminin, luminol, lysozyme, mercaptoethanol, $\mathrm{MgCl}_{2}, \mathrm{MPP}^{+}$, MPTP, sodium azide, 6-OHDA, Pluronic F-68, protease inhibitor, retinoic acid, sodium cacodylate trihydrate, poly-L-ornithine, thionin acetate, Tween-80, trypsin.

Vector Laboratories: Vectastain ${ }^{\circledR}$ ABC Kit Standard, Vectastain ${ }^{\circledR} A B C$ Kit Elite. 


\subsubsection{List of media}

LB-medium: $\quad 10 \mathrm{~g} / \mathrm{l}$ tryptone, $5 \mathrm{~g} / \mathrm{l}$ yeast extract, $5 \mathrm{~g} / \mathrm{l} \mathrm{NaCl}$.

LB-plate: $\quad$ LB-medium, $2 \%(\mathrm{~m} / \mathrm{v})$ Agar.

SOC: $\quad 20 \mathrm{~g} / \mathrm{l}$ trypton, $5 \mathrm{~g} / \mathrm{l}$ yeast extract, $10 \mathrm{mM} \mathrm{NaCl}, 10 \mathrm{mM} \mathrm{MgCl}_{2}, 10$ $\mathrm{mM} \mathrm{MgSO}_{4}, 20 \mathrm{mM}$ glucose.

SH-SY5Y cells: $\quad$ DMEM (Dulbecco's modified Eagle Medium), $15 \%$ (v/v) FCS, $100 \mathrm{U} / \mathrm{ml}$ penicillin/ $100 \mu \mathrm{g} / \mathrm{ml}$ streptomycin.

CSM14.1 cells: $\quad$ DMEM (Dulbecco's modified Eagle Medium), 10\% (v/v) FCS, 100 $\mathrm{U} / \mathrm{ml}$ penicillin/ $100 \mu \mathrm{g} / \mathrm{ml}$ streptomycin.

Midbrain neurons: DMEM F12, 2,5 g/l BSA, 2 mM a-glutamine, 0,9\% glucose, $5 \mathrm{mg} / \mathrm{l}$ insulin, $1 \%(\mathrm{w} / \mathrm{v}) \mathrm{N} 1,100 \mathrm{U} / \mathrm{ml}$ penicillin/ $100 \mathrm{\mu g} / \mathrm{ml}$ streptomycin, 5\% (v/v) DMEM-F12 without glutamine.

CMF-medium: $\quad 90 \%(v / v)$ distilled water, $10 \%(\mathrm{v} / \mathrm{v})$ HBSS.

Opti-MEM ${ }^{\circledR}$ : $\quad$ reduced serum medium (PAA, Cölbe).

\subsubsection{List of buffer and solutions}

Blocking solution for IHC: $\quad 10 \%(\mathrm{v} / \mathrm{v})$ NGS in PBS or TBS.

Blocking solution for WB: $\quad 5 \%(\mathrm{w} / \mathrm{v})$ milk in TBS-T.

Buffer Z:

$8 \mathrm{M}$ urea, $100 \mathrm{mM} \mathrm{NaCl}, 20 \mathrm{mM}$ Hepes, $\mathrm{pH}$

8.0, $5 \mathrm{mM}$ imidazole (for purification under denaturing conditions).

Chloroform solution: $\quad 80 \%$ chloroform $(\mathrm{v} / \mathrm{v}), 10 \%$ ethanol $(95 \%)(\mathrm{v} / \mathrm{v})$, $10 \%$ diethylether $(\mathrm{v} / \mathrm{v})$.

Coomassie-fixing solution: $\quad$ for Tat-Hsp70 and Hsp70: 50\% (v/v) methanol, 10\% (v/v) acetic acid, 40\% $\mathrm{H}_{2} \mathrm{O}$; for TAT-HA: 40\% methanol (v/v), $10 \%$ acetic acid (v/v), 50\% $\mathrm{H}_{2} \mathrm{O}$.

Coomassie-staining solution: $\quad$ 0,05\% Coomassie Brilliant Blue G-250 (w/v), 10\% acetic acid (v/v), 50\% methanol (v/v), 40\% $\mathrm{H}_{2} \mathrm{O}$.

Coomassie-destaining solution: $5 \%$ methanol (v/v), $7 \%$ acetic acid $(\mathrm{v} / \mathrm{v}), 88 \% \mathrm{H}_{2} \mathrm{O}$.

DAB-staining solution: $50 \mathrm{ml}$ Tris GN (pH 7.6) with 25 mg DAB powder, $100 \mu \mathrm{l}$ ammonium chloride $(40 \mathrm{mg} / 200 \mu \mathrm{l}), 150 \mu \mathrm{l}$ 
glucose oxidase $(3 \mathrm{mg} / 1 \mathrm{ml}), 400 \mu \mathrm{l}$ glucose $(200$ $\mathrm{mg} / 800 \mu \mathrm{l})$.

Dialysis buffer:

$0.2 \mathrm{M} \mathrm{NaHCO}_{3}, 50 \%$ (v/v) glycerol, (3 mM sodium azide) (to covalently link protein to the amine reactive dye FITC).

Chemiluminescent detection reagent-1: $2.5 \mathrm{mM}$ luminol, $0.4 \mathrm{mM}$-coumar acid, $0.1 \mathrm{M}$ Tris- $\mathrm{HCl}, \mathrm{pH} 8.5$.

Chemiluminescent detection reagent-2: $18 \% \mathrm{H}_{2} \mathrm{O}_{2}(\mathrm{v} / \mathrm{v}), 0.1 \mathrm{M}$ Tris, $\mathrm{pH}$ 8.5.

Electrophoresis buffer:

Formalin Acetic solution:

GuHCL buffer:

$\mathrm{H}_{2} \mathrm{O}_{2}$ solution:

Incubation solution - for IHC:

Nissl-buffer solution:

Nissl-stock solution:

Nissl-working solution:

PBS:

Permealization buffer:

Protein buffer:

SDS-Sample buffer (2x):

TBS:

TBS-T:
$25 \mathrm{mM}$ Tris- $\mathrm{HCl}, 0.2 \mathrm{mM}$ glycin, $0.1 \%$ SDS (w/v), $\mathrm{pH} 8.3$.

$1 \%(\mathrm{v} / \mathrm{v})$ glacial acetic acid, 1\% ( $/ \mathrm{v})$ formaldehyde ( $39 \%$ stock) in $\mathrm{H}_{2} \mathrm{O}$.

$6 \mathrm{M}$ guanidine hydrochloride, $100 \mathrm{mM} \mathrm{NaCl}, 20 \mathrm{mM}$ Hepes (pH 8.0). $10 \%$ methanol $(\mathrm{v} / \mathrm{v}), 3 \% \mathrm{H}_{2} \mathrm{O}_{2}(\mathrm{v} / \mathrm{v})$ in TBS.

$2 \%$ NGS (v/v) in PBS.

$0.7 \%$ sodium acetate $(\mathrm{w} / \mathrm{v}), 0.2 \%$ glacial acetic acid ( $v / v)$ in $1 \mathrm{l} \mathrm{H}_{2} \mathrm{O}$.

$1 \%$ thionin acetate $(\mathrm{w} / \mathrm{v})$ in $\mathrm{H}_{2} \mathrm{O}$.

mix $10 \%$ stock solution $+80 \%$ buffer solution $(\mathrm{v} / \mathrm{v})$.

$9.55 \mathrm{~g}$ of PBS powder in 11 millipore $\mathrm{H}_{2} \mathrm{O}$, autoclaved.

(for ICC and IHC) $0.1 \%-0.3 \%$ Triton X-100 (v/v) in PBS or TBS.

$10 \mathrm{mM}$ Tris pH10, 20\% glycerol (v/v), $274 \mathrm{mM}$ $\mathrm{NaCl}, 0.1 \%$ Pluronic (w/v), $0.02 \%$ Tween-80 buffer $(\mathrm{v} / \mathrm{v})$ (for native purified protein).

$0.127 \quad \mathrm{M}$ Tris-base, $\mathrm{pH}$ 6.8, $4 \quad \mathrm{mM}$ ethylenediaminetetraacetic acid, 4\% SDS (w/v), $2 \%$ 2-mercaptoethanol (v/v), 20\% glycerol (v/v), 0.015\% bromphenol blue $(\mathrm{w} / \mathrm{v})$.

$150 \mathrm{mM} \mathrm{NaCl}, 10 \mathrm{mM}$ Tris-HCl, pH 9.0.

$0.1 \%$ Tween in TBS, pH 7.6. 
Transfer buffer:

Tris GN:

Trypsin solution:
$192 \mathrm{mM}$ glycine, 20\% methanol (v/v), $25 \mathrm{mM}$ Tris$\mathrm{HCl}, \mathrm{pH} 8.3$.

$12.11 \mathrm{~g} / \mathrm{l}$ Tris $\mathrm{pH} 7.6$.

$25 \mathrm{mg}$ trypsin, $10 \mathrm{ml} \mathrm{CMF} \mathrm{(for} \mathrm{primary} \mathrm{culture).}$

\subsubsection{Table of antibodies}

\begin{tabular}{|c|c|c|c|}
\hline Primary Antibody & Species & Company & Working dilution \\
\hline Hemagglutinin (HA) & mouse & Covance Inc., NJ, USA & $\begin{array}{l}1: 200(\text { ICC) } \\
1: 3000(\mathrm{WB})\end{array}$ \\
\hline Hsp70 & goat & $\begin{array}{c}\text { Santa Cruz Biotechnology, CA, } \\
\text { USA, }\end{array}$ & $1: 500(\mathrm{WB})$ \\
\hline Hsp70 & mouse & $\begin{array}{c}\text { Stressgen Bioreagents, BC, } \\
\text { Canada }\end{array}$ & 1:200 (IHC) \\
\hline Actin & mouse & $\begin{array}{l}\text { Chemicon International, Temecula, } \\
\text { CA, USA }\end{array}$ & 1:5000 (WB) \\
\hline $\begin{array}{c}\text { Tyrosine hydroxylase } \\
\text { (TH) }\end{array}$ & rabbit & $\begin{array}{l}\text { Advanced Immunochemical Inc., } \\
\text { CA, USA }\end{array}$ & $\begin{array}{l}1: 500(\mathrm{ICC}) \\
1: 1000(\mathrm{IHC})\end{array}$ \\
\hline Secondary Antibody & Species & Company & Working dilution \\
\hline IgG-HRP & $\begin{array}{l}\text { goat anti- } \\
\text { mouse }\end{array}$ & $\begin{array}{c}\text { Santa Cruz Biotechnology, CA, } \\
\text { USA }\end{array}$ & $1: 3000$ \\
\hline IgG-HRP & $\begin{array}{l}\text { donkey anti- } \\
\text { goat }\end{array}$ & $\begin{array}{c}\text { Santa Cruz Biotechnology, CA, } \\
\text { USA }\end{array}$ & $1: 5000$ \\
\hline Cy3-conjugated & $\begin{array}{l}\text { goat anti- } \\
\text { mouse }\end{array}$ & $\begin{array}{l}\text { Jackson ImmunoResearch } \\
\text { Laboratories Inc., PA, USA }\end{array}$ & $1: 500$ \\
\hline Cy3-conjugated & $\begin{array}{l}\text { goat anti- } \\
\text { rabbit }\end{array}$ & $\begin{array}{l}\text { Jackson ImmunoResearch } \\
\text { Laboratories Inc., PA USA }\end{array}$ & $1: 200$ \\
\hline $\begin{array}{c}\text { Alexa 680-conjugated } \\
\text { (Cy5.5.) }\end{array}$ & $\begin{array}{l}\text { goat anti- } \\
\text { mouse }\end{array}$ & Molecular Probes, OR, USA & $1: 200$ \\
\hline Biotin-conjugated IgG & $\begin{array}{c}\text { goat anti- } \\
\text { rabbit }\end{array}$ & $\begin{array}{l}\text { Jackson ImmunoResearch } \\
\text { Laboratories, Inc., PA, USA }\end{array}$ & $1: 200$ \\
\hline
\end{tabular}




\subsection{Statistics}

KyPlot (Version 2.0 Beta 15, 1997-2001 Koichi Yoshioka, Tokyo, Japan) was used to perform statistical analysis. All in vitro experiments were performed at least in triplicate and were repeated at least three times. Data are given as mean \pm S.E. Intergroup differences were considered significant at $p<0.05^{*}, p<0.01^{* *}, p<0.001^{* * *}$ according to one-way analysis of variance (ANOVA) followed by Tukey's post-hoc test if the variances of the groups were homogeneous. In case of nonehomogeneous variances, the Dunett-T3-test was used. 


\section{RESULTS}

\subsection{Efficient transduction of SH-SY5Y cells with Tat-Hsp70}

We verified the purity and concentration of our fusion proteins purified from bacterial extracts on Coomassie-stained PAA gels. We show representative pictures of native isolated Tat-Hsp70 (Figure 5), Hsp70 (Figure 6) and Tat-HA (Figure 7) after Ni-affinity chromatography $(\mathrm{A})$ and gel filtration $(\mathrm{B})$.

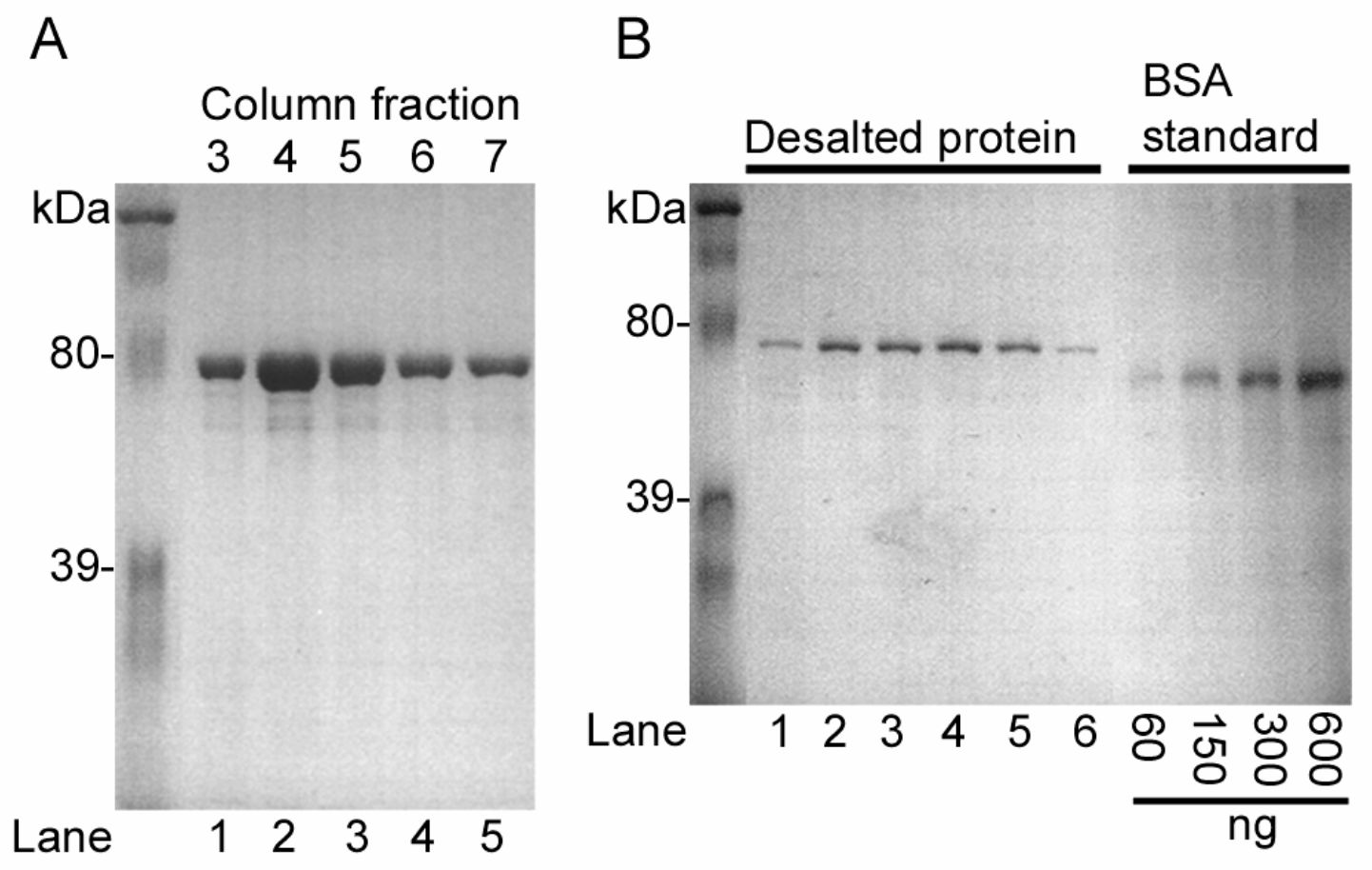

Figure 5. Tat-Hsp70 was isolated to high purity.

Coomassie-stained SDS-PAGE gels showing purity and concentration of Tat-Hsp70 purified under native conditions. Tat-Hsp70 is approximately $77 \mathrm{kDa}$ in size. (A) Tat-Hsp70 was purified by metalaffinity chromatography using Ni-tris-carboxymethyl-ethylene-diamine. Protein was eluted by stepwise addition of binding buffer containing increased concentrations of imidazole (0.1-5 M, lane 1-5). (B) We removed salt by gel filtration on Sephadex size exclusion columns. Protein purity was assessed via Coomassie-stained PAA gels (lane 1-6). BSA was used as a protein standard (60, 150, 300, $600 \mathrm{ng}$ ). 
A

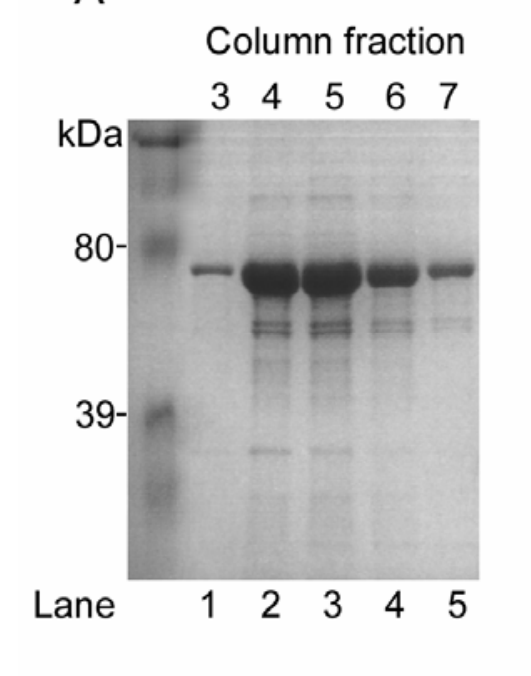

B

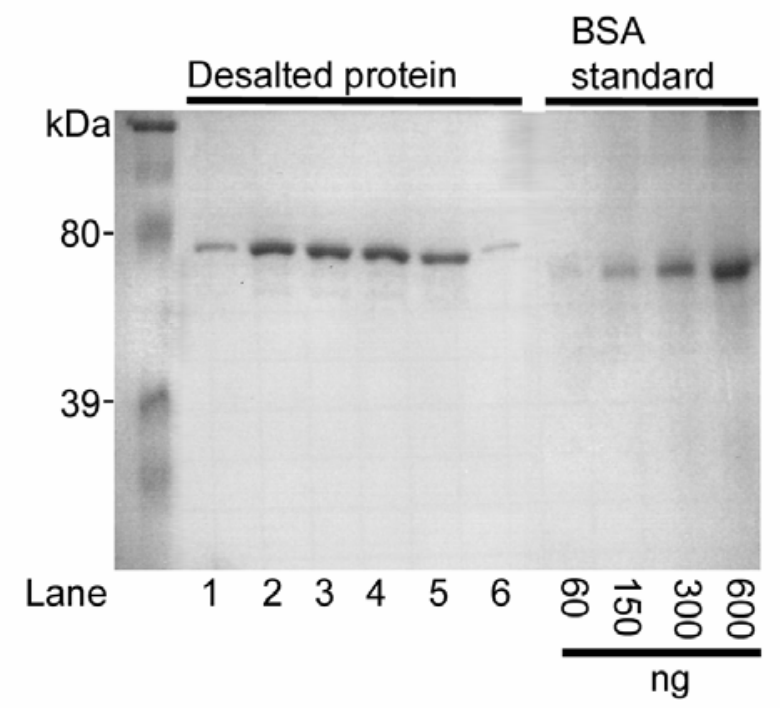

Figure 6. Hsp70 was isolated to high purity.

Coomassie-stained SDS-PAGE gels showing purity and concentration of Hsp70 purified under native conditions. Hsp70 is $70 \mathrm{kDa}$ in size. (A) Hsp70 was purified by metal-affinity chromatography using Ni-tris-carboxymethyl-ethylene-diamine. Protein was eluted by stepwise addition of binding buffer containing increased concentrations of imidazole (0.1-5 M, lane 1-5). (B) We removed salt by gel filtration on Sephadex size exclusion columns. Protein purity was assessed via Coomassie-stained PAA gels (lane 1-6). BSA was used as a protein standard (60, 150, 300, $600 \mathrm{ng}$ ).

A

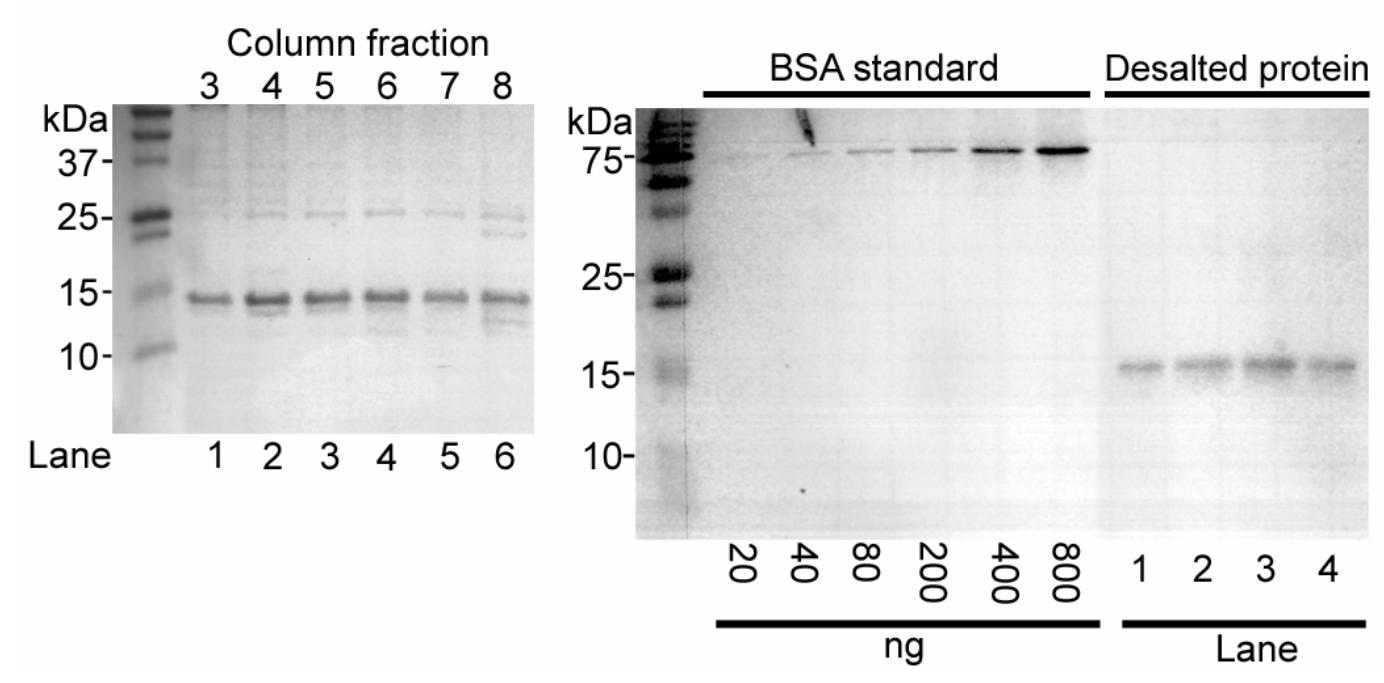

Figure 7. Tat-HA was also isolated to high purity but at a lower yield than with Tat-Hsp70 and Hsp70.

Coomassie-stained SDS-PAGE gels showing purity and concentration of Tat-HA purified under native conditions. Tat-HA is approximately $8 \mathrm{kDa}$ in size. (A) Tat-HA was purified by metal-affinity chromatography using Ni-resin. Protein was eluted by stepwise addition of binding buffer containing increased concentrations of imidazole (0.1-5 M, lane 1-6). (B) We removed salt by gel filtration on Sephadex size exclusion columns. Protein purity was assessed via Coomassie-stained PAA gels (lane 1-4). BSA was used as a protein standard (20, 40, 80, 200, 400, $800 \mathrm{ng})$. 
To investigate whether the purification procedure influences the transduction efficiency of Tat fusion proteins, we treated SH-SY5Y cells with Tat-Hsp70 or Hsp70 (250 $\mathrm{nM}$ ) isolated using 3 different protocols (see section 2.2 and Figure 4). Cell lysates were examined by Western blot analysis. After $30 \mathrm{~min}$ incubation with protein, only native isolated Tat-Hsp70 (Figure 8. A, lane 2) was protected from degradation by trypsin, whereas Tat-Hsp70 purified under denaturing conditions (Figure 8. A, lane 3, 4) and different preparations of Hsp70 (Figure 8. A, lane 5, 6, 7) were degraded. This suggests that only native purified Tat-Hsp70 transduced these cells in vitro. No protein was detectable in the medium after trypsinisation (Figure 8. A, lane 8, 9), indicates that trypsin treatment was effective. After a $1 \mathrm{~h}$ protein treatment, all different preparations of Tat-Hsp70 transduced cells (Figure 8. B, lane 2, 3, 4), while Hsp70 failed to cross cellular membranes (Figure 8. B, lane 5, 6, 7). However, when cells were incubated with protein for $4 \mathrm{~h}$, different purifications of Hsp70 were also taken up by the cells (Figure 8. C, lane 5, 6, 7), albeit with less efficiency compared to different preparations of Tat-Hsp70 (Figure 8. C, lane 2, 3, 4). Native as well as denaturing isolations of Tat-Hsp70 or Hsp70 transduced cells within $24 \mathrm{~h}$. For native purified and denatured protein, when urea was slowly removed, a higher intracellular amount was detectable (Figure 8. D, lane 2, 3, 5, 6) compared to denatured protein, when urea was removed in one rapid step (Figure 8. D, lane 4, 7). This result suggested a lesser intracellular stability of recombinant protein when purified under conditions less favorable to refolding into its native conformation.

To examine kinetics of the uptake and the stability of native purified protein, SH-SY5Y lysates were prepared at different time points (up to $96 \mathrm{~h}$ ) after addition of native isolated Tat-Hsp70 (Figure 9. A, lane 3-10). As shown by Western blot analysis using an anti-HA antibody, the fusion protein quickly transduced the cells (Figure 9. A, lane 3). Using densitometric analysis we showed that over $11 \%$ of Tat-Hsp70 was still detectable after $96 \mathrm{~h}$ (lane 10) compared to the $2 \mathrm{~h}$ time point, at which the highest amount was detected (Figure 9. A, lane 5). To estimate the increase in total amount of Hsp70 by Tat-mediated transduction, we next used a primary antibody against Hsp70 (Figure 9. B). The intracellular amount of recombinant Hsp70 was approximately 4 times higher than the endogenous one $1 \mathrm{~h}$ after adding the recombinant protein (Figure 9. B, lane 2), as determined by densitometric analysis of $\mathrm{x}$-ray films. 

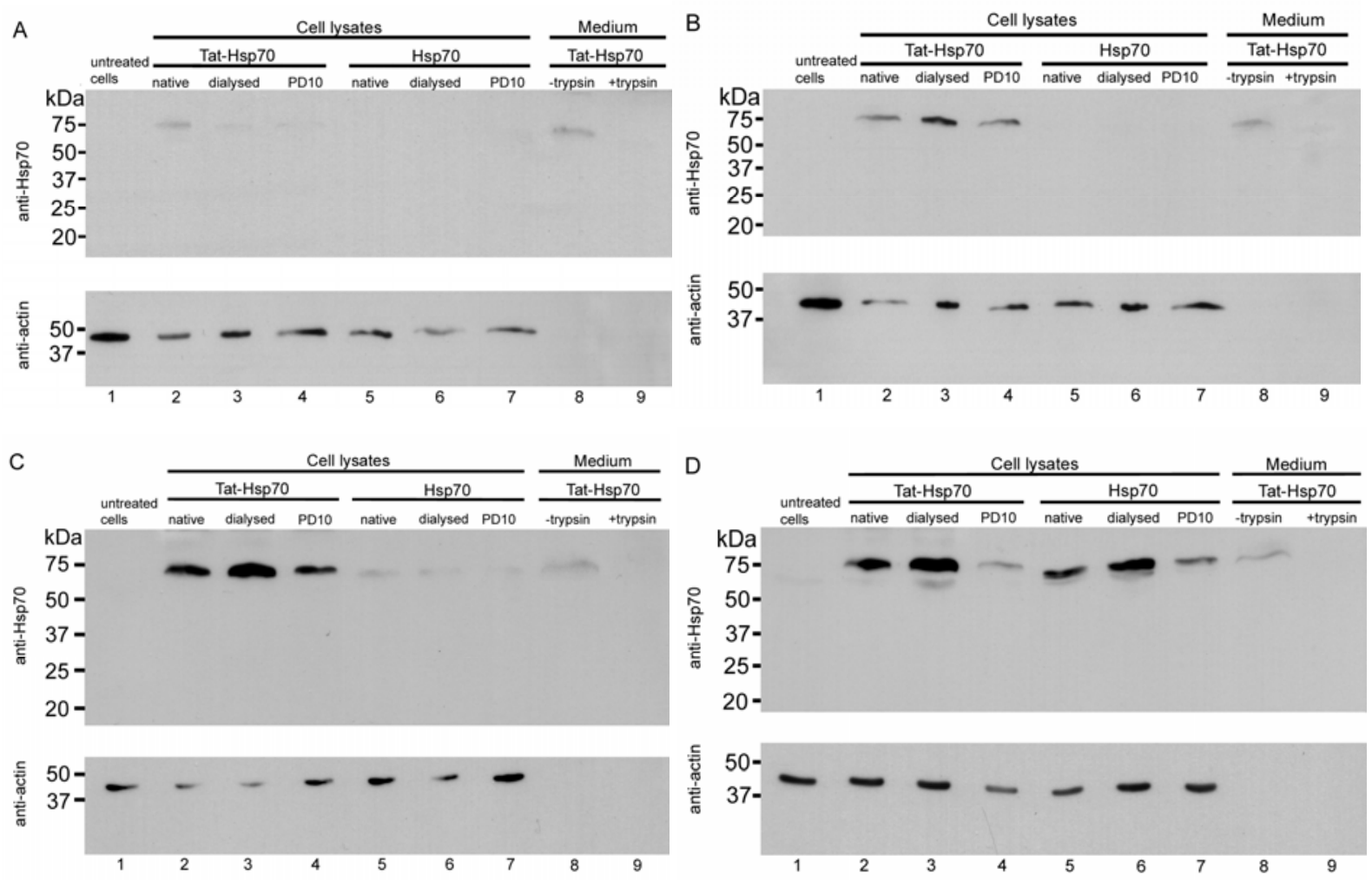

Figure 8. Native isolated Tat-Hsp70 rapidly penetrates SH-SY5Y neuroblastoma cells, compared with Tat-Hsp70 purified under denaturing protocols and different preparations of Hsp70.

SH-SY5Y neuroblastoma cells were treated with Tat-Hsp70 or Hsp70 (250 nM) isolated either under denaturing or native conditions. Cells were trypsin-treated and then lysed after $30 \mathrm{~min}(\mathrm{~A}), 1 \mathrm{~h}(\mathrm{~B}), 4 \mathrm{~h}$ $(C)$, or $24 \mathrm{~h}(\mathrm{D})$. The lysates were used for Western blot analysis with antibodies directed against Hsp70 or actin. This belongs to the body of the text.

A

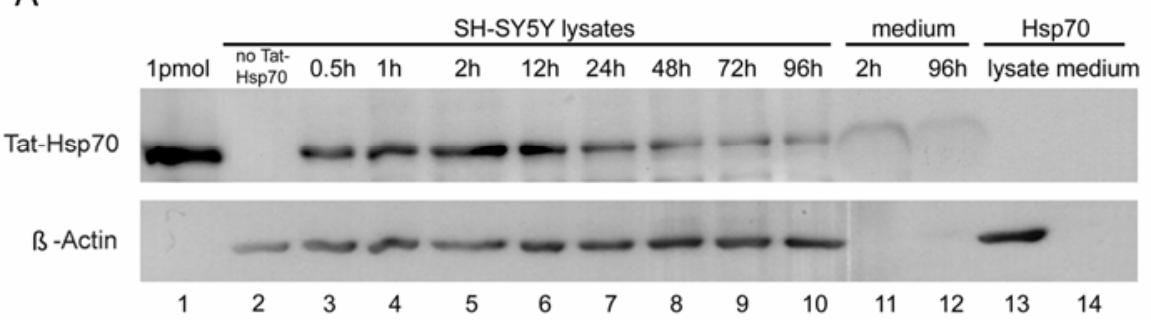

B

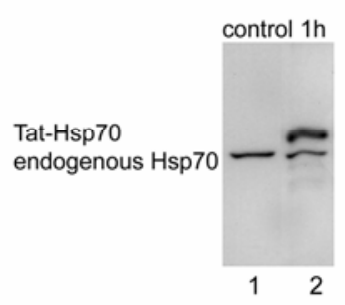

Figure 9. Native isolated Tat-Hsp70 rapidly transduces $\mathrm{SH}-\mathrm{SY} 5 \mathrm{Y}$ neuroblastoma cells and is stable inside the cells.

(A) SH-SY5Y cell lysates were prepared after Tat-Hsp70 treatment (250 nM) at different time points. Hsp70 treated cells $(250 \mathrm{nM})$ were used as control. Western blots were performed using an antibody against the HA-tag of Tat-Hsp70. Lane 1, purified Tat-Hsp70 (1 pmol), lane 2, lysate of untreated cells, lane 3-10, lysates of cells treated with Tat-Hsp70 for the indicated time intervals, lane 11 and 12, medium treated with Tat-Hsp70 for the indicated time periods, lane 13 and 14, cell lysate and medium of Hsp70 treated cells. (B) The ratio of recombinant and endogenous Hsp70 is approximately 4:1. For quantification, cell lysates for the $1 \mathrm{~h}$ time point after Tat-Hsp70 treatment were used. Lane 1, lysates of untreated cells, lane2, lysates of Tat-Hsp70-treated cells. A goat anti-Hsp70 antibody was used. 
Thus, native isolated Tat-Hsp70 quickly and efficiently transduces SH-SY5Y neuroblastoma cells and is stable there for at least several days. We confirmed efficient transduction of the native isolated Tat-Hsp70 by immunocytochemistry (Figure 10). To exclude possible artifacts that have been described using methanol or paraformaldehyde to fix cells (Richard et al., 2003) we imaged live SH-SY5Y cells treated with fluorescently labeled Tat-Hsp70 or Hsp70 (Figure 11). Fluorescence microscopy on these unfixed cells revealed a cellular signal only for the Tat-Hsp70 treated cells, confirming that the Tat domain is necessary for an efficient transduction (Figure 11. A-F). We also performed live imaging with confocal microscopy to demonstrate the subcellular distribution of the protein $2 \mathrm{~h}$ and $7 \mathrm{~h}$ after Tat-Hsp70 or Hsp70 treatment (Figure 11. G-L). For Tat-Hsp70-treated cells an intracellular signal was detectable (Figure 11. H), whereas for Hsp70 no immunofluorescence was observed after $2 \mathrm{~h}$ (Figure 11. K). The punctated fluorescence of Tat-Hsp70 treated cells suggests an endosomal uptake mechanism as the major pathway of transduction. $7 \mathrm{~h}$ after protein treatment, the immunofluorescence signal of FITClinked Tat-Hsp70 was increased (Figure 11. N). Moreover, also for the FITC-linked Hsp70 treated cells a cellular signal was detectable (Figure 11. Q).

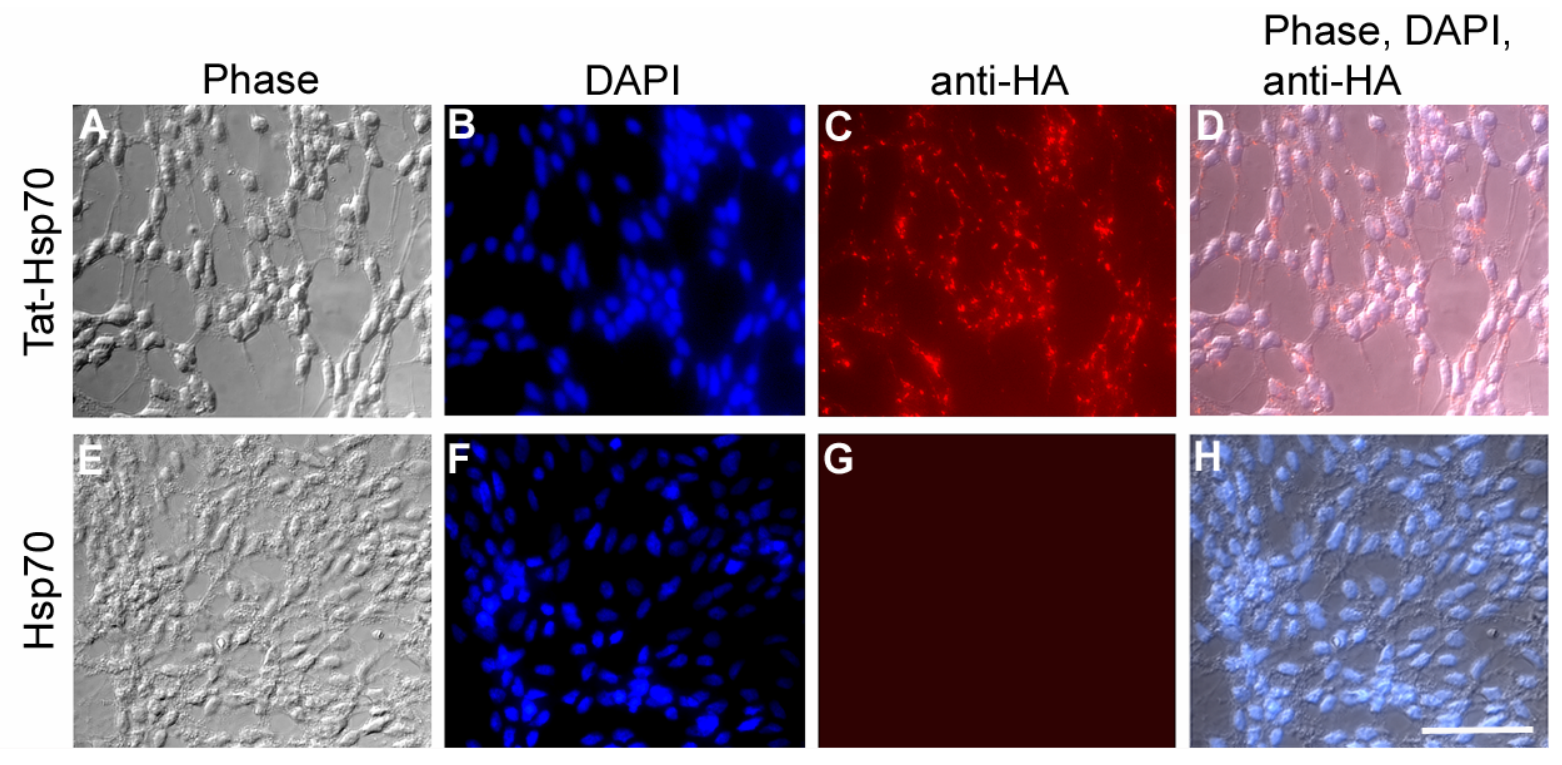

Figure 10. Tat-Hsp70 isolated under native conditions transduces SH-SY5Y cells.

Tat-Hsp70 and Hsp70 (500 nM) were added into the cell medium. We performed immunocytochemistry with an anti-hemaglutinin antibody (C, D, G, H) and stained for DAPI (B, F). Transduction of Tat-Hsp70 (C) and $\mathrm{Hsp70}(\mathrm{G})$ is visualized by fluorescence microscopy $4 \mathrm{~h}$ after cell fixation. Merged pictures include phase, DAPI and anti-HA staining (D, H). scale bar: $50 \mu \mathrm{m}$. 

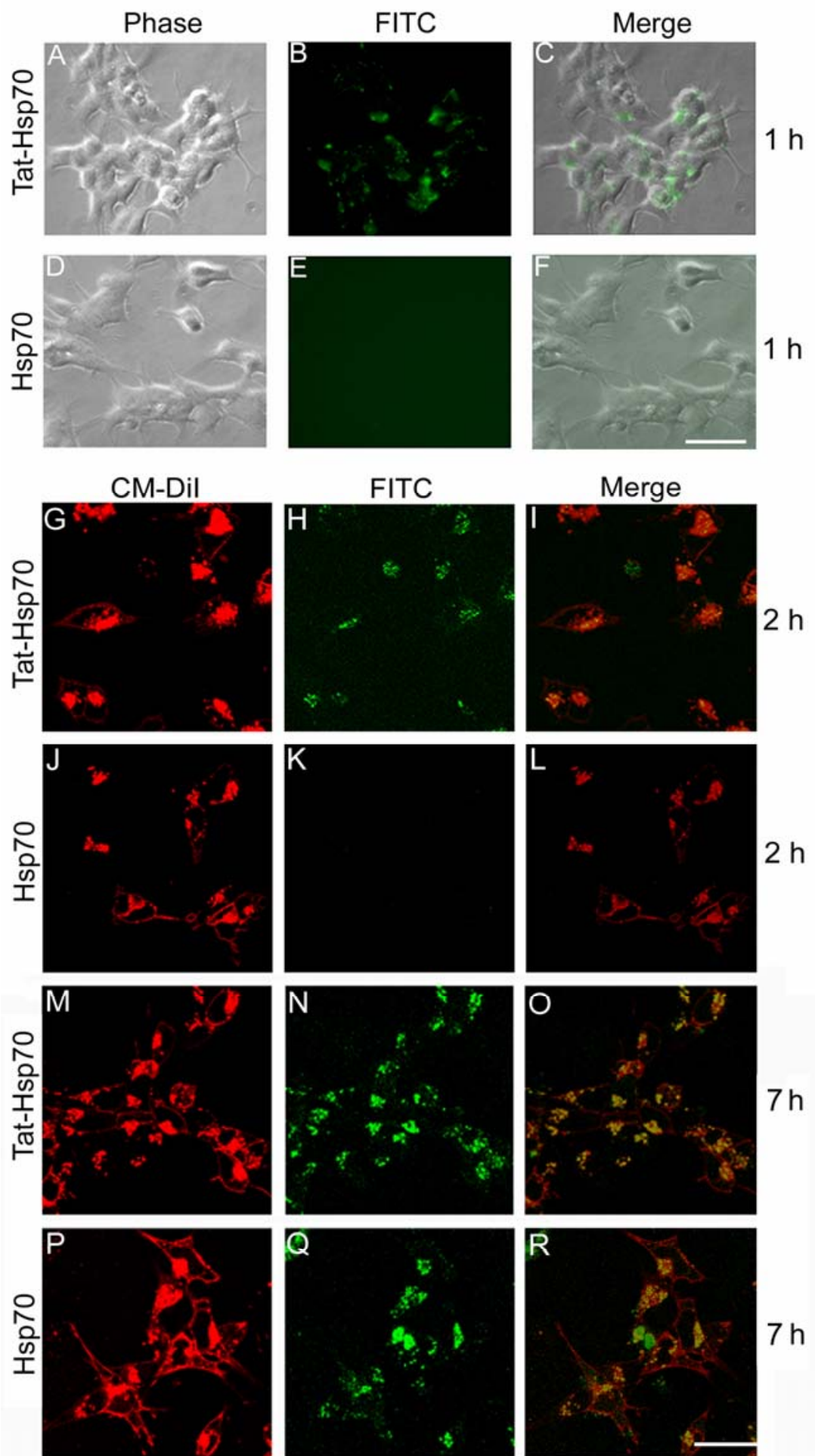

Figure 11. Native purified Tat-Hsp70 efficiently transduces SH-SY5Y cells, as visualized via imaging of live cells.

Tat-Hsp70 and Hsp70 were covalently linked to an amine reactive dye (FITC) and applied on SH-SY5Y cells. FITC-Tat-Hsp70 and FITC-Hsp70 (200 nM) treated cells were washed with PBS before live-recordings were carried out by fluorescence microscopy (A-F) $1 \mathrm{~h}$ after protein treatment, and by confocal microscopy $2 \mathrm{~h}(\mathrm{G}-\mathrm{L})$ and $7 \mathrm{~h}(\mathrm{M}-\mathrm{R})$ after protein treatment. Cellular labeling was performed with CM-Dil (G, J, M, P). scale bars: $25 \mu \mathrm{m}$ 


\subsection{Tat-Hsp70 isolated under native conditions displays the highest intracellular chaperone activity}

As we had shown that native isolated Tat-Hsp70 transduced cells efficiently, we proceeded to examine whether different preparations of Tat-Hsp70 and Hsp70 display variable chaperone activities within cells. To address this question, we assessed Tat-Hsp70-mediated folding of a chaperone-dependent yellow fluorescent protein (cdYFP) in CSM 14.1 and SH-SY5Y cells. Figure 12. A and 12. D show cumulative histograms (i.e. the probability density functions: PDF) of cdYFP folding computed for all imaged cells of different conditions. Curve shifts (to the right on the $x$-axis) indicate an enhanced intracellular chaperone activity as compared to the control cells.

The cdYFP folding biosensor demonstrated that exogenously applied Tat-Hsp70 and, to a lesser extent, Hsp70 enhanced intracellular chaperone activity. Tat-Hsp70 isolated under native conditions (Figure 12. A, thick red line and red line in the inset) provided highest folding efficiency with up to 2.6 fold increase in the maximum of cdYFP/ECFP fluorescence intensity ratio (note also Figure 12. B/c: cell with high folding activity) compared to control cells. For Tat protein samples isolated under denaturing conditions either by quickly (Figure 12. A, thin red line) or slowly (Figure 12. A, dashed red line) removing urea and imidazole, lower cdYFP/ECFP fluorescence intensities were detected. For Hsp70 (Figure 12. A: green lines) a slight increase in chaperone activity was observed (note also Figure $12 \mathrm{~B} / \mathrm{b}$ : representative cell with intermediate folding activity) with maximum increase in cdYFP fluorescence intensity for the native purified Hsp70 (Figure 12. A, thick green line) compared with Hsp70 preparations under denaturing conditions (Figure 12. A, thin and dashed green lines). Rat nigrostriatal CSM 14.1 control cells (Figure 12. A, blue line, normalized to 1) displayed low folding activity in control cells (Figure 12. B/a, blue color-coded cell). The second peak in the cumulative histogram of control cells suggests that, in some cells, cdYFP was folded into a fluorescent conformation without recombinant protein treatment. Quantification of foldase activities (PDF) demonstrated no significant effect for any Hsp70 treatment on cdYFP folding (Fig. 12. C, bar 2: $3.0 \pm 1.5 \%$, bar 3: $12.8 \pm 6.1 \%$, bar $4: 27.5 \pm 9.7 \%$ ) compared with control (Fig. 12. C, bar 1: $2.5 \pm 2.1 \%$ ). The PDF for native purified Tat-Hsp70 was significant

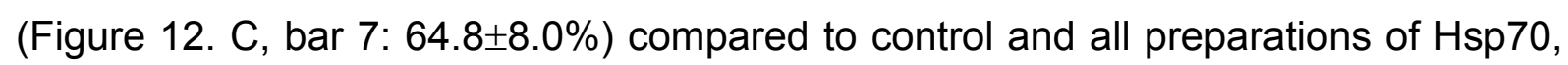


including the native isolated one (Figure 12. $\mathrm{C}$, bar 2: $3.0 \pm 1.5 \%$, bar $3: 12.8 \pm 6.1 \%$, bar 4: $27.5 \pm 9.7 \%$ ), whereas Tat-Hsp70 purified under denaturing conditions showed significant effects compared to control, but no significant effect compared to native isolated Hsp70 (Figure 12. C, bar 5: 45.3 $\pm 8.3 \%$, bar 6: $46.9 \pm 9.1 \%$ ).
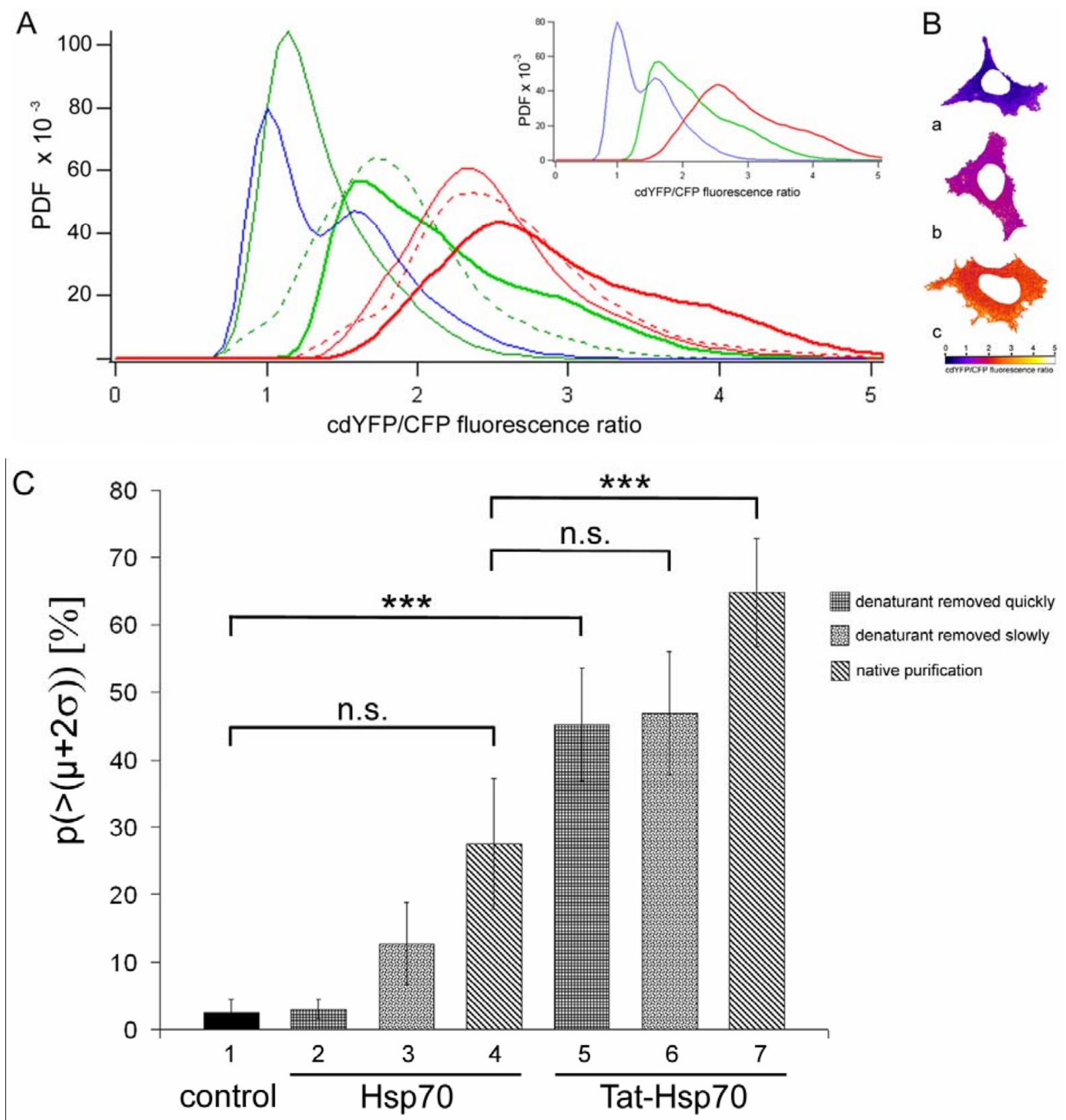


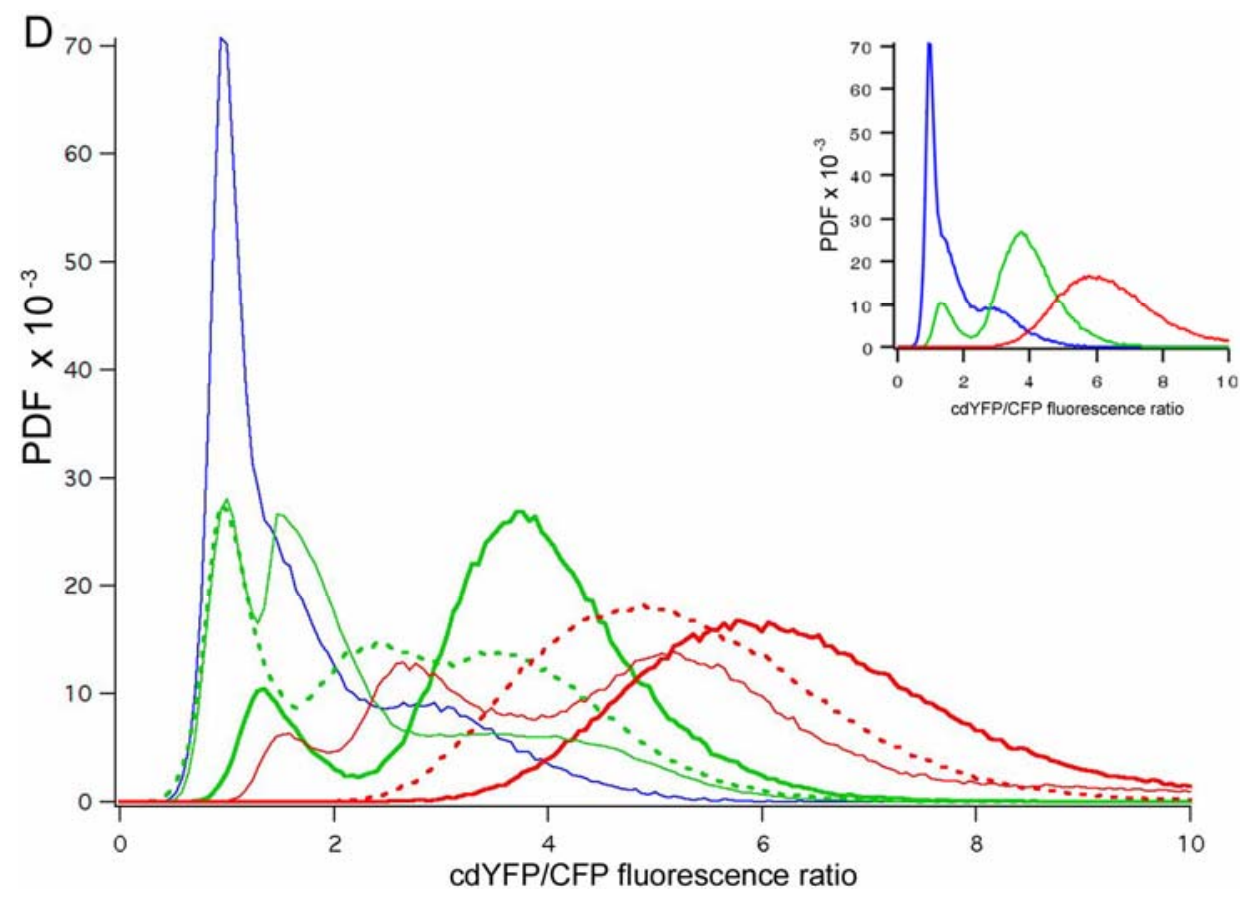

E

a
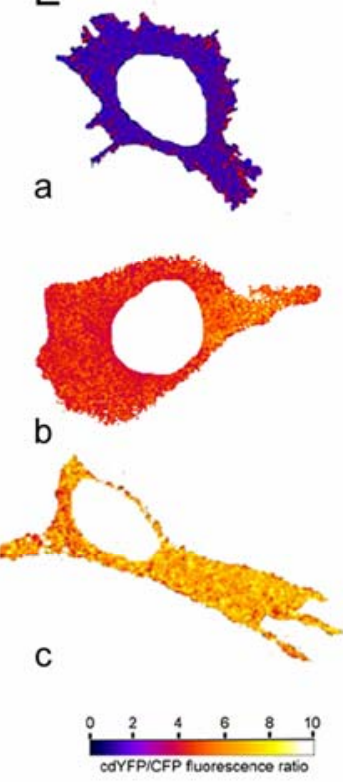

$\mathrm{F}$

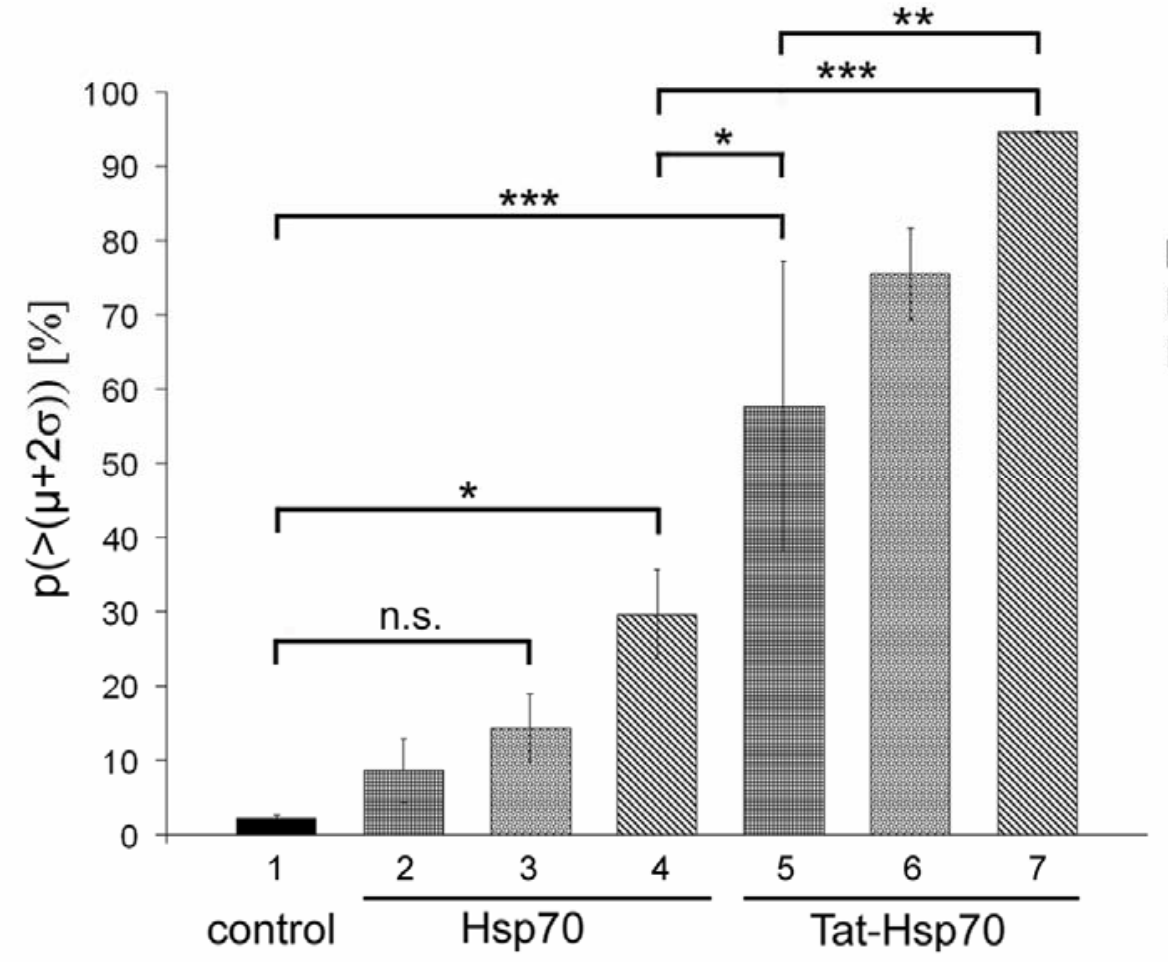

Figure 12. Tat-Hsp70 purified in its native conformation provides highest chaperone activity on the cdYFP folding sensor in CSM 14.1 and SH-SY5Y cells.

cdYFP/ECFP fluorescence intensity ratios in control, Hsp70-treated or Tat-Hsp70-treated CSM 14.1 (A-C) and SH-SY5Y (D-F) cells were evaluated. cdYFP and ECFP double-transfected cells were treated with different preparations (native and denaturing protocols) of Tat-Hsp70 and Hsp70 for 24 hours. We recorded pictures by confocal microscopy. (A, D) Cumulative probability density functions (PDF) of 15 cells per conditions are shown. cdYFP folding efficiency is expressed by the ratio of cdYFP fluorescence and ECFP fluorescence intensity and is normalized to the control folding response (cdYFP/ECFP fluorescence intensity ratio of 1, blue curve). Green curves represent Hsp70- 
treated cdYFP/ECFP transfected CSM 14.1 (A) and SH-SY5Y cells (D), and red curves represent TatHsp70-treated cells (thin lines: denaturant was removed quickly via Sephadex PD10 column; dashed line: denaturant was removed slowly via dialysis; thick line: protein isolated under not denaturing conditions). The inset singles out the lines for control (blue), Hsp70 (green) and Tat-Hsp70 (red) isolated under native conditions. Representative CSM 14.1 (B) and SH-SY5Y (E) cells are displayed in false color to indicate low (blue), intermediate (red) and high folding activity (yellow). Color coding is shown in the bar. (a) cdYFP/ECFP fluorescence intensity ratio in a representative control cell, (b) cdYFP/ECFP fluorescence intensity ratio in a representative cell treated with Hsp70, (c) cdYFP/ECFP fluorescence intensity ratio in a representative cell treated with Tat-Hsp70, both isolated without denaturant. Statistical analysis of Tat-Hsp70 mediated cdYFP folding in CSM 14.1 (C) and SH-SY5Y (F) cells. Probability density functions (PDF) were generated from the cumulative histograms of experiments on the same condition by re-normalization to unity. For each cell, the probability of exceeding the threshold at the mean $(\mu)+2 x$ the standard deviation of the control distribution (the " $2 \sigma$ threshold"), i.e., the probability of obtaining higher cdYFP ratios than contained in the control was obtained by integration of the normalized folding ratio histogram values exceeding the $2 \sigma$ threshold. Probabilities for different Hsp70 preparations are shown in bars 2-4, and probabilities for different TatHsp70 preparations are shown in bars $5-7\left({ }^{*} p<0.05,{ }^{* *} p<0.01,{ }^{* * *} p<0.001\right)$.

To confirm our result that native isolated Tat-Hsp70 causes the highest intracellular chaperone activity, we repeated the experiment on human neuroblastoma SH-SY5Y cells (Figure 12. D.). Tat-Hsp70-transduced cells (Figure 12. D, red lines) caused the largest shift in the PDF of chaperone activity. A sixfold-increase in the maximum of cdYFP/ECFP fluorescence intensity ratio could be observed for cells treated with native isolated Tat-Hsp70 (Figure 12. D. thick red line; note also Figure 12. E/c: cell with high folding activity), while cells treated with Tat-Hsp70 purified using denaturing conditions provided less folding activity (Figure 12. D, thin and dashed red line). Hsp70 purified under denaturing conditions showed no or only low-increased cdYFP fluorescence intensity (Figure 12. D, thin or dashed green lines) compared with SH-SY5Y control cells (Figure 12. D, blue line; Figure 12. E/a: cell with low folding activity). Only for native isolated Hsp70 (Figure 12. D, thick green line, Figure 12.E/b: cell with intermediate folding activity) a 3.8 fold significant increase in the maximum of cdYFP/ECFP fluorescence intensity was observed, (Figure 12. F, bar 4, $29.6 \pm 5.9 \%$ ) compared with the control (Figure 12. F, bar 1, 2.3 \pm 0.5 ).

In contrast to the results in CSM cells, the PDF were statistically significant for all

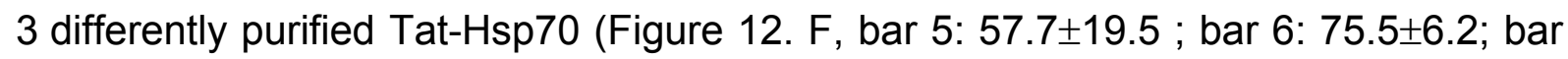
7: $94.5 \pm 0.2 \%$ ) compared with the control (Figure 12. $\mathrm{F}$, bar 1) and native isolated Hsp70 (Figure 12. F, bar 4). However, Tat-Hsp70 isolated using non-denaturing 
conditions offered the largest shift in the PDF for both neuroblastoma as well as nigro-striatal cell lines (Figure 12. C, bar 7 and Figure 12. F, bar 7, and the insets, Figure 12. A and 11. D), and was statistically significant compared to denatured Tat-Hsp70, when urea was removed quickly. To examine whether the chaperone activity of recombinant proteins purified using different protocols correlates with neuroprotection of cells against oxidative stress, we performed viability assays.

\subsection{Native purified Tat-Hsp70 is protective against different toxic stimuli}

We tested the effect of Tat-Hsp70, Hsp70, Tat-HA or buffer treatment under conditions of oxidative stress, using either 6-OHDA or $\mathrm{MPP}^{+}$to induce cell death of SH-SY5Y human neuroblastoma cells or primary dopaminergic midbrain neurons.

\subsubsection{Only native isolated Tat-Hsp70 protects SH-SY5Y cells against 6-OHDA induced cell death in vitro}

We confirmed changes in functionality of proteins purified using different protocols by testing their protective capacity against 6-OHDA toxicity. Tat-Hsp70-mediated neuroprotection of SH-SY5Y cells against 6-OHDA was highly dependent on the protein purification protocol employed (Figure 13). No significant protection of Tat-Hsp70 isolated under denaturing conditions for different 6-OHDA concentrations could be observed (Figure 13, bar 3, 5, 10, 12, 17, 19), whereas Tat-Hsp70 isolated under native conditions provided a significant protection against 40 and $50 \mu \mathrm{M}$ 6-OHDA (Figure 13, bar 1,8). Slowly removing the denaturant by dialysis did not render a protein with significant protective effect (Figure 13, bar 3, 10). Independent from the purification protocol, neither Hsp70 without the Tat sequence (Figure 13, bar 2, 4, 6, 9, 11, 13) nor the Tat domain alone (Figure 13, bar 7, 14, native purified) provided a protective effect. For higher concentrations of 6-OHDA, no rescue effect by any of the tested proteins was detectable (Figure 13, bars for $60 \mu \mathrm{m} 6$-OHDA application). As we had demonstrated that native isolated Tat-Hsp70 showed the most efficient cell transduction, the strongest effect in folding of the cdYFP folding mutant, and significant protection of SH-SY5Y cells against 6-OHDA, we decided to perform further experiments with recombinant proteins purified under non-denaturing protocols. 


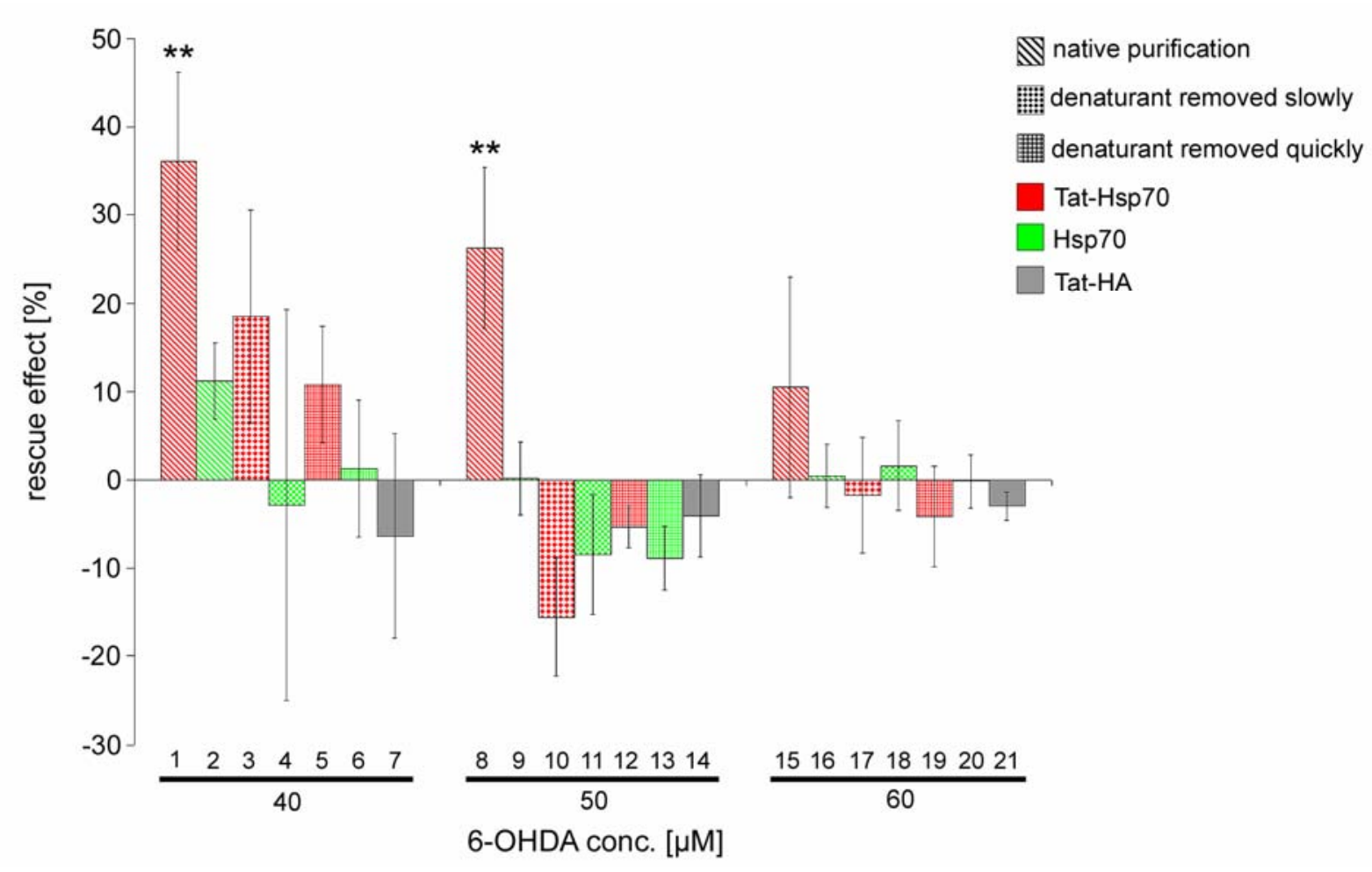

Figure 13. Tat-Hsp70 purified in its native conformation protects SH-SY5Y cells against 6-hydroxydopamine (6-OHDA) induced cell death, whereas Tat-Hsp70 isolated under denaturing conditions does not.

Tat-Hsp70 and Hsp70 were isolated under either denaturing or native conditions. Protein (250 nM) was added into the cell culture medium before 6-OHDA was applied at different concentrations (40-60 $\mu \mathrm{M}) 1.5 \mathrm{~h}$ later. Cell viability was assessed $24 \mathrm{~h}$ after 6-OHDA treatment using the WST-1 reagent. Values were normalized against buffer treated cells $\left({ }^{* *} p<0.01\right)$.

\subsubsection{Tat-Hsp70 protects dopaminergic midbrain neurons against MPP $^{+}$ toxicity}

The effect of Tat-Hsp70 on neuronal survival was evaluated in primary mesencephalic neurons. Cultures were either untreated or treated with buffer, Hsp70, Tat-HA or Tat-Hsp70 on day 4 in vitro (DIV 4). On DIV 5, the number of dopaminergic (DA) neurons not treated with $\mathrm{MPP}^{+}$was similar in all experimental groups (Figure 14. A, D, bars 1-5). Treatment of cultures with $6 \mu \mathrm{M} \mathrm{MPP}^{+}$for $24 \mathrm{~h}$ on DIV 4 resulted in a 45-56 \% decrease in cell survival, which was similar in control (no protein), buffer, Hsp70 and Tat-HA treated cultures (Figure 14. B, D, bars 6-9). Treatment with Tat-Hsp70 significantly inhibited the loss of TH-positive neurons (Figure 14. C, D, bar 10). Additionally, $\mathrm{MPP}^{+}$treatment reduced the mean length of neurites of DA midbrain neurons by $50 \%$ compared with untreated control condition (Figure 15. A, B, 
$\mathrm{D}$, bars 1 and 6 ). Neurite processes of $\mathrm{TH}$-positive neurons treated with no protein, buffer, Hsp70 and Tat-HA were similarly damaged by $\mathrm{MPP}^{+}$treatment (Figure 15. D, bars 6-9), whereas Tat-Hsp70 blocked $\mathrm{MPP}^{+}$-induced degeneration of neurites by $50 \%$ (Figure 15. C, D, bar 10).
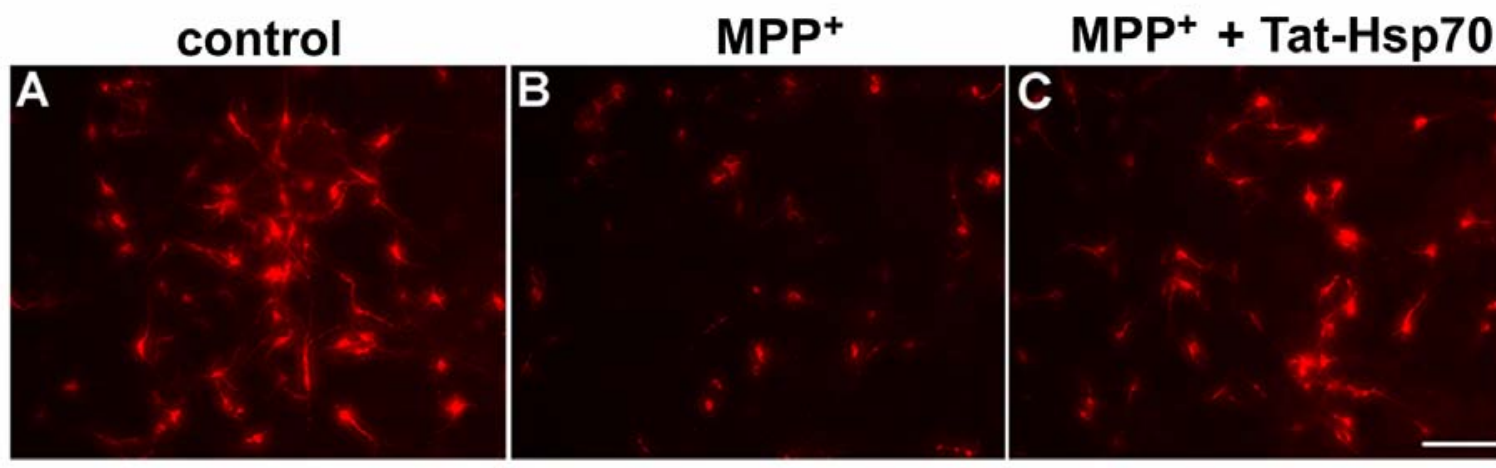

$\mathrm{D}$

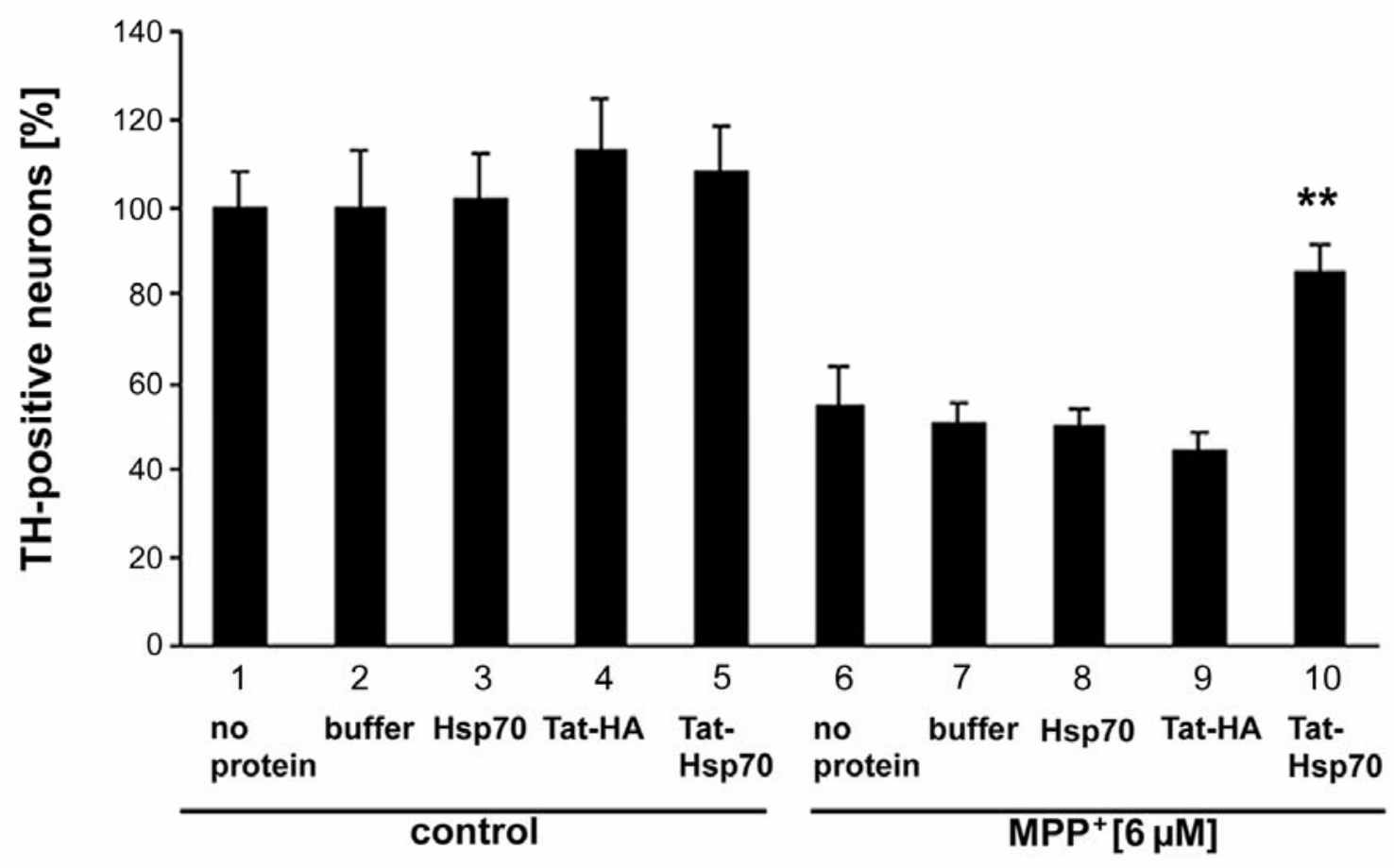

Figure 14. Tat-Hsp70 protects cultured dopaminergic midbrain neurons against $\mathrm{MPP}^{+}$toxicity. Mesencephalic neurons (A) Untreated, or (B) $24 \mathrm{~h}$ after the application of $6 \mu \mathrm{M} \mathrm{MPP}^{+}$, or (C) $24 \mathrm{~h}$ after $\mathrm{MPP}^{+}$treatment preceded by Tat-Hsp70 application. Scale bar: $100 \mu \mathrm{m}$. (D) Fraction of TH-positive midbrain neurons. Results are average \pm SEM $\left(n=4, p<0.01^{* *}\right.$ compared with results represented in bars 6-9). Conditions were normalized against control condition (100\%). 

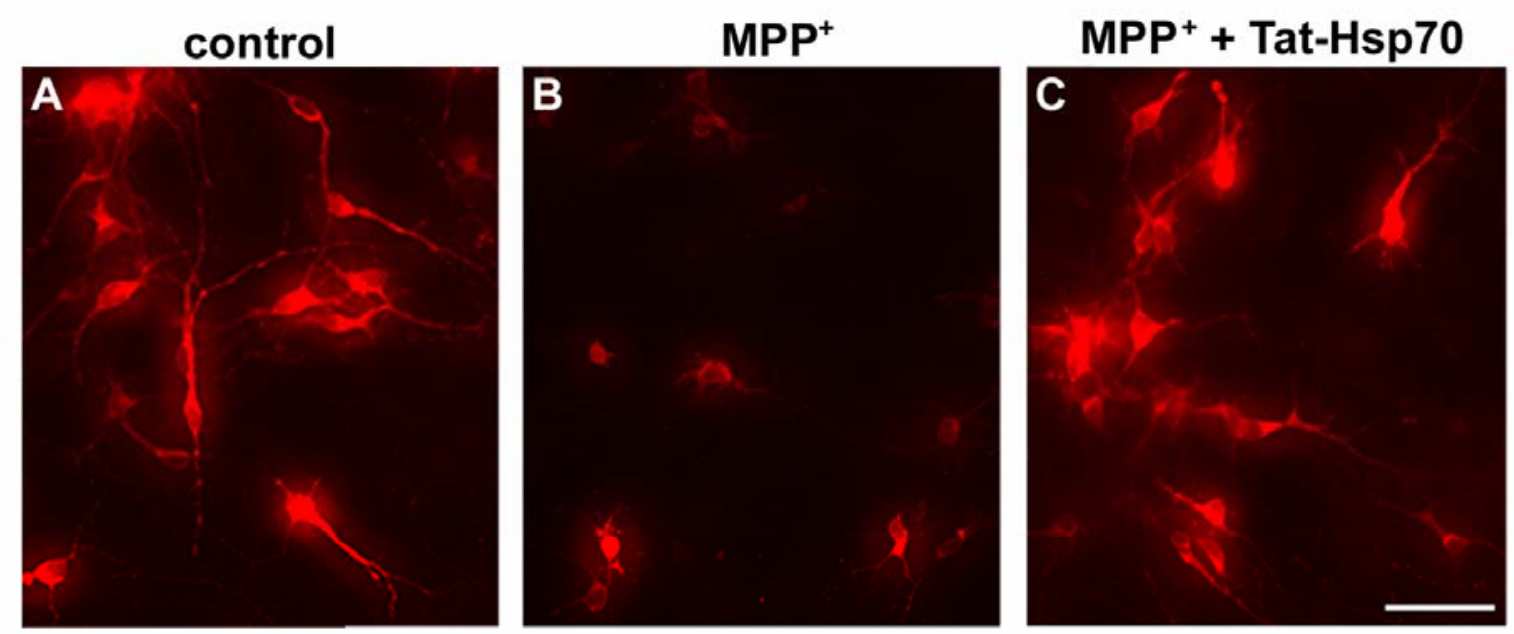

D

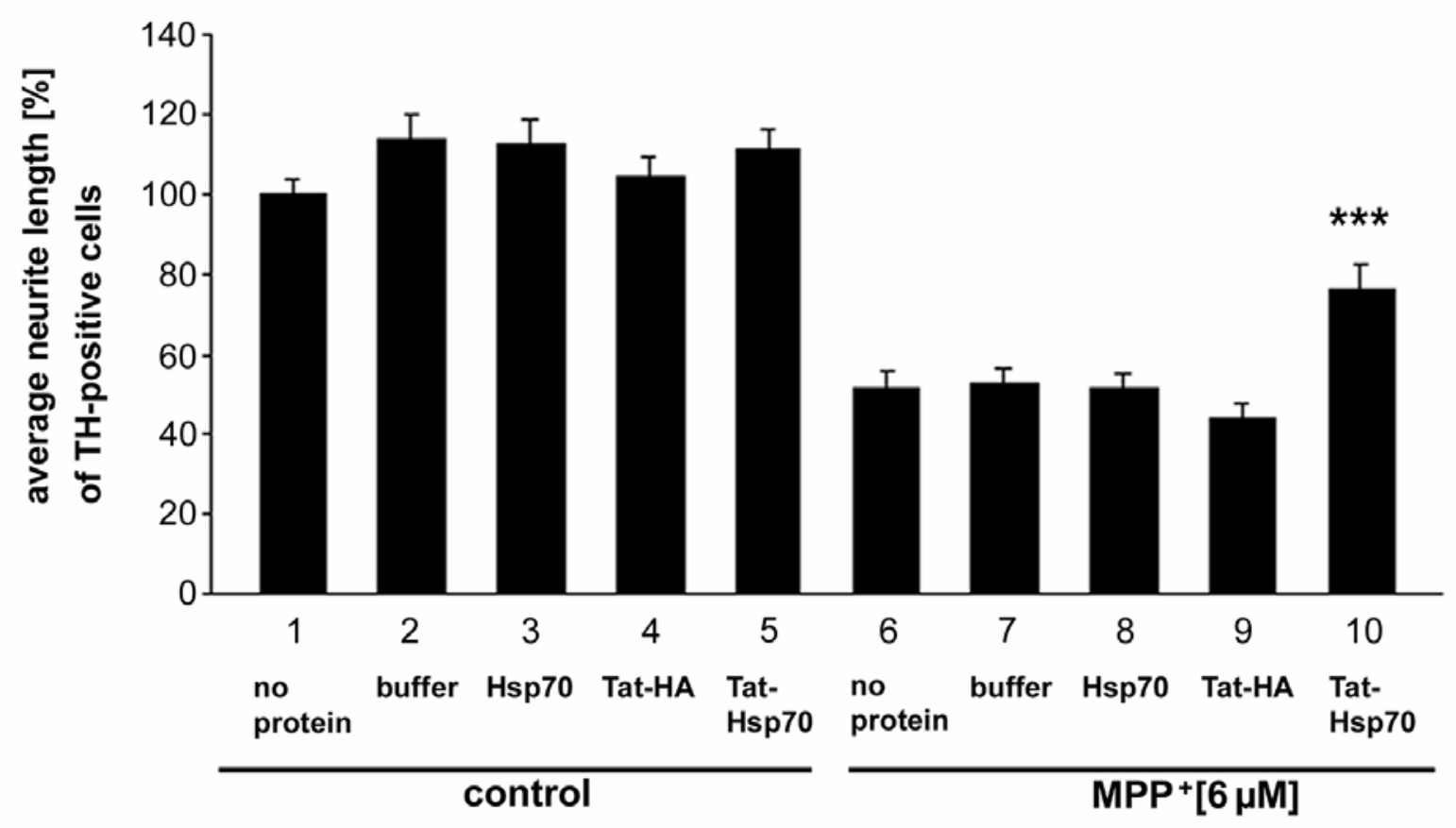

Figure 15. Tat-Hsp70 protects cultured mesencephalic dopaminergic neurons from MPP ${ }^{+}$ induced loss of their processes.

TH-positive neurons were visualized by immunocytochemical staining. (A) Untreated cell culture. (B) $24 \mathrm{~h}$ application of $\mathrm{MPP}^{+}[6 \mu \mathrm{M}](\mathrm{C})$ Tat-Hsp70 and $\mathrm{MPP}^{+}$treatment. Scale bar $50 \mu \mathrm{m}$. (D) To determine the length distribution of neurites, untreated control condition was set to $100 \%$ for each experiment. Neurite length of Tat-Hsp70, Hsp70, Tat-HA and buffer-treated cultures (with and without $\mathrm{MPP}^{+}$application) were normalized against untreated control. Results are average \pm SEM. $(n \geq 3$, $\mathrm{p}<0.001^{* * *}$ compared with bars 6-9). 


\subsection{Systemically applied Tat-Hsp70 co-localizes with dopaminergic neurons in} the substantia nigra pars compacta and with TH-positive amacrine cells in the mouse retina

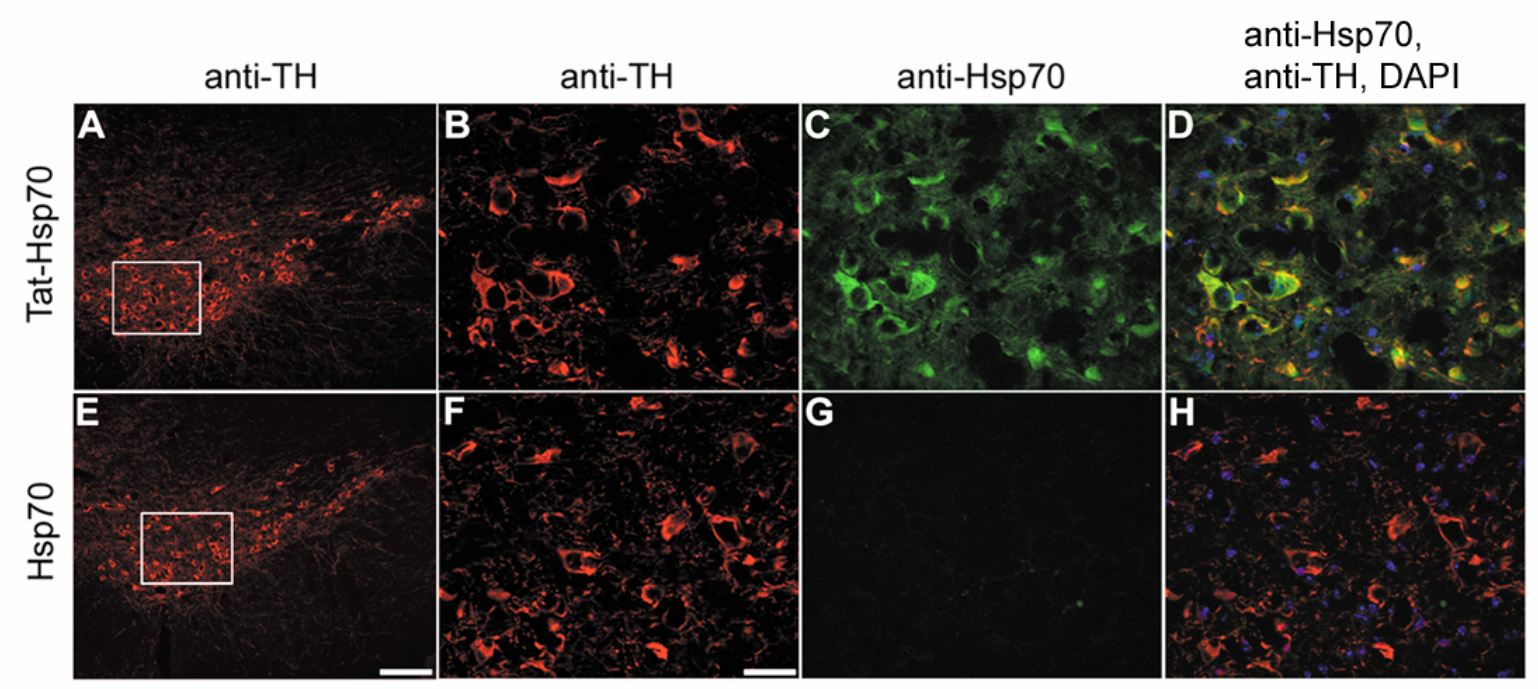

Figure 16. Tat-Hsp70 transduces the substantia nigra pars compacta after intraperitoneal injection .

Brain sections including the area of the substantia nigra (A, E) of mice intraperitoneally injected with Tat-Hsp70 (A, B, C, D) or Hsp70 without the Tat domain (E, F, G, H) are shown. Immunohistochemistry was performed using an antibody against tyrosine hydroxylase (A, B, E, F) as a marker for dopaminergic neurons and against $\operatorname{Hsp70}(C, G)$. Merged pictures of tyrosine hydroxylase, Hsp70 immunopositive neurons and DAPI-staining are shown in $(D, H)$. Scale bar $=200 \mu m(A, E)$ or $50 \mu \mathrm{m}(\mathrm{B}-\mathrm{D} ; \mathrm{F}-\mathrm{H})$.

Previous studies have shown that the HIV Tat domain mediates the delivery of certain cargoes like glial cell line-derived neurotrophic factor (GDNF), $X$-chromosome-linked inhibitor of apoptosis protein (XIAP) or the B-cell lymphoma $x$ protein (Bcl- $\mathrm{K}_{\mathrm{L}}$ ) into the brain (Diem et al., 2005; Dietz et al., 2006b; Guegan et al., 2006). To determine whether Tat-Hsp70 could be systemically applied in in vivo models for PD and whether it reaches the substantia nigra pars compacta ( $\mathrm{SNpc}$ ) and the retina, we intraperitoneally (i.p.) injected Tat-Hsp70 or Hsp70 and performed immunohistochemical analysis. Brain sections from Tat-Hsp70-treated mice displayed a bright staining when an antibody against Hsp70 was applied (Figure 16. C), indicating transduction of Tat-Hsp70 through the BBB into the brain, including tyrosine-hydroxylase-positive neurons in the SNpc (Figure 16. A, B, D). Mice injected with Hsp70 that did not include the Tat domain, showed a weak signal for Hsp70 staining (Figure 16. G), suggesting no transduction across the BBB into the SNpc (Figure 16. G, H). Moreover, we found that i.p. injected Tat-Hsp70 is also detectable 
in the different cell layers of the retina (Figure 17), suggesting that even distal parts of the central nervous system could be transduced after i.p. injection of Tat-Hsp70 within a few hours. Successful transduction of the SNpc and retina after systemic Tat-Hsp70 application encouraged us to test the effect of the recombinant protein in an in vivo model for PD.

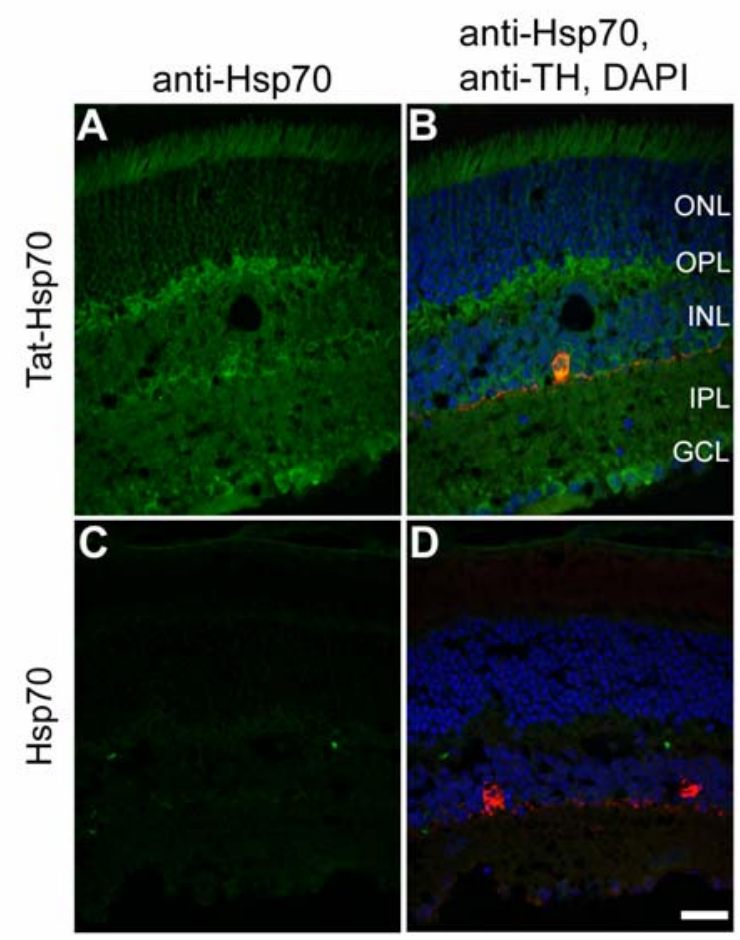

Figure 17. Tat-Hsp70 transduces dopaminergic amacrine cells in the mouse retina after intraperitoneal injection.

Retinal sections of mice intraperitoneally injected with Tat-Hsp70 (A, B) or Hsp70 without the Tat domain $(C, D)$ are shown. Immunohistochemistry was performed using an antibody against tyrosine hydroxylase (red color: anti-TH in: B, D) as a marker for dopaminergic neurons and against Hsp70 (green color). Merged pictures of tyrosine hydroxylase (red color), Hsp70 immunopositive neurons (green color) and DAPI-staining (blue color) are shown in (B, D). Scale bar $=25 \mu \mathrm{m}(\mathrm{D})$.

\subsection{Tat-Hsp70 protects dopaminergic neurons in the SNpc against systemic application of MPTP}

To examine whether Tat-Hsp70 protects against MPTP toxicity in vivo, we treated mice during and after MPTP intoxication with Tat-Hsp70 or control proteins (see section 2.7.1 and Figure 18). Using stereologic analysis, we found that treatment with Tat-Hsp70 reduced the loss of DA neurons in the SNpc; compared with PBS treated mice (Figure 19. A, D, G, bar 1), a reduction in the cell number by $48 \%-54 \%$ was 
observed after 5 consecutive injections of MPTP (30 mg/kg) (Figure 19. B, E, G, bars 2, 3, 4). Tat-Hsp70 but not the control treatments reduced the loss of $\mathrm{TH}$-positive cell bodies (Figure 19. C, F, G, bar 5). To rule out that the observed decrease in TH-positive cells in the SNpc merely reflects a transient cellular atrophy and downregulation of $\mathrm{TH}$ expression rather than true cell death of DA neurons, we also counted Nissl-positive neurons in the SNpc. The total number of neurons in the PBS control group was $17,202 \pm 767$ as compared to $9,460 \pm 735$ in the MPTP treated group. These values further decreased slightly with buffer $(9,073 \pm 532)$ and Tat-HA $(8,777 \pm 435)$ application under MPTP treatment but increased cell numbers were detected for Tat-Hsp70 injected mice $(13,100 \pm 658)$. These data confirmed our results from the TH-positive cell counting.

\section{Protein treatment}

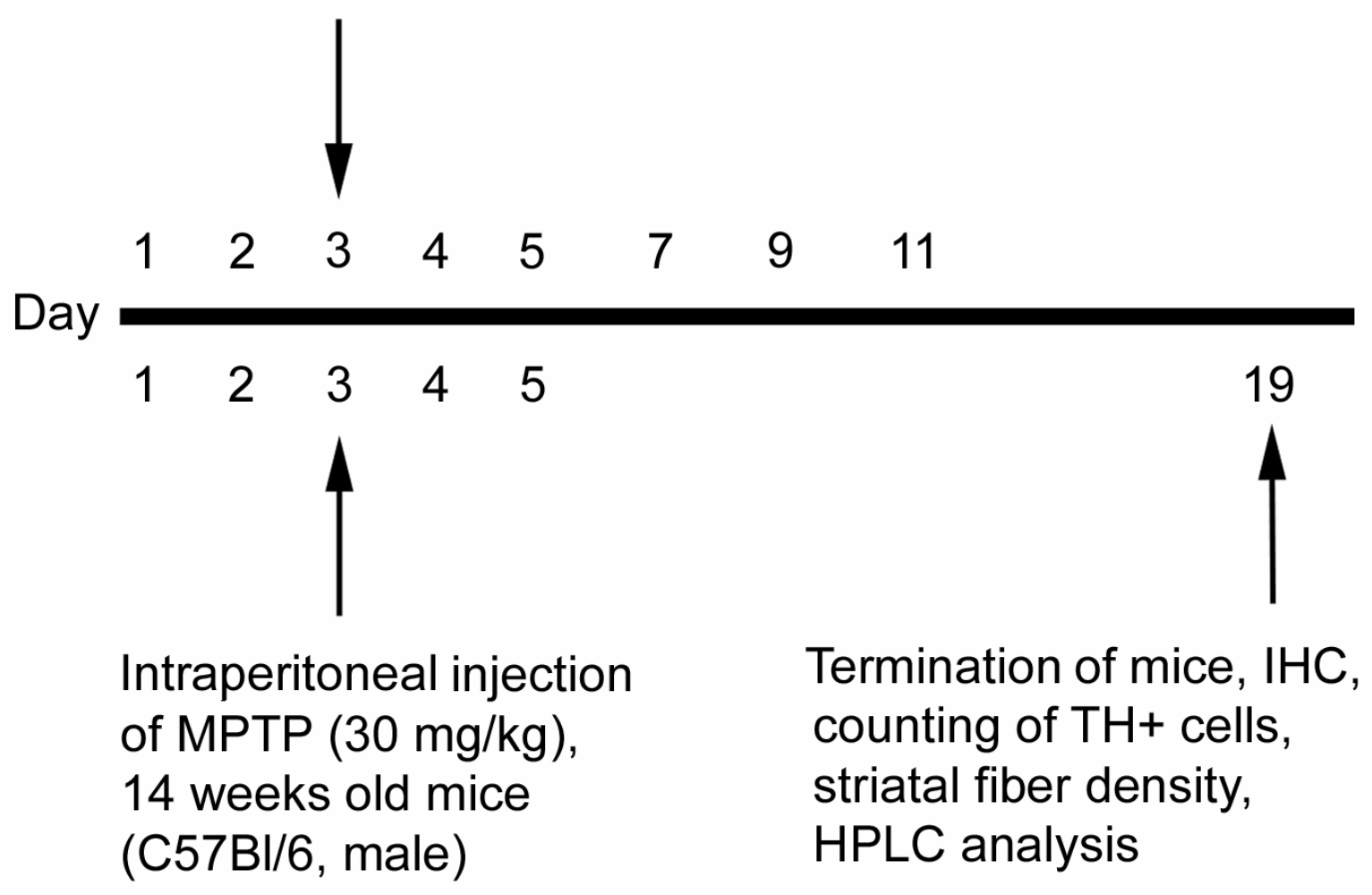

Figure 18. MPTP and protein treatment of mice.

On days 1, 2, 3, 4, 5, 7, 9, and 11 of the MPTP experiment, 14 weeks-old C57BL/6 mice were i.p. injected $5 \mathrm{nmol}$ Tat-Hsp70 or control protein Tat-HA, dialysis buffer, or PBS, always at the same time of the day. On five consecutive days (1, 2, 3, 4, 5 of the experiment), $30 \mathrm{mg} / \mathrm{kg}$ MPTP were i.p. injected $6 \mathrm{~h}$ after protein application. On day 19 mice were sacrificed and brains were prepared for immunostaining and HPLC analysis. 


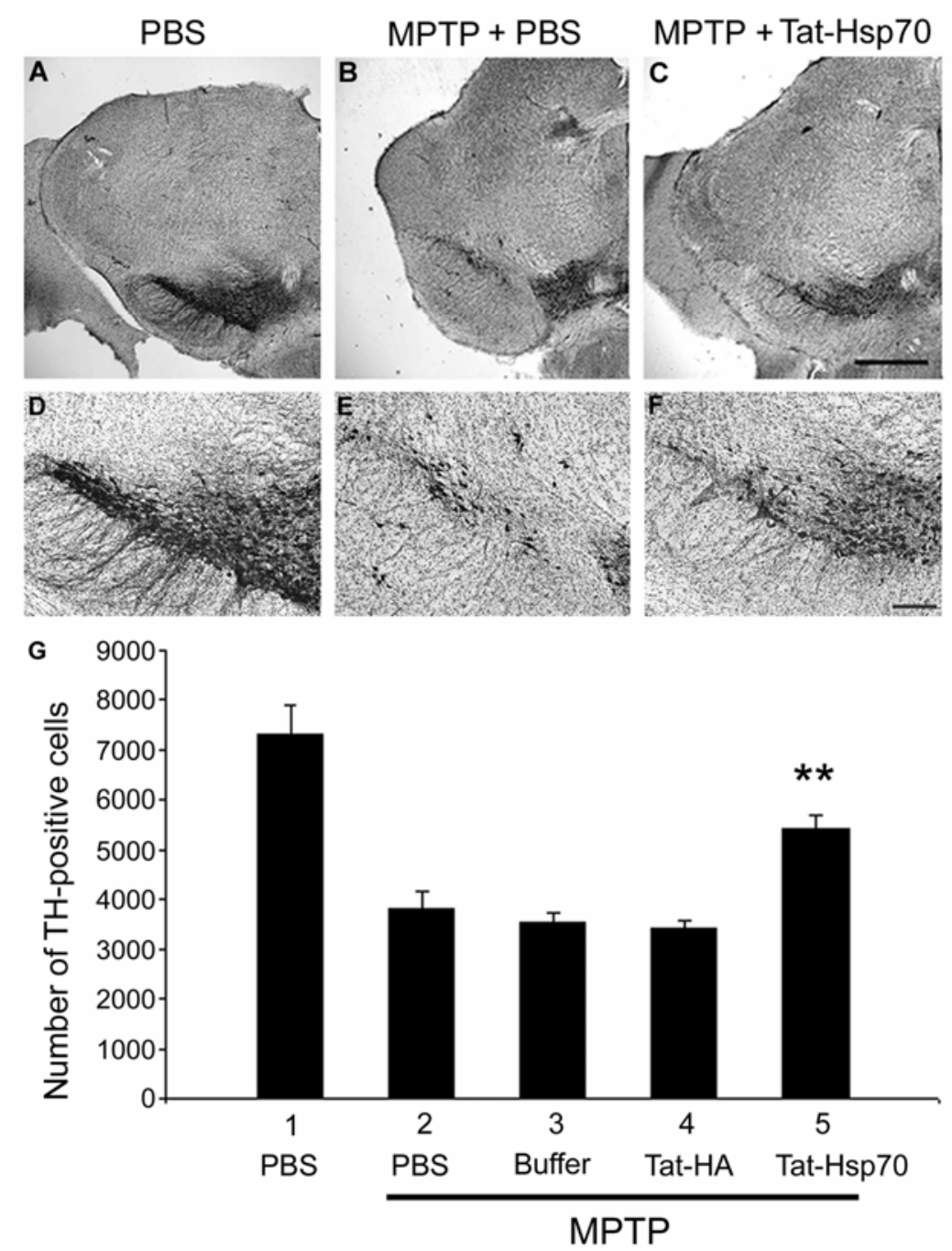

Figure 19. Tat-Hsp70 protects TH-positive, dopaminergic somata in the substantia nigra pars compacta (SNpc) against MPTP-induced cell death.

(A-F) Tyrosine-hydroxylase-immunopositive neurons in coronal brain sections of the midbrain after PBS, MPTP + PBS or Tat-Hsp70 + MPTP treatment (Scale bar: $600 \mu \mathrm{m}$ in A, B, C; scale bar: $150 \mu \mathrm{m}$ in D, E, F). PBS control (A, D), only MPTP (B, E) and MPTP + Tat-Hsp70 treatment (C, F). (G) Quantitative analysis of TH-positive neurons in SNpc. Results are average \pm SEM. (PBS: $n=5$; PBS + MPTP: $n=6$; buffer + MPTP: $n=7$; Tat-HA + MPTP: $n=7$; Tat-Hsp70 + MPTP: $n=6 ; p<0.01^{* *}$ compared with bars 2-4).

The integrity and function of DA neurons does not only depend on the survival of its somata but also on the rescue of its neurites and synaptic terminals. To determine whether the rescue of DA neurons by Tat-Hsp70 treatment also preserved their striatal axon terminals, we evaluated striatal fiber density and catecholamine levels (Figure 20. and Figure 21. A, B, C). MPTP decreased striatal fiber density by $63 \%$ $72 \%$ (Figure 20. B, D, bars 2-4) compared with PBS-treated controls (Figure 20. A, D, bar 1). There was a significant increase by $16 \%-27 \%$ in the density of the striatal 
network of DA fibers in Tat-Hsp70 treated animals as compared with other MPTP treated animals (Figure 20. C, D, bar 5 compared with bars 2-4, $p<0.05$ ). Striatal dopamine and its metabolites dihydroxyphenylacetic acid (DOPAC) and homovanillic acid (HVA) were quantified by HPLC. There was a strong depletion of dopamine $(>90 \%)$, DOPAC (>80\%) and HVA (>55\%) following MPTP treatment as compared with the PBS-treated group (Figure 21. A, B, C). Although a moderate increase in dopamine and metabolites was detected with Tat-Hsp70 treatment, it did not reach statistical significance.

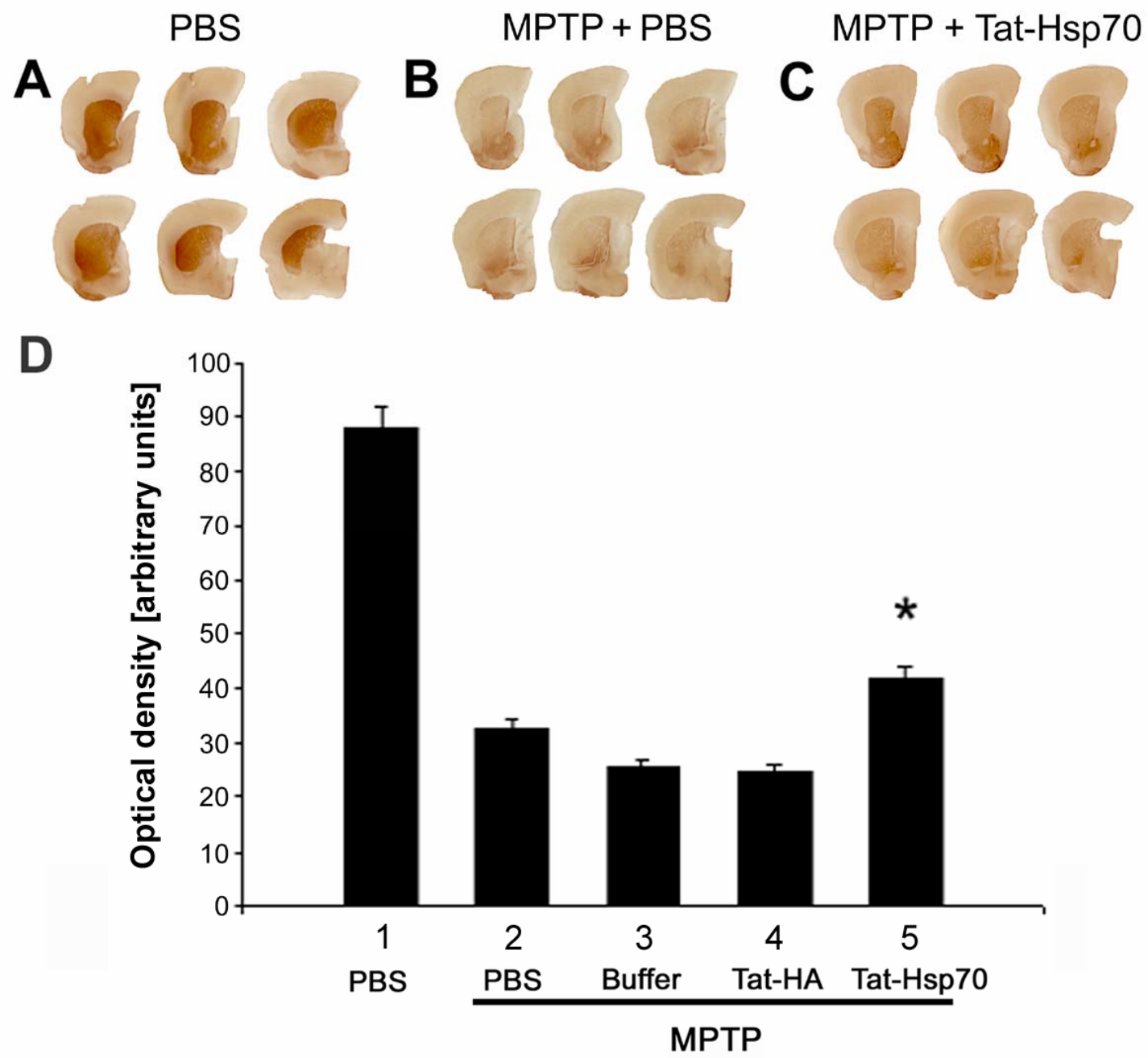

Figure 20. Tat-Hsp70 diminishes MPTP-induced decrease in dopaminergic striatal fiber density. TH-staining of the striatum for PBS (A), MPTP + PBS (B) and MPTP + Tat-Hsp70 (C) injected animals (D). Evaluation of striatal fiber density was normalized against TH-staining of the cortex. Results are average \pm SEM (PBS: $n=5$; PBS + MPTP: $n=6$; buffer + MPTP: $n=7$; Tat-HA + MPTP; $n=7$; Tat-Hsp70 + MPTP: $n=6 ; p<0.05^{\star}$ ). 

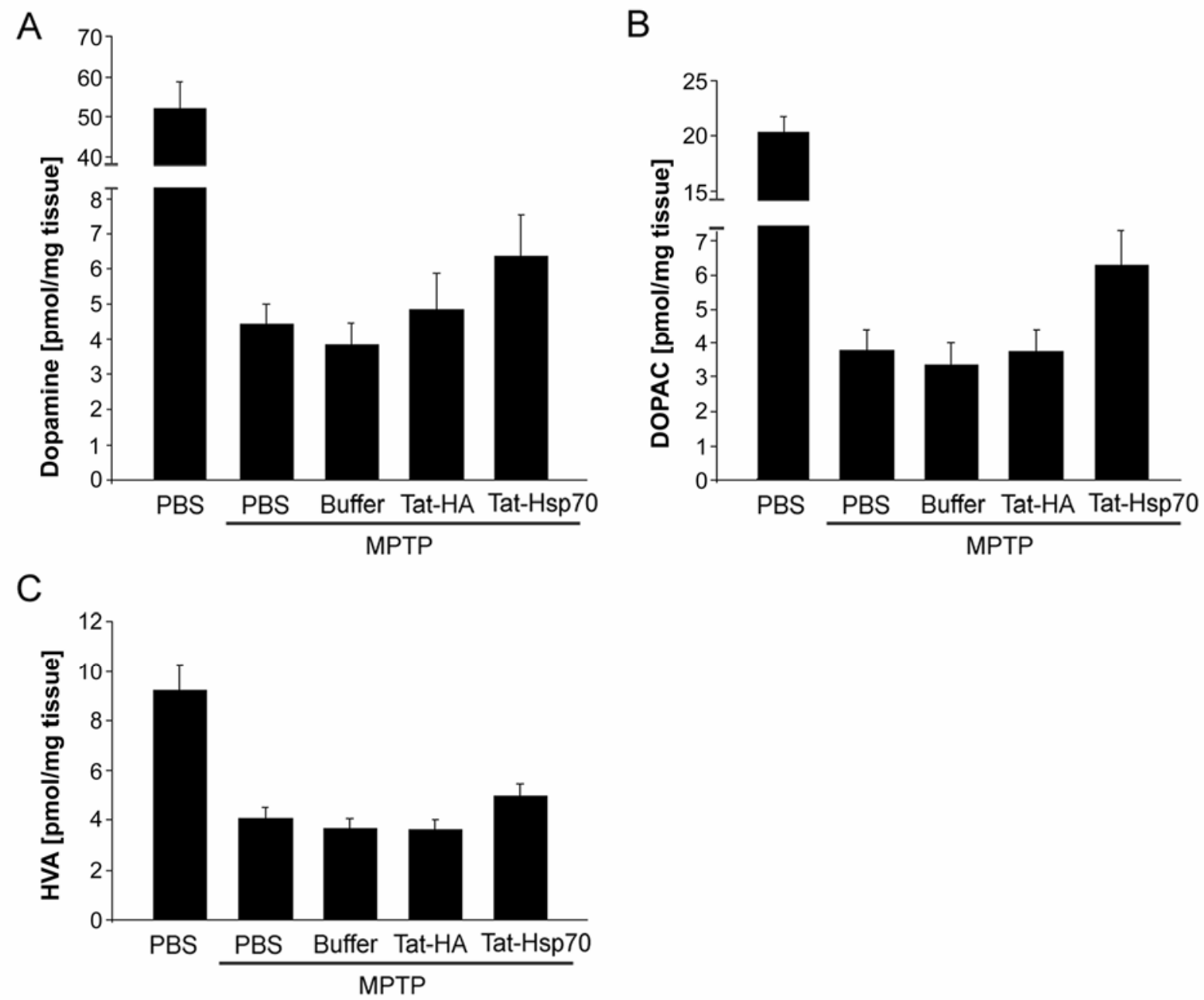

Figure 21. In vivo transduction of Tat-Hsp70 does not protect against the MPTP-induced decrease in striatal catecholamine concentrations.

14 days after the last MPTP injection, mice were sacrificed and concentrations of dopamine $(A), 3,4-$ dihydroxyphenylacetic acid (DOPAC) (B) and homovanillic acid (HVA) (C) in the striatum were measured by HPLC analysis. Results are average \pm SEM. None of the differences among the MPTPtreated groups were statistically significant (PBS: $n=5$, PBS + MPTP: $n=6$, buffer +MPTP: $n=7$, Tat-HA + MPTP: $n=7$, Tat-Hsp70 + MPTP: $n=6$ ).

To rule out that Tat-Hsp70 diminished neuronal damage by interfering with MPTP metabolism we measured $\mathrm{MPP}^{+}$concentrations (pg/mg tissue, average \pm S.E.M) in the $\mathrm{SN}$ and in the striatum after protein application and 90 min after i.p. injection of MPTP (Figure 22). We did not detect a difference in $\mathrm{MPP}^{+}$levels among the different treatment groups, either in the midbrain (PBS: $13.46 \pm 1.89$, MPTP + Tat-HA: $11.29 \pm 1.03$, MPTP + Tat-Hsp70: 11.68 \pm 2.86 ) or in the striatum (PBS: $12.67 \pm 1.2$; MPTP + Tat-HA: 10.49 $\pm 1.95 ;$ MPTP + Tat-Hsp70: 16.63 \pm 2.47$)$, consistent with direct protection of neuronal survival and integrity by Tat-Hsp70. 


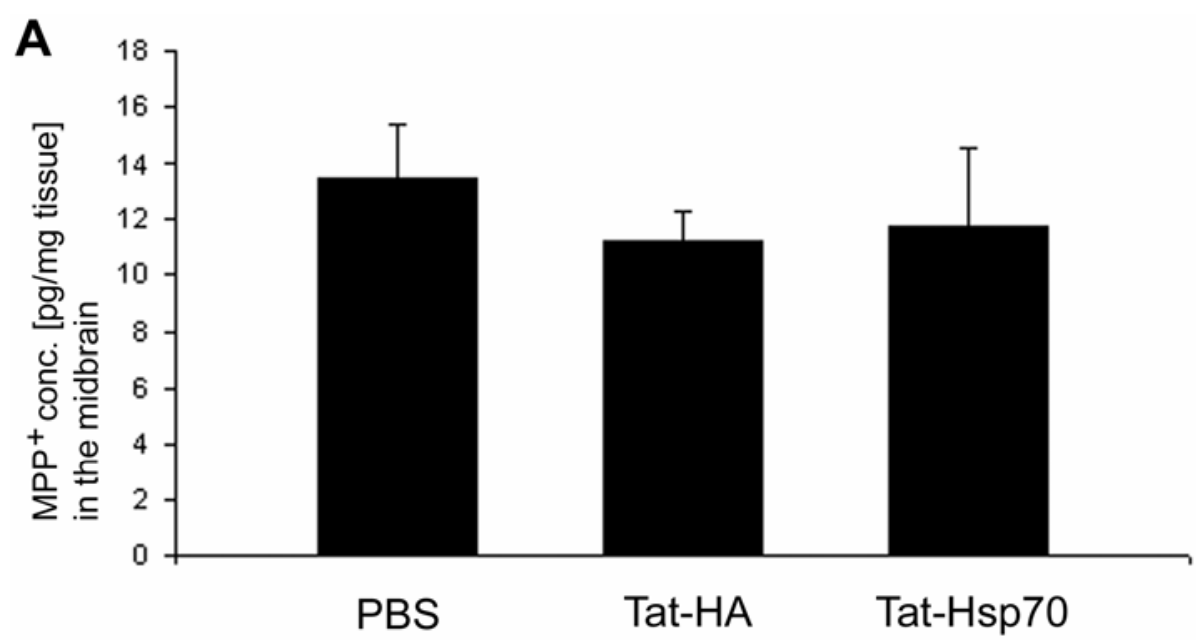

B

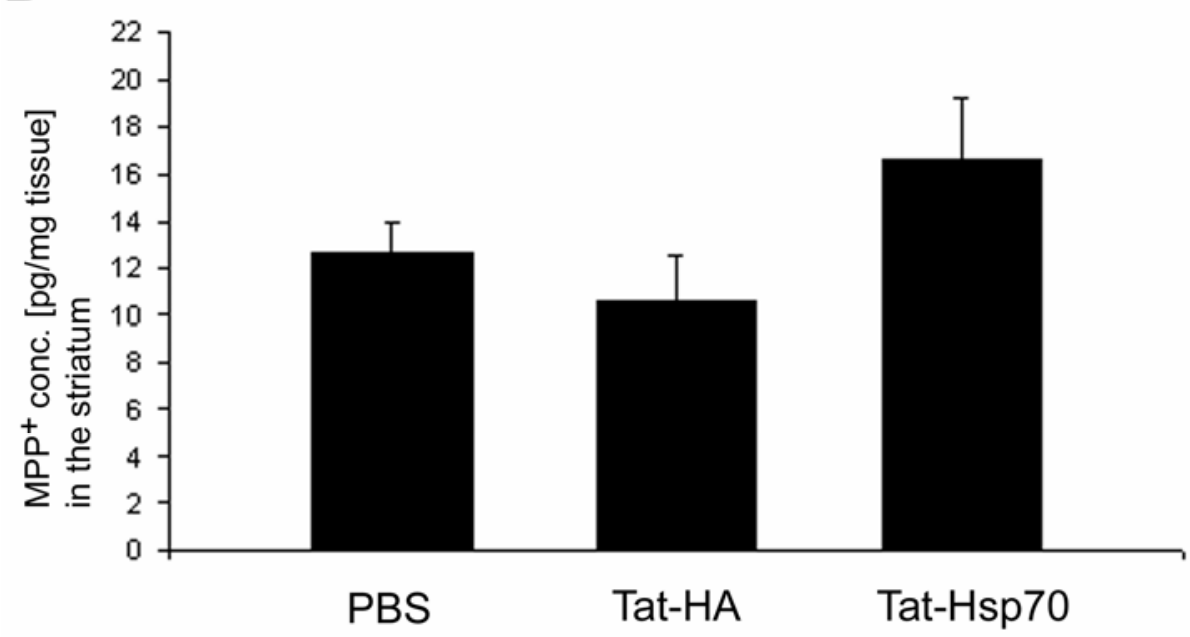

Figure 22. Application of Tat fusion protein does not alter $\mathrm{MPP}^{+}$levels in the midbrain or the striatum after MPTP injection.

$\mathrm{MPP}^{+}$levels were determined by HPLC analysis from midbrain tissue (A) and striatum (B) dissected $90 \mathrm{~min}$ after intraperitoneal MPTP application. None of the resulting differences were statistically significant. $(n=3$.)

\subsection{Intraperitoneal and intraocular injections of MPTP or 6-OHDA fail to cause degeneration of dopaminergic amacrine interneurons in the mouse retina}

Toxins such as 1-methyl-4-phenyl-1,2,3,6-tetrahydropyridine (MPTP) or 6hydroxydopamine (6-OHDA) have been used to induce degeneration of dopaminergic (DA) neurons in the nigrostriatal pathway and to reproduce pathological characteristics of Parkinson's disease (PD) (Przedborski, 2004; Schober, 2004). DA neurons are also present in the retina, and visual impairments in PD patients have been reported (Bodis-Wollner, 1990; Bodis-Wollner, 2003). 
Therefore, we examined the vulnerability of DA amacrine interneurons in the retina against MPTP or 6-OHDA-induced cell death and wanted to test the therapeutic potential of systemically applied Tat-Hsp70. TH-staining of retinal sections (Figure 23. A-C) revealed that the subacute i.p. injection of MPTP did not induce amacrine cell death (Figure 23. D, bars 1-4). As expected, Tat-Hsp70 had no effect on the survival rate of DA neurons (Figure 23. D, bar 5) in this paradigm. Interestingly, the retinas were taken from the same animals in which about $50 \%$ DA cell death in the SNpc was induced (see section 3.5 and Figure 19), indicating that the systemic application of the same dose of the toxin has very different consequences on different DA neuronal populations in the central nervous system. We next measured the $\mathrm{MPP}^{+}$level in the eye, striatum and midbrain 90 min after i.p. injection of MPTP. The $\mathrm{MPP}^{+}$concentration was quantified by HPLC (Figure 24). We detected a strong difference in $\mathrm{MPP}^{+}$levels among the different treatment groups. The $\mathrm{MPP}^{+}$ concentration in the eye was 9 times lower $(1.63 \pm 0.33)$ compared with $\mathrm{MPP}^{+}$in the

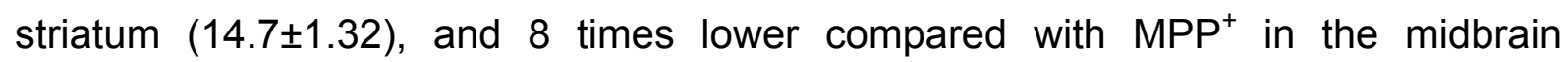
(12.69 \pm 0.73$)$. Similar $\mathrm{MPP}^{+}$concentrations for midbrain and striatum were measured in previous experiments (see section 3.5 and Figure 22). Possible reasons for the survival of retinal amacrine cells after systemic MPTP application was a less efficient transfer of MPTP across the blood-retina barrier (BRB) into the eye, a less efficient conversion into toxic $\mathrm{MPP}^{+}$in the retina or a general higher resistance against toxic insults of retinal DA neurons compared with DA neurons in the SN. Therefore, we directly injected high doses of MPTP or $\mathrm{MPP}^{+}$into the eye. No significant reduction in the DA cell number after i.o. injection of either MPTP $(<20 \mu \mathrm{g} / \mu$ l; data not shown) or $\mathrm{MPP}^{+}(50$ and $200 \mu \mathrm{g} / \mu \mathrm{l}$ ) were observed (Figure 25). To see whether DA neurons in the retina are generally insensitive to high doses of toxin, we injected 6-OHDA (30 and $60 \mu \mathrm{g} / \mu \mathrm{l}$ ), which did not induce a significant reduction in the DA amacrine cell number (Figure 25). 


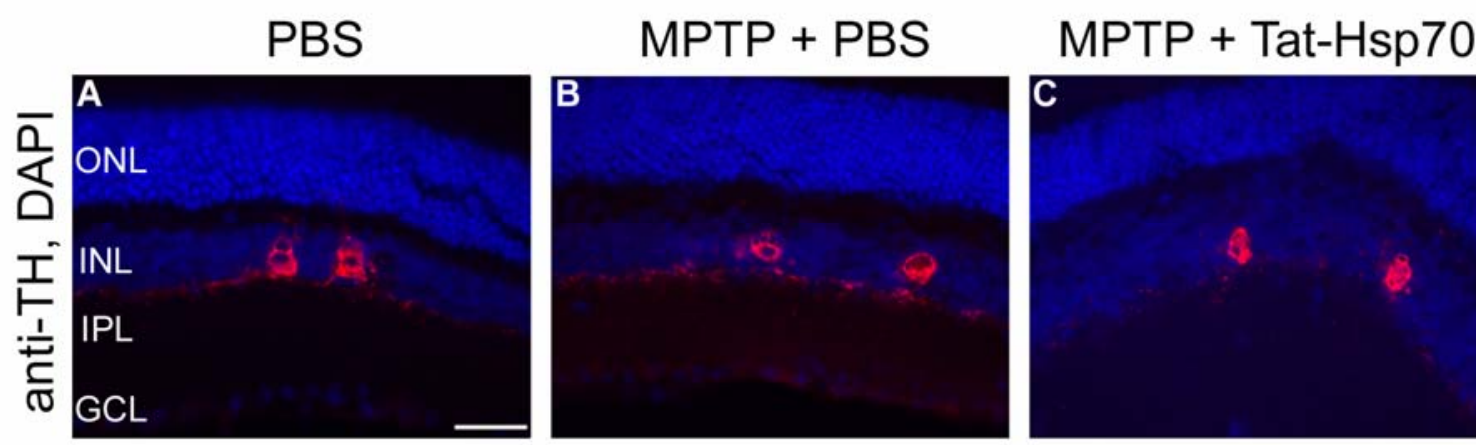

D

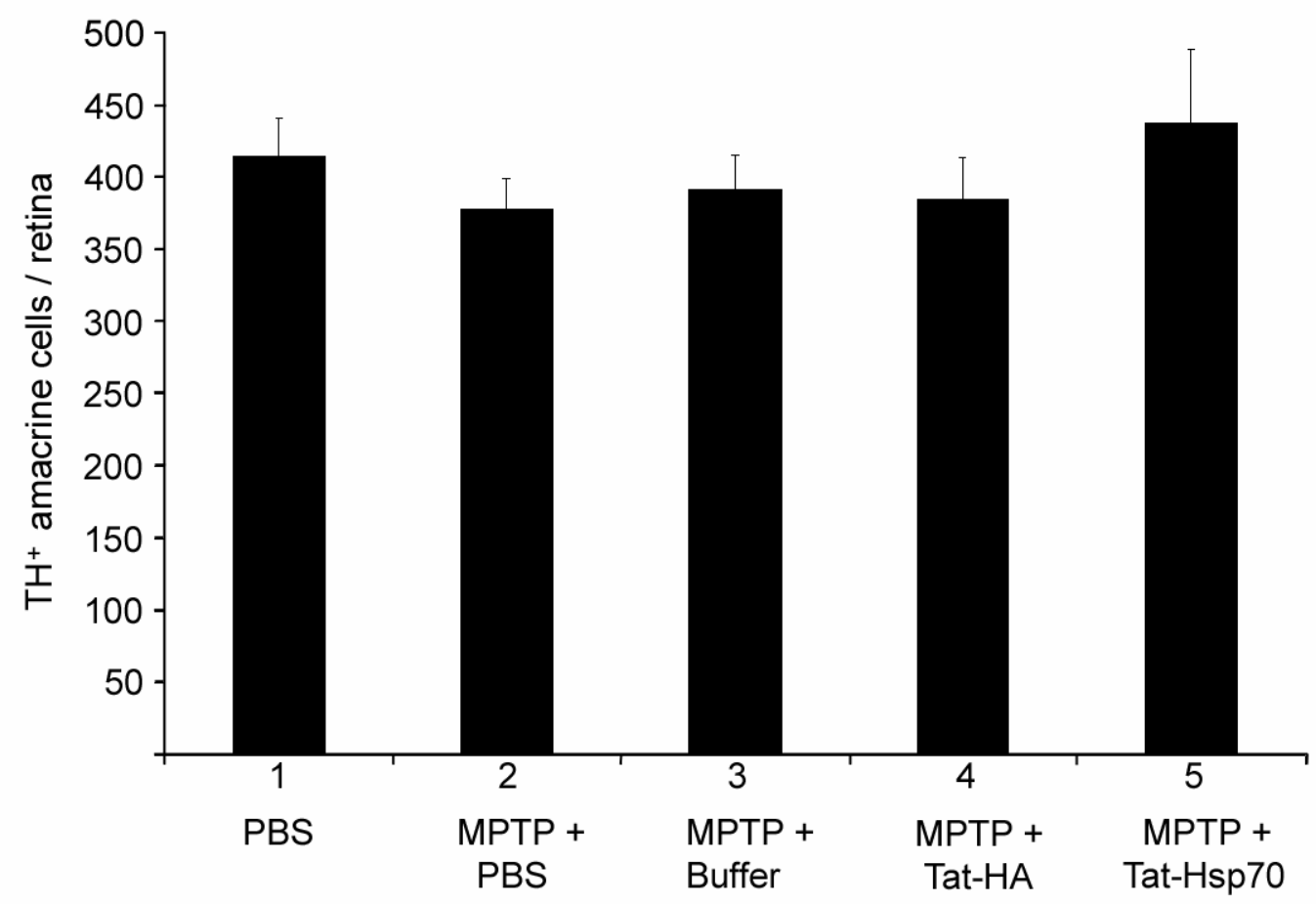

Figure 23. Subacute MPTP application fails to induce cell death in retinal amacrine cells.

TH-positive neurons were visualized by immunohistochemical staining (red color: tyrosine hydroxylase, blue color: DAPI). (A) PBS treated mice. (B) MPTP and PBS treated mice. (C) MPTP and Tat-Hsp70 treated mice. Scale bar: $50 \mu \mathrm{m}$. (D) Quantification of TH-positive amacrine cells. Tyrosinehydroxylase-immunopositive amacrine cells in the inner nuclear layer of the retina of each $3^{\text {rd }}$ slice were counted and the total number of DA amacrine cells was interpolated. Results are average \pm SEM. (PBS: $n=5$; PBS + MPTP: $n=6$; buffer + MPTP: $n=7$; Tat-HA + MPTP: $n=7$; Tat-Hsp70 + MPTP: $n=6)$. 


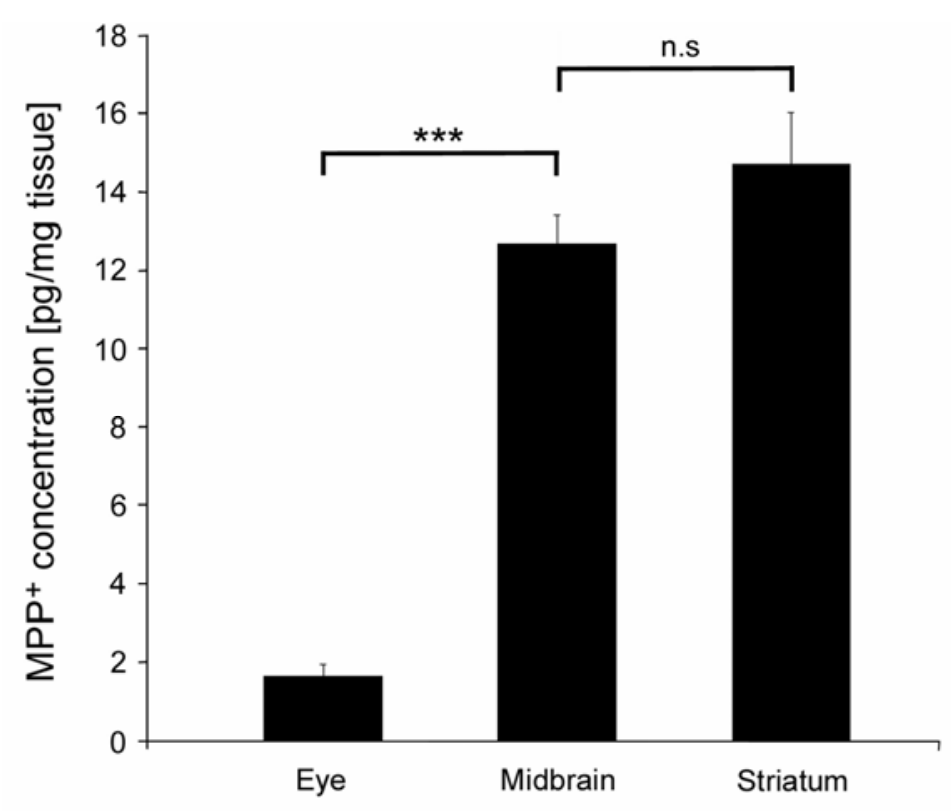

Figure 24. The $\mathrm{MPP}^{+}$level in the eye is significantly lower compared with the $\mathrm{MPP}^{+}$level in the striatum or midbrain 90 min after i.p. injection of MPTP.

$\mathrm{MPP}^{+}$levels were determined by HPLC analysis of samples from eye, midbrain tissue and striatum dissected 90 min after intraperitoneal MPTP application $\left(n \geq 3, p<0.001^{* * *}\right)$.

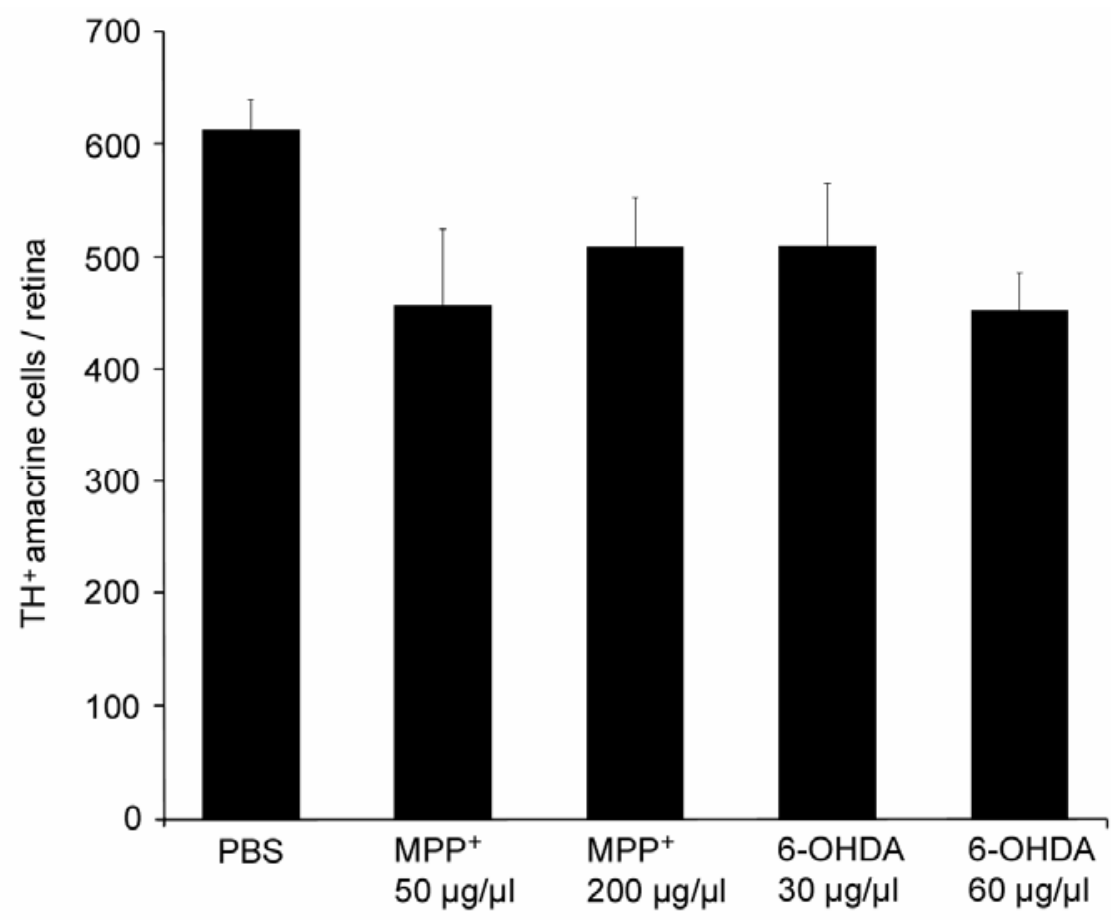

Figure 25. Intraocular injection of $\mathrm{MPP}^{+}$or 6-OHDA fails to induce cell death in retinal amacrine cells.

Mice were injected intraocularly (i.o.) with $\mathrm{MPP}^{+}(0.5 \mu \mathrm{l}$ of 50 or $200 \mu \mathrm{g} / \mu \mathrm{l}), 6$-OHDA $(0.5 \mu \mathrm{l}$ of 30 or 60 $\mu \mathrm{g} / \mu \mathrm{l})$, or PBS as control into the right eye $(n=4)$. For quantitative analysis, each $3^{\text {rd }}$ slice of the retina was used to count tyrosine-hydroxylase-immunopositive amacrine cells in the inner nuclear layer and the total number of DA amacrine cells was interpolated. Results are average \pm SEM. 


\section{DISCUSSION}

\subsection{The molecular mechanism behind the CPP-mediated cargo uptake}

During endocytosis, the Tat fusion protein is left inside a vesicle that it must escape to enter the cytoplasm. The escape of Tat fusion proteins from the vesicle is the limiting factor in the efficiency of transduction (Jones, 2007) and depends on several factors. As the major driving force for Tat to escape endosomes, a decrease in the endosomal pH-gradient was identified (Wadia et al., 2004), meaning that buffering the $\mathrm{pH}$ in endosomes inhibits Tat tranduction. Dowdy has observed that more than $90 \%$ of the fluorescent signal from labeled proteins appears in punctated vesicle, not in the nucleus or cytoplasm. For the transduction of Tat-Hsp70, we also observed a punctated immunofluorescence inside the cells (see section 3.1; Nagel et al., 2008), suggesting that most of the Tat-Hsp70 was transduced via endocytosis. How much of our transduced protein remained inside the vesicles and never entered the cytoplasm was not quantified. Although the application of endosomolytic agents like chloroquine might enhance the functionality of Tat-Hsp70 in vitro, such an approach would not be feasible in vivo and in therapeutic strategies. Other limiting factors might be the membrane potential: Membrane depolarizing compounds have inhibitory effects on the interaction of the transduction domain with the cell surface, rather than inhibiting the membrane translocation step (Gump and Dowdy, 2007). Currently, many questions about the endocytic uptake of Tat and other CPPs remain to be resolved. Besides the different transduction pathways discussed in section 1.5.2, it is important to examine the influence of the conformation of CPP fusion proteins on transduction efficiency and intracellular functionality, and how that in turn is dependent on the purification procedure.

\subsection{Transduction efficiency and functionality of Tat fusion proteins is influenced by the purification procedure}

To examine the widespread conviction that denatured CPPs may transduce cells more efficiently than correctly folded ones (Schwarze et al., 2000; Vocero-Akbani et al., 2000; Vocero-Akbani et al., 2001; Esposito et al., 2007), we decided on a protein that fulfilled two criteria. First, we needed to use a protein whose function and activity 
could be closely monitored and quantified. Second, we gave preference to a protein known to be involved in disease-related processes. Hsp70 is known to chaperone misfolded proteins (Mayer and Bukau, 2005) and prevents their aggregation. Misfolded and aggregated proteins are associated with neurodegenerative diseases such as Alzheimer's disease and PD.

Western blot analysis showed that Tat-Hsp70 purified under native conditions entered the cells most efficiently. This, however, does not preclude the possibility that protein purified under denaturing conditions might have a stronger intracellular effect. An elegant method to precisely quantify the intracellular overall chaperone activity is the use of a chaperone-dependent YFP folding biosensor that has recently been developed in our lab (Liman et al., 2005). Besides offering the opportunity to closely monitor its chaperoning activity, Hsp70 is also an opportune protein to test different preparation procedures because of its known function to protect cells from oxidative stress and apoptotic stimuli (Giffard and Yenari, 2004; Lai et al., 2005; Yenari et al., 2005). Hsp70 protects cells by its chaperone function; moreover, it directly interferes with pro-apoptotic factors (Yenari et al., 2005). Here, we investigated the neuroprotective properties of Tat-Hsp70 against 6-OHDA-induced cell death.

Our results suggest that the purification procedure strongly influences uptake of Tat fusion proteins or their activity. Native isolated Tat-Hsp70 was most efficient in cell transduction, had the strongest effect in folding of the cdYFP folding mutant and caused significant protection of SH-SY5Y cells against 6-OHDA. We also tested protein preparations isolated under denaturing conditions, with either the denaturant removed quickly, as suggested by most current protocols (Becker-Hapak et al., 2001), or by removing the denaturant slowly. The latter is likely to promote at least partial refolding of the protein, while quick removal of urea is more likely to result in a denatured, high energy state of the protein (Mukhopadhyay, 1997).

In our study, we show that Tat fusion protein preparations in which the denaturant has been removed slowly show a higher activity as compared to preparations in which the denaturant was quickly removed, albeit with a lower activity as compared to preparations in which the protein was never denatured in the first place. Furthermore, we showed that SH-SY5Y cells treated with different preparations of Hsp70 transduce cells with less efficiency compared to Tat-Hsp70 treated cells. This suggests a Tat-independent, less efficient uptake mechanism. Our data confirm previous studies, showing that the internalization process of recombinant Hsp70 
appears slowly within 6-8 h (Fujihara and Nadler, 1999), whereas Tat-Hsp70 isolated without denaturant transduces cells within $30 \mathrm{~min}$. The discrepancy between our results and earlier recommendations by S. Dowdy's lab (Nagahara et al., 1998) may be due to the fact that different proteins were examined. A precise quantification of their intracellular activity is not available for all proteins, making the empirical selection of the best purification strategy more challenging. Interestingly, Hsp70 and Tat-Hsp70 isolated under denaturing conditions showed extended cdYFP/ECFP fluorescence intensities, with several local maxima in the cumulative histograms (PDF, Figure 12. D: Hsp70: thin and dashed green lines; Tat-Hsp70: thin red line). These local maxima are due to different populations of cells with different chaperone activities. The second peaks in the cumulative histograms of SH-SY5Y cells treated with Tat-Hsp70 or Hsp70 purified under denaturing conditions could result from endogenous chaperone activity, because it was also observed in control CSM 14.1 and SH-SY5Y cells. For different cells treated with native isolated Tat-Hsp70, the chaperone activity seemed to be similar in different cells (Figure 12. A. D: thick red lines). In both CSM 14.1 and in SH-SY5Y cells, the PDF for native purified Tat-Hsp70 were single peak curves shifted farthest to the right, suggesting not only highest folding activity but also a similar cdYFP folding in all Tat-Hsp70-transduced cells.

To confirm the enhanced neuroprotection of Tat-Hsp70 purified under native conditions, dopaminergic SH-SY5Y cells (Tiffany-Castiglioni et al., 1982; Ross et al., 1985; Yenari et al., 2005), which express the dopamine uptake system (TiffanyCastiglioni et al., 1982; Decker et al.,1993) were used. Since 6-OHDA is a common neurotoxin used in degeneration models, where it causes respiratory inhibition and oxidative stress (Schober, 2004), several in vitro and in vivo studies have been shown that 6-OHDA can induce cell death of catecholaminergic SH-SY5Y cells (Storch et al., 2000) and other cell lines (Abad et al., 1995; Wu et al., 1996; Hou et al., 1997). As the mode of cell death is mainly apoptotic (Blum et al., 2001; Gorman et al., 2005), we indeed expected that Tat-Hsp70 would protect the cells. Increased cell survival was only observed for cells treated with native purified Tat-Hsp70, which correlates well with its chaperone activity. In contrast, previous studies have reported cytoprotective effects of Tat-Hsp70 isolated under denaturing conditions against thermal stress and hypoxia (Wheeler et al., 2003) as well as nitrosative stress and glutamate-induced toxicity in vitro (Lai et al., 2005). These cell death models differ from our model (e.g. in apoptotic stimulus and cell type). In the earlier work, it has not 
been examined whether recombinant proteins that had never been denatured would provide an even higher protection. To our knowledge, this work is the first to systematically investigate the influence of protein purification on the transduction efficiency and functionality of recombinant Tat fusion proteins. Expression of TatHsp70 in E.coli, and the purification under native conditions still rendered high protein yields, which is not the case for all proteins. Future research is required to determine general rules for designing the most auspicious purification strategy for each specific Tat fusion protein. Based on our results Tat-Hsp70 isolated under non-denaturing conditions was the most promising one to test its effect in models for PD.

\subsection{Tat-Hsp70 protects dopaminergic neurons in vitro and in vivo}

As Tat-Hsp70 isolated under native conditions provides highest transduction efficiency, chaperone activity and neuroprotection against 6-OHDA in vitro, we investigated whether the native isolated Tat-Hsp70 fusion protein was neuroprotective in the MPTP model for PD in vitro and in vivo. Previous results have shown that increased expression of Hsp70 contributes to the protection of different cell lines against excitotoxicity, and oxidative and thermal stress (Amin et al., 1995; Wong et al., 1996; Kelly et al., 2001; Quigney et al., 2003; Lai et al., 2005). Our results indicate that Tat-Hsp70 treatment reduces not only the death of DA midbrain neurons from MPP ${ }^{+}$toxicity in vitro and from MPTP toxicity in vivo, but also protects the neuritic processes in vitro and striatal axon terminals in vivo. In contrast to our findings, purely anti-apoptotic treatments like adenoviral gene transfer of XIAP or the caspase inhibitor zVAD-fmk were not able to protect DA terminals from their demise. Only a combination of XIAP and GDNF provided protection for both somata and axon terminals against MPTP toxicity (Eberhardt et al., 2000), which indicates that axonal degeneration and the loss of neuronal somata might be independent processes (Finn et al., 2000). Our findings underline the therapeutic potential of Hsp70: Like some other drugs, Hsp70 interferes with many components of the "death cascade", which appears to be necessary to protect DA neurons in their integrity from MPTP toxicity and potentially in PD.

These findings are in line with the result of an adeno-associated virus (AAV)-Hsp70 injection in the MPTP mouse model (Dong et al., 2005). At this point, we cannot determine whether an application of Tat-Hsp70 after the onset of MPTP treatment 
would be beneficial. However, DA cell loss in the SN induced by high-dose MPTP ceases a few days after MPTP application (Tatton and Kish, 1997), while the number of these cells continues to decline in PD patients. Thus, even if later studies reveal that the time window for therapeutic Tat-Hsp70 application closes briefly after the first MPTP application in the mouse, it might still be beneficial to impede DA neuron decline in patients. For identifying an approach that may be used for the treatment of Parkinson's disease patients in the near future, investigation of Tat fusion protein kinetics would be useful. As a first step, long-term applications and detailed examination of the time window of Tat-Hsp70-mediated protection after MPTP intoxication in our mouse model would be beneficial. Furthermore, in vivo live imaging of fluorescently labeled Tat-Hsp70 could be used to monitor protein distribution after i.p. injection and for quantification in different tissues.

Another way to increase the levels of Hsp70 is the application of geldanamycin. In the MPTP mouse model, preservation of tyrosine hydroxylase immunoreactivity and dopamine content was observed by intracerebral ventricular injection of geldanamycin $24 \mathrm{~h}$ prior to MPTP treatment (Shen et al., 2005). Further in vivo studies have shown the protection of Hsp70 in various models of injury (Yenari et al., 1998; Dong et al., 2005; Yenari et al., 2005), including models in which a-synuclein aggregation and toxicity is observed (Klucken et al., 2004; Song et al., 2004). Breeding of Hsp70-overexpressing mice with $\alpha$-synuclein transgenic mice reduced the development of $\alpha$-synuclein phenotypes, suggesting that Hsp70 can reduce the amount of misfolded and aggregated a-synuclein species and protects mice from a-synuclein-dependent toxicity (Klucken et al., 2004). However, these studies lack the most highly aggregated $\alpha$-synuclein species - at least in vivo - to recapitulate further features of LB. The laboratory of T. Südhof was the first one to show the formation of these $\alpha$-synuclein aggregations in the mouse midbrain using continuous low-level minipump infusions of MPTP (Fornai et al., 2005). Further conformations are missing so far. The subacute MPTP paradigm used in our experiment does not induce aggregates, which is in line with other studies (Shimoji et al., 2005). Therefore, in the present work it was not possible to test whether Hsp70 interacts with $\alpha$-synuclein. We cannot rule out the possibility that Hsp70 provides neuroprotection by interfering with the generation of toxic $\alpha$-synuclein oligomers. It is currently not possible to detect such oligomers in brain tissue. 
In contrast to our findings, the MPTP-induced decline in the striatal dopamine level was significantly inhibited by AAV-Hsp70 (Dong et al., 2005). In our model, the depletion in the level of dopamine and its metabolites DOPAC and HVA after subacute application of MPTP was only moderately but not significantly elevated in the Tat-Hsp70-treated animal group compared with control groups. This discrepancy is not likely to be a result of the different forms of application, i.e. AAV-mediated versus Tat-mediated, but rather of the intensity of the insult. The application of $4 \times 20 \mathrm{mg} / \mathrm{kg}$ MPTP spaced by $24 \mathrm{~h}$ intervals (Dong et al., 2005) led to only a $50 \%$ reduction of striatal dopamine concentration, whereas our treatment with $5 \times 30 \mathrm{mg} / \mathrm{kg}$ MPTP led to a $91 \%$ decrease. This strong depletion may be more difficult to alleviate by therapeutic treatments. Because loss of TH-fiber density was reduced by Tat-Hsp70 treatment, chances are high that dopamine concentration may also be restored at later time points, which we did not investigate. This suggests on the one hand a concomitant rescue of TH-positive somata in the SNpc and their cell processes in the striatum, on the other hand decreased functionality of synaptic terminals and distal axons as the major site of MPTP damage in neurons (Linder et al. 1987). Although initial data suggest a regeneration of DA terminals 90 days after MPTP injection (Kowsky et al., 2007), it remains to be examined whether surviving neurons can regain function after a longer regeneration period. RET (rearranged during transfection) receptor tyrosine kinase activation by its ligand GDNF may play a role in the recovery of striatal dopamine levels (Kowsky et al., 2007). A restoration of dopamine levels may also be possible in our MPTP model and have to be investigated in future studies. Behavioral tests after long survival times would also be desirable. In mouse models it has remained difficult to reliably detect behavioral correlates for PD. Recently, Liebetanz et al. (2007) established a complex running wheel, which detects latent motor deficits in the MPTP mouse model for PD and could be helpful to detect an MPTP-induced behavioral phenotype in our paradigm. Theoretically, the Tat-Hsp70-mediated protection in our MPTP model could occur due to interference of recombinant protein with MPTP, changing MPTP uptake into the brain or conversion into $\mathrm{MPP}^{+}$. To address this question, we measured the $\mathrm{MPP}^{+}$concentrations in the midbrain and in the striatum. We did not detect a difference in $\mathrm{MPP}^{+}$levels among the different treatment groups, suggesting inhibition of cell death by Tat-Hsp70. 


\subsection{Dopaminergic amacrine interneurons in the mouse retina are resistant against parkinsonian toxins}

Dopamine is one of the major control systems of visual functions. Impairment of the dopamine system during retinal degeneration could give rise to many of the visual abnormalities observed during aging and in neurodegenerative diseases like PD (Bodis-Wollner, 1990; Djamgoz et al. ,1997). DA amacrine interneurons play an important role in visual defects of PD (Bodis-Wollner and Tagliati, 1993).

MPTP has been used to reproduce these parkinsonian features in different animal models (Wong et a., 1985; Ambrosio et al., 1988; Bodis-Wollner, 1990; Cuenca et al., 2005). For instance, in mice and goldfish retina, MPTP induces untrastructural features of degeneration (Adams et al., 1992; Villani et al., 2001), or dopamine depletion (Qu et al., 1988; Guarnieri et al.,1994). However, publications quantifying the MPTP-induced TH-positive amacrine cell death in the retina are rare, and the results appear to be in contrast to published dopamine depletion after toxin treatment. For instance, in a subacute MPTP paradigm, neither Chen et al. (2003) nor Tatton et al. (1990) could show a permanent loss of DA amacrine cells after i.p. injection of MPTP. Even though differential vulnerability of DA neurons in different regions of the midbrain has been identified (Liss et al., 2005), there are no reports comparing properties of DA neurons in the retina and DA neurons in the SNpc, where MPTP-induced DA cell death is well reported (Xia et al. 2001; Dong et al., 2005; Dietz et al., 2008; Nagel et al., 2008). In our study, systemic MPTP application by i.p. injection did not induce DA amacrine cell death. This could be due to the 8-fold lower $\mathrm{MPP}^{+}$concentration that we measured in the retina compared with the midbrain. The lower $\mathrm{MPP}^{+}$concentration might be the result of a less efficient transfer of MPTP across the BRB into the eye, or caused by a less efficient conversion of MPTP to MPP ${ }^{+}$in the eye. This is possibly because of a lesser activity of glial MAO-B, which converts MPTP into its toxic metabolite, MPP ${ }^{+}$A compensation of the lower intraretinal concentration of $\mathrm{MPP}^{+}$, by applying higher systemic doses of MPTP, is precluded by its acute toxicity (Jackson-Lewis and Przedborski, 2007). An alternative toxin used in PD models is 6-OHDA (Yazulla and Studholme, 1997). In goldfish, it has been shown that the intraocular injection of 6-OHDA depletes dopamine, accompanied by an eradication of tyrosine-hydroxylase immunopositive cells (Lin and Yazulla, 1994). Therefore, 6-OHDA might be suitable to address questions of neurodegeneration. To examine whether in the mouse, 
retinal DA neurons were vulnerable to one-time local application of parkinsonian toxins, we locally injected $\mathrm{MPP}^{+}$or $6-\mathrm{OHDA}$ into the eye. Even at high doses, for neither of the applied toxins did we observe amacrine cell death. The uptake of such toxins via the dopamine transporter (DAT) into retinal amacrine cells might be less efficient than in DA neurons of striatum and midbrain. Although a strong immunoreactivity of DAT in rodent amacrine cells has been published (Cheng et al., 2006), the affinity for $\mathrm{MPP}^{+}$or 6-OHDA-uptake has not been examined and its role in clearance of those toxins is unclear. However, Cuenca et al. (2005), who performed systemic injections of MPTP $(0.3 \mathrm{mg} / \mathrm{kg})$ in monkeys for 2 years observed a dramatic decrease in TH-expression and a great loss of DA amacrine cell bodies.

Considering this earlier work, our results might indicate that only chronic paradigms of toxin application render reproducible models to study degeneration in amacrine cells of the retina. The acute application of acute MPP ${ }^{+}$or $6-\mathrm{OHDA}$ in the mouse retina might be not useful to examine mechanisms of DA neuronal degeneration. The establishment of reproducible models targeting the DA system in the retina would enhance the development of selective, cell specific targeting molecules for new therapeutic strategies.

\subsection{Future CPP application - a combination of efficiency and specificity}

A major impediment in the treatment of neurodegenerative diseases is the presence of the BBB, which precludes the entry of therapeutic molecules from the brain (Kumar et al., 2007). The development of improved transduction properties for many CPP fusion proteins allows new therapeutic strategies to be pursued. The design of CPP with selective affinity for different cells is the major focus of current research. For example specifically killing tumor cells while leaving other cells intact can be done by the link of CPP with a peptide cargo that specifically acts in tumor cells (Dietz and Bähr, 2005). A related strategy involves organelle-specific delivery by insertion of an organelle-specific protease recognition site between the CPP and its cargo, leading to GFP accumulation in mitochondria in vitro or in the brain in vivo (Del Gaizo and Payne, 2003). With growing knowledge about the role of apoptotic players in neurodegenerative diseases, CPP-mediated drug targeting with caspase inhibitors (Onteniente, 2004), members of the Bcl-2 family (Soane and Fiskum, 2005) or inhibition of nitric oxide synthase (NOS) were performed (Bernatchez et al., 2005). However, all these CPP fusion constructs act on single molecular targets. Targeting 
multiple substrates in the brain with hybrid molecules or a drug cocktail might offer synergistic neuroprotective effects.

Another strategy was developed with the discovery of RNA interference (Tuschl and Borkhardt, 2002). These 20-25 nucleotide-long double-stranded RNA molecules are involved in shaping the chromatin structure of a genome and in the RNA interference (RNAi) pathway, where the siRNA interferes with the expression of a specific gene. The complexity of these pathways is only now being elucidated but siRNA holds great promise for therapeutic application in humans. The main limitation of siRNA technology is the inability of naked siRNA to cross cellular membranes. Therefore, groups of scientists have started to focus on research for efficient delivery systems to increase the ability of small interfering RNA (siRNA) to cross cell membranes. An obvious method to enhance the cellular uptake of siRNA molecules is the conjugation of siRNA duplexes to CPPs (Meade and Dowdy, 2007). While recent published studies have shown successful CPP-siRNA delivery, Dowdy reports the difficulties with inducing siRNA uptake by CPPs, e.g. the conjugations of cationic CPPs and anionic cargoes failed to internalize into cells (Meade and Dowdy, 2007). To overcome this problem, alternative noncovalent complexing siRNA packaging schemes with cationic cell-penetrating peptides were used. Among the few published data, the most promising methodology that has been developed is the synthesis of the cell-specific targeting ligand rabies virus glycoprotein (RVG) with a polyarginine motif for siRNA complexing (RVG-9G; Kumar et al., 2007). Systemic administration of RVG-9R/siRNA complexes to GFP transgenic mice caused a GFP knockdown within the brain, suggesting an efficient transduction of siRNA across the BBB, without GFP affection in other tissues. This approach of cell specific siRNA delivery could prove to be valuable in other tissues if the cell specific targeting properties of other peptide ligands could be utilized (Meade and Dowdy, 2007). This observation offers hope that the CPP approach could improve the realization of siRNA therapeutics. 


\section{SUMMARY}

The hallmark of Parkinson's disease (PD) is the loss of dopaminergic (DA) neurons in the substantia nigra (SN), the depletion of striatal dopamine levels, and the presence of intraneuronal proteinaceous cytoplasmatic inclusions, termed "Lewy bodies". Such inclusions are caused by genetic abnormalities and environmental factors that induce protein misfolding and pathological aggregation. The heat shock protein 70 (Hsp70) reduces protein misfolding and aggregation and has been shown to protect cells against oxidative stress and apoptotic stimuli in various models of neurodegenerative diseases. To deliver bacterially expressed Hsp70 across cellular membranes and into the brain, we linked it to a cell-penetrating peptide (CPP) derived from the human immunodeficiency virus (HIV) trans-activator of transcription (Tat). Because the impact of the purification procedure on the functionality of Tat fusion proteins had not been systematically examined before, we investigated the therapeutic potential of different recombinant protein preparations. We tested Tat-Hsp70 transduction efficiency and quantified Tat-Hsp70-mediated folding of a chaperone-dependent yellow fluorescent protein (cdYFP). The foldase activity of Tat-Hsp70 preparations was consistent with its protection against 6-hydroxydopamine (6-OHDA) and 1methyl-4-phenylpyridinium $\left(\mathrm{MPP}^{+}\right)$-induced cell death in vitro. Tat-Hsp70 isolated under native conditions had the strongest foldase and neuroprotective effect. We therefore tested it in the in vivo MPTP mouse model of PD. We proved that systemically applied Tat-Hsp70 crosses the blood-brain barrier (BBB) and reduces the death of DA neurons induced by 1-methyl-4-phenyl-1,2,3,6-tetrahydropyridine (MPTP), and also protects axon terminals. Moreover, after systemic application, we detected Tat-Hsp70 in the retina, which prompted us to examine whether membranepermeable Hsp70 would also rescue DA amacrine interneurons against parkinsonian toxins. However, application of MPTP or 6-OHDA failed to induce DA amacrine cell death, indicating that the application of neurotoxins exert different effects on DA neurons in the mouse retina compared with those in the SN. In conclusion, the type of purification procedure used has a high impact on the pharmacological properties of Tat fusion proteins, which needs to be considered in therapeutic or basic research applications. Moreover, we demonstrate that the delivery of a molecular chaperone via a cell-penetrating peptide provides protection in in vivo and in vitro PD models, which further validates Hsp70 as a target molecule in neurodegenerative diseases. 


\section{ACKNOWLEDGEMENTS}

I $\mathrm{m}$ very thankful to Prof. Dr. Mathias Bähr, Head of the Department of Neurology, for his support and for giving me the opportunity to work in his laboratory. I would like deeply to thank my supervisor Dr. Gunnar P. H. Dietz for his strong support and deep encouragement in all scientific challenges. I express my sincere thanks to Prof. Dr. Rüdiger Hardeland for agreeing to be the referee and main examiner of my thesis as well as to Prof. Dr. Ralf Heinrich for granting permission to be the co-referee of my Ph.D. thesis. I would like thank Prof. Dr. Detlef Doenecke and Prof. Dr. Erst A. Wimmer for being my examiners; Prof. Dr. Gerhard Braus and Prof. Dr. Christoph Leuschner for agreeing to be the reviewers of my thesis.

Many thanks to all colleagues in the laboratory in Waldweg for creating a pleasant working atmosphere. I am particularly grateful to Lars Tönges and Andreas Ohlenbusch for cloning and sequencing the Tat-Hsp70 construct. Thanks to Christoph Dohm for establishing the in vitro viability assays and the gift of the cdYFP construct. For excellent technical assistance I want to thank Birgit Dietz and Christine Poser; Veronique Planchamp for help in preparation of primary midbrain cultures. Thanks a million to Manuel Garrido and Katrin Meuer for their care and many useful scientific discussions. I am grateful to Johannes Schlachetzki, Bettina Goerike, Petranka Krumova, Barbara Müller, Zinayida Shevtsova, Katrin Eckermann and Johanna Knöferle for making my life in the lab and beyond it more interesting.

Many thanks to Björn Falkenburger, Charlotte Pöppelmeyer, Sebastian Kowsky, Prof. Dr. J. B. Schulz and Prof. Dr. Fred S. Wouters, for their support and collaborations. I would like to thank Cathy Ludwig for proofreading my thesis.

Thanks also to Katarzyna Lisowska (Dept. of Tumor Biology, Centre of Oncology, Gliwice, Poland) for the kind gift of the rat Hsp70.1 clone. S.F. Dowdy (San Diego; CA) kindly provided the pTat-HA vector. This work would not be possible without financial support of the Research Center for Molecular Physiology of the Brain (CMPB) of the "Deutsche Forschungsgemeinschaft" (DFG), the German Neuroscience Society and the German Society of Neurology / "Stiftung Felgenhauer". Special thanks to Christian Westendorf for his deep friendship.

Finally, I want to express my appreciation for my parents and my sister for all their support and continuous encouragement. 


\section{REFERENCES}

Abad F, Maroto R, Lopez MG, Sanchez-Garcia P, Garcia AG (1995) Pharmacological protection against the cytotoxicity induced by 6hydroxydopamine and $\mathrm{H}_{2} \mathrm{O}_{2}$ in chromaffin cells. Eur J Pharmacol 293:55-64.

Adams JD, Pickford MS, Wong CG (1992) The acute retinal histopathology of MPTP. Neurotoxicology 13:541-549.

Albani D, Peverelli E, Rametta R, Batelli S, Veschini L, Negro A, Forloni G (2004) Protective effect of TAT-delivered alpha-synuclein: relevance of the C-terminal domain and involvement of HSP70. Faseb J 18:1713-1715.

Ambrosio S., Blesa R., Mintenig G. M., Palacios-Araus L., Mahy N. and Gual A. (1988) Acute effects of 1-methyl-4-phenyl-1,2,3,6-tetrahydropyridine (MPTP) on catecholamines in heart, adrenal gland, retina and caudate nucleus of the cat. Toxicol Lett 44:1-6.

Amin V, Cumming DV, Coffin RS, Latchman DS (1995) The degree of protection provided to neuronal cells by a pre-conditioning stress correlates with the amount of heat shock protein 70 it induces and not with the similarity of the subsequent stress. Neurosci Lett 200:85-88.

Andersen JK (2004) Oxidative stress in neurodegeneration: cause or consequence? Nat Med 10:S18-25.

Andrew R, Watson DG, Best SA, Midgley JM, Wenlong H, Petty RK (1993) The determination of hydroxydopamines and other trace amines in the urine of parkinsonian patients and normal controls. Neurochem Res 18:1175-1177.

Auluck PK, Chan HY, Trojanowski JQ, Lee VM, Bonini NM (2002) Chaperone suppression of alpha-synuclein toxicity in a Drosophila model for Parkinson's disease. Science 295:865-868.

Auluck PK, Meulener MC, Bonini NM, Chan HY, Trojanowski JQ, Lee VM (2005) Mechanisms of Suppression of alpha-Synuclein Neurotoxicity by Geldanamycin in Drosophila. J Biol Chem 280:2873-2878.

Becker-Hapak M, McAllister SS, Dowdy SF (2001) TAT-mediated protein transduction into mammalian cells. Methods 24:247-256.

Beere HM, Wolf BB, Cain K, Mosser DD, Mahboubi A, Kuwana T, Tailor P, Morimoto RI, Cohen GM, Green DR (2000) Heat-shock protein 70 inhibits apoptosis by 
preventing recruitment of procaspase- 9 to the Apaf-1 apoptosome. Nat Cell Biol 2:469-475.

Bernatchez PN, Bauer PM, Yu J, Prendergast JS, He P, Sessa WC (2005) Dissecting the molecular control of endothelial NO synthase by caveolin-1 using cell-permeable peptides. Proc Natl Acad Sci U S A 102:761-766.

Biedler JL, Helson L, Spengler BA (1973) Morphology and growth, tumorigenicity, and cytogenetics of human neuroblastoma cells in continuous culture. Cancer Res 33:2643-2652.

Blum D, Torch S, Lambeng N, Nissou M, Benabid AL, Sadoul R, Verna JM (2001) Molecular pathways involved in the neurotoxicity of 6-OHDA, dopamine and MPTP: contribution to the apoptotic theory in Parkinson's disease. Prog Neurobiol 65:135-172.

Bodis-Wollner I. (1990) Visual deficits related to dopamine deficiency in experimental animals and Parkinson's disease patients. Trends Neurosci 13:296-302.

Bodis-Wollner I. (2003) Neuropsychological and perceptual defects in Parkinson's disease. Parkinsonism Relat Disord 9:S83-89.

Bodis-Wollner I, Tagliati M (1993) The visual system in Parkinson's disease. Adv Neurol 60:390-394.

Borsello T, Forloni G (2007) JNK signalling: a possible target to prevent neurodegeneration. Curr Pharm Des 13:1875-1886.

Bove J, Prou D, Perier C, Przedborski S (2005) Toxin-induced models of Parkinson's disease. NeuroRx 2:484-494.

Braak H, Braak E (2000) Pathoanatomy of Parkinson's disease. J Neurol 247:II3-10.

Braak H, Muller CM, Rub U, Ackermann H, Bratzke H, de Vos RA, Del Tredici K (2006) Pathology associated with sporadic Parkinson's disease--where does it end? J Neural Transm Suppl:89-97.

Budihardjo I, Oliver H, Lutter M, Luo X, Wang X (1999) Biochemical pathways of caspase activation during apoptosis. Annu Rev Cell Dev Biol 15:269-290.

Bukau B, Horwich AL (1998) The Hsp70 and Hsp60 chaperone machines. Cell 92:351-366.

Cao G, Pei W, Ge H, Liang Q, Luo Y, Sharp FR, Lu A, Ran R, Graham SH, Chen J (2002) In Vivo Delivery of a Bcl-xL Fusion Protein Containing the TAT Protein Transduction Domain Protects against Ischemic Brain Injury and Neuronal Apoptosis. J Neurosci 22:5423-5431. 
Chen M, Wang J (2002) Initiator caspases in apoptosis signaling pathways. Apoptosis 7:313-319.

Chen ST, Hsu JR, Hsu PC, Chuang JI (2003) The retina as a novel in vivo model for studying the role of molecules of the Bcl-2 family in relation to MPTP neurotoxicity. Neurochem Res 28:805-814.

Cheng Z, Zhong YM, Yang XL (2006) Expression of the dopamine transporter in rat and bullfrog retinas. Neuroreport 17:773-777.

Console S, Marty C, Garcia-Echeverria C, Schwendener R, Ballmer-Hofer K (2003) Antennapedia and HIV transactivator of transcription (TAT) "protein transduction domains" promote endocytosis of high molecular weight cargo upon binding to cell surface glycosaminoglycans. J Biol Chem 278:3510935114.

Creagh EM, Sheehan D, Cotter TG (2000b) Heat shock proteins--modulators of apoptosis in tumour cells. Leukemia 14:1161-1173.

Cuenca N., Herrero M. T., Angulo A., de Juan E., Martinez-Navarrete G. C., Lopez S., Barcia C. and Martin-Nieto J. (2005) Morphological impairments in retinal neurons of the scotopic visual pathway in a monkey model of Parkinson's disease. J Comp Neurol 493:261-273.

Dauer W, Kholodilov N, Vila M, Trillat AC, Goodchild R, Larsen KE, Staal R, Tieu K, Schmitz Y, Yuan CA, Rocha M, Jackson-Lewis V, Hersch S, Sulzer D, Przedborski S, Burke R, Hen R (2002) Resistance of alpha -synuclein null mice to the parkinsonian neurotoxin MPTP. Proc Natl Acad Sci U S A 99:14524-14529.

Dauer W, Przedborski S (2003) Parkinson's disease: mechanisms and models. Neuron 39:889-909.

Decker DE, Althaus JS, Buxser SE, VonVoigtlander PF, Ruppel PL (1993) Competitive irreversible inhibition of dopamine uptake by 6-hydroxydopamine. Res Commun Chem Pathol Pharmacol 79:195-208.

Dehmer T, Heneka MT, Sastre M, Dichgans J, Schulz JB (2004) Protection by pioglitazone in the MPTP model of Parkinson's disease correlates with I kappa $B$ alpha induction and block of NF kappa B and iNOS activation. J Neurochem 88:494-501. 
Del Gaizo V, Payne RM (2003) A novel TAT-mitochondrial signal sequence fusion protein is processed, stays in mitochondria, and crosses the placenta. Mol Ther 7:720-730.

Diem R, Taheri N, Dietz GP, Kuhnert A, Maier K, Sattler MB, Gadjanski I, Merkler D, Bähr M (2005) HIV-Tat-mediated Bcl-XL delivery protects retinal ganglion cells during experimental autoimmune optic neuritis. Neurobiol Dis 20:218226.

Dietz GPH, Bähr M (2004) Delivery of bioactive molecules into the cell: the Trojan horse approach. Mol Cell Neurosci 27:85-131.

Dietz GPH, Bähr M (2005) Peptide-enhanced cellular internalization of proteins in neuroscience. Brain Res Bull 68:103-114.

Dietz GPH, Kilic E, Bähr M (2002) Inhibition of neuronal apoptosis in vitro and in vivo using TAT-mediated protein transduction. Mol Cell Neurosci 21:29-37.

Dietz GPH, Dietz B, Bähr M (2006a) Bcl-x(L) increases axonal numbers but not axonal elongation from rat retinal explants. Brain Res Bull 70:117-123.

Dietz GPH, Valbuena PC, Dietz B, Meuer K, Mueller P, Weishaupt JH, Bähr M (2006b) Application of a blood-brain-barrier-penetrating form of GDNF in a mouse model for Parkinson's disease. Brain Res 1082:61-66.

Dietz GPH, Bähr M (2007) Synthesis of Cell Penetrating Peptides and Their Application in Neurobiology. In: Neuroprotection (Borsello T, ed), pp 181-198. Totowa, NJ: The Humana Press Inc.

Dietz GPH, Stockhausen Nee Peters KV, Dietz B, Falkenburger BH, Valbuena P, Opazo F, Lingor P, Meuer K, Weishaupt JH, Schulz JB, Bähr M (2008) Membrane-permeable $\mathrm{Bcl}-\mathrm{x}(\mathrm{L})$ prevents MPTP-induced dopaminergic neuronal loss in the substantia nigra. J Neurochem 104:757-765.

Djamgoz M. B., Hankins M. W., Hirano J. and Archer S. N. (1997) Neurobiology of retinal dopamine in relation to degenerative states of the tissue. Vision Res 37:3509-3529.

Dodel RC, Du Y, Bales KR, Ling ZD, Carvey PM, Paul SM (1998) Peptide inhibitors of caspase-3-like proteases attenuate 1-methyl-4-phenylpyridinum-induced toxicity of cultured fetal rat mesencephalic dopamine neurons. Neuroscience 86:701-707. 
Dong Z, Wolfer DP, Lipp HP, Bueler H (2005) Hsp70 gene transfer by adenoassociated virus inhibits MPTP-induced nigrostriatal degeneration in the mouse model of Parkinson disease. Mol Ther 11:80-88.

Duan W, Zhu X, Ladenheim B, Yu QS, Guo Z, Oyler J, Cutler RG, Cadet JL, Greig $\mathrm{NH}$, Mattson MP (2002) p53 inhibitors preserve dopamine neurons and motor function in experimental parkinsonism. Ann Neurol 52:597-606.

Duchardt F, Fotin-Mleczek M, Schwarz H, Fischer R, Brock R (2007) A comprehensive model for the cellular uptake of cationic cell-penetrating peptides. Traffic 8:848-866.

Eberhardt O, Coelln RV, Kugler S, Lindenau J, Rathke-Hartlieb S, Gerhardt E, Haid S, Isenmann S, Gravel C, Srinivasan A, Bahr M, Weller M, Dichgans J, Schulz JB (2000) Protection by synergistic effects of adenovirus-mediated Xchromosome-linked inhibitor of apoptosis and glial cell line-derived neurotrophic factor gene transfer in the 1-methyl-4-phenyl-1,2,3,6tetrahydropyridine model of Parkinson's disease. J Neurosci 20:9126-9134.

Embury J, Klein D, Pileggi A, Ribeiro M, Jayaraman S, Molano RD, Fraker C, Kenyon N, Ricordi C, Inverardi L, Pastori RL (2001) Proteins linked to a protein transduction domain efficiently transduce pancreatic islets. Diabetes 50:17061713.

Ericson C, Georgievska B, Lundberg C (2005) Ex vivo gene delivery of GDNF using primary astrocytes transduced with a lentiviral vector provides neuroprotection in a rat model of Parkinson's disease. Eur J Neurosci 22:2755-2764.

Esposito A, Dohm CP, Kermer P, Bahr M, Wouters FS (2007) alpha-Synuclein and its disease-related mutants interact differentially with the microtubule protein tau and associate with the actin cytoskeleton. Neurobiol Dis 26:521-531.

Fawell S, Seery J, Daikh Y, Moore C, Chen LL, Pepinsky B, Barsoum J (1994) Tatmediated delivery of heterologous proteins into cells. Proc Natl Acad Sci U S A 91:664-668.

Ferrari A, Pellegrini V, Arcangeli C, Fittipaldi A, Giacca M, Beltram F (2003) Caveolae-mediated internalization of extracellular HIV-1 tat fusion proteins visualized in real time. Mol Ther 8:284-294.

Finn JT, Weil M, Archer F, Siman R, Srinivasan A, Raff MC (2000) Evidence that Wallerian degeneration and localized axon degeneration induced by local neurotrophin deprivation do not involve caspases. J Neurosci 20:1333-1341. 
Fischer R, Fotin-Mleczek M, Hufnagel H, Brock R (2005) Break on through to the other side-biophysics and cell biology shed light on cell-penetrating peptides. Chembiochem 6:2126-2142.

Fischer A. J., Seltner R. L., Poon J. and Stell W. K. (1998) Immunocytochemical characterization of quisqualic acid- and $\mathrm{N}$-methyl-D-aspartate-induced excitotoxicity in the retina of chicks. J Comp Neurol 393:1-15.

Fischer A. J., Schmidt M., Omar G. and Reh T. A. (2004) BMP4 and CNTF are neuroprotective and suppress damage-induced proliferation of Muller glia in the retina. Mol Cell Neurosci 27:531-542.

Fittipaldi A, Ferrari A, Zoppe M, Arcangeli C, Pellegrini V, Beltram F, Giacca M (2003) Cell membrane lipid rafts mediate caveolar endocytosis of HIV-1 Tat fusion proteins. J Biol Chem 278:34141-34149.

Fjord-Larsen L, Johansen JL, Kusk P, Tornoe J, Gronborg M, Rosenblad C, Wahlberg LU (2005) Efficient in vivo protection of nigral dopaminergic neurons by lentiviral gene transfer of a modified Neurturin construct. Exp Neurol 195:49-60.

Foerg C, Ziegler U, Fernandez-Carneado J, Giralt E, Rennert R, Beck-Sickinger AG, Merkle HP (2005) Decoding the entry of two novel cell-penetrating peptides in HeLa cells: lipid raft-mediated endocytosis and endosomal escape. Biochemistry 44:72-81.

Fornai F, Schluter OM, Lenzi P, Gesi M, Ruffoli R, Ferrucci M, Lazzeri G, Busceti CL, Pontarelli F, Battaglia G, Pellegrini A, Nicoletti F, Ruggieri S, Paparelli A, Sudhof TC (2005) Parkinson-like syndrome induced by continuous MPTP infusion: convergent roles of the ubiquitin-proteasome system and alphasynuclein. Proc Natl Acad Sci U S A 102:3413-3418.

Frankel AD, Pabo CO (1988) Cellular uptake of the tat protein from human immunodeficiency virus. Cell 55:1189-1193.

Fujihara SM, Nadler SG (1999) Intranuclear targeted delivery of functional NFkappaB by $70 \mathrm{kDa}$ heat shock protein. Embo J 18:411-419.

Gabai VL, Mabuchi K, Mosser DD, Sherman MY (2002) Hsp72 and stress kinase cjun $\mathrm{N}$-terminal kinase regulate the bid-dependent pathway in tumor necrosis factor-induced apoptosis. Mol Cell Biol 22:3415-3424.

Galazka G, Stasiolek M, Walczak A, Jurewicz A, Zylicz A, Brosnan CF, Raine CS, Selmaj KW (2006) Brain-derived heat shock protein 70-peptide complexes 
induce NK cell-dependent tolerance to experimental autoimmune encephalomyelitis. J Immunol 176:1588-1599.

Garrido C, Gurbuxani S, Ravagnan L, Kroemer G (2001) Heat shock proteins: endogenous modulators of apoptotic cell death. Biochem Biophys Res Commun 286:433-442.

Gässler CS, Wiederkehr T, Brehmer D, Bukau B, Mayer MP (2001) Bag-1M accelerates nucleotide release for human Hsc70 and Hsp70 and can act concentration-dependent as positive and negative cofactor. J Biol Chem 276:32538-32544.

Ghahremani MH, Keramaris E, Shree T, Xia Z, Davis RJ, Flavell R, Slack RS, Park DS (2002) Interaction of the c-Jun/JNK pathway and cyclin-dependent kinases in death of embryonic cortical neurons evoked by DNA damage. J Biol Chem 277:35586-35596.

Giasson BI, Duda JE, Murray IV, Chen Q, Souza JM, Hurtig HI, Ischiropoulos H, Trojanowski JQ, Lee VM (2000) Oxidative damage linked to neurodegeneration by selective alpha-synuclein nitration in synucleinopathy lesions. Science 290:985-989.

Giffard RG, Yenari MA (2004) Many mechanisms for hsp70 protection from cerebral ischemia. J Neurosurg Anesthesiol 16:53-61.

Giffard RG, Xu L, Zhao H, Carrico W, Ouyang Y, Qiao Y, Sapolsky R, Steinberg G, Hu B, Yenari MA (2004) Chaperones, protein aggregation, and brain protection from hypoxic/ischemic injury. J Exp Biol 207:3213-3220.

Gonzalez-Polo RA, Soler G, Fuentes JM (2004) MPP+: mechanism for its toxicity in cerebellar granule cells. Mol Neurobiol 30:253-264.

Gorman AM, Szegezdi E, Quigney DJ, Samali A (2005) Hsp27 inhibits 6hydroxydopamine-induced cytochrome c release and apoptosis in PC12 cells. Biochem Biophys Res Commun 327:801-810.

Gratton JP, Yu J, Griffith JW, Babbitt RW, Scotland RS, Hickey R, Giordano FJ, Sessa WC (2003) Cell-permeable peptides improve cellular uptake and therapeutic gene delivery of replication-deficient viruses in cells and in vivo. Nat Med 9:357-362.

Green DR, Kroemer G (2004) The pathophysiology of mitochondrial cell death. Science 305:626-629. 
Green M, Loewenstein PM (1988) Autonomous functional domains of chemically synthesized human immunodeficiency virus tat trans-activator protein. Cell 55:1179-1188.

Guarnieri T., Virgili M., Carraro S. and Villani L. (1994) Quinolinic acid but not MK801 protects the dopaminergic system from 1-methyl-4-phenyl-1,2,3,6tetrahydropyridine-induced toxicity in goldfish retina. Neurochem Int 24:559564.

Guegan C, Braudeau J, Couriaud C, Dietz GP, Lacombe P, Bahr M, Nosten-Bertrand M, Onteniente B (2006) PTD-XIAP protects against cerebral ischemia by antiapoptotic and transcriptional regulatory mechanisms. Neurobiol Dis 22:177186.

Gump JM, Dowdy SF (2007) TAT transduction: the molecular mechanism and therapeutic prospects. Trends Mol Med 13:443-448.

Haas SJ, Wree A (2002) Dopaminergic differentiation of the Nurr1-expressing immortalized mesencephalic cell line CSM14.1 in vitro. J Anat 201:61-69.

Hacker U, Albrecht R, Maniak M (1997) Fluid-phase uptake by macropinocytosis in Dictyostelium. J Cell Sci 110:105-112.

Hartmann A, Michel PP, Troadec JD, Mouatt-Prigent A, Faucheux BA, Ruberg M, Agid $Y$, Hirsch EC (2001) Is Bax a mitochondrial mediator in apoptotic death of dopaminergic neurons in Parkinson's disease? J Neurochem 76:1785-1793.

Hartmann A, Hunot S, Michel PP, Muriel MP, Vyas S, Faucheux BA, Mouatt-Prigent A, Turmel H, Srinivasan A, Ruberg M, Evan GI, Agid Y, Hirsch EC (2000) Caspase-3: A vulnerability factor and final effector in apoptotic death of dopaminergic neurons in Parkinson's disease. Proc Natl Acad Sci U S A 97:2875-2880.

Hague A, Paraskeva C (2004) Apoptosis and disease: a matter of cell fate. Cell Death Differ 11:1366-1372.

Herting B, Bietenbeck S, Scholz K, Hahner A, Hummel T, Reichmann H (2007) [Olfactory dysfunction in Parkinson's disease : Its role as a new cardinal sign in early and differential diagnosis.]. Nervenarzt 17:17.

Hotchkiss RS, McConnell KW, Bullok K, Davis CG, Chang KC, Schwulst SJ, Dunne JC, Dietz GPH, Bähr M, McDunn JE, Karl IE, Wagner TH, Cobb JP, Coopersmith CM, Piwnica-Worms D (2006) TAT-BH4 and TAT-Bcl-xL 
peptides protect against sepsis-induced lymphocyte apoptosis in vivo. J Immunol 176:5471-5477.

Hou JG, Cohen G, Mytilineou C (1997) Basic fibroblast growth factor stimulation of glial cells protects dopamine neurons from 6-hydroxydopamine toxicity: involvement of the glutathione system. J Neurochem 69:76-83.

Izmailova E, Bertley FM, Huang Q, Makori N, Miller CJ, Young RA, Aldovini A (2003) HIV-1 Tat reprograms immature dendritic cells to express chemoattractants for activated T cells and macrophages. Nat Med 9:191-197. Epub 2003 Jan 2021. Jackson-Lewis V, Przedborski S (2007) Protocol for the MPTP mouse model of Parkinson's disease. Nat Protoc 2:141-151.

Jeang KT, Xiao H, Rich EA (1999) Multifaceted activities of the HIV-1 transactivator of transcription, Tat. J Biol Chem 274:28837-28840.

Johannes L, Goud B (2000) Facing inward from compartment shores: how many pathways were we looking for? Traffic 1:119-123.

Jones SW, Christison R, Bundell K, Voyce CJ, Brockbank SM, Newham P, Lindsay MA (2005) Characterisation of cell-penetrating peptide-mediated peptide delivery. Br J Pharmacol 145:1093-1102.

Jones AT (2007) Macropinocytosis: searching for an endocytic identity and role in the uptake of cell penetrating peptides. J Cell Mol Med 11:670-684.

Kaufmann SH, Earnshaw WC (2000) Induction of apoptosis by cancer chemotherapy. Exp Cell Res 256:42-49.

Kaplan IM, Wadia JS, Dowdy SF (2005) Cationic TAT peptide transduction domain enters cells by macropinocytosis. J Control Release 102:247-253.

Kelly S, Yenari MA (2002) Neuroprotection: heat shock proteins. Curr Med Res Opin 18:s55-60.

Kelly S, Bieneman A, Horsburgh K, Hughes D, Sofroniew MV, McCulloch J, Uney JB (2001) Targeting expression of hsp70i to discrete neuronal populations using the Lmo-1 promoter: assessment of the neuroprotective effects of hsp70i in vivo and in vitro. J Cereb Blood Flow Metab 21:972-981.

Kelly S, Zhang ZJ, Zhao H, Xu L, Giffard RG, Sapolsky RM, Yenari MA, Steinberg GK (2002) Gene transfer of HSP72 protects cornu ammonis 1 region of the hippocampus neurons from global ischemia: influence of Bcl-2. Ann Neurol 52:160-167. 
Kerr JF, Wyllie AH, Currie AR (1972) Apoptosis: a basic biological phenomenon with wide-ranging implications in tissue kinetics. Br J Cancer 26:239-257.

Kilic E, Dietz GPH, Hermann DM, Bähr M (2002) Intravenous TAT-Bcl-XI is protective after middle cerebral artery occlusion in mice. Ann Neurol 52:617-622.

Kilic U, Kilic E, Dietz GPH, Bähr M (2003) Intravenous TAT-GDNF is protective after focal cerebral ischemia in mice. Stroke 34:1304-1310.

Kirik D, Rosenblad C, Bjorklund A (1998) Characterization of behavioral and neurodegenerative changes following partial lesions of the nigrostriatal dopamine system induced by intrastriatal 6-hydroxydopamine in the rat. Exp Neurol 152:259-277.

Klevenyi P, Andreassen O, Ferrante RJ, Schleicher JR, Jr., Friedlander RM, Beal MF (1999) Transgenic mice expressing a dominant negative mutant interleukin1 beta converting enzyme show resistance to MPTP neurotoxicity. Neuroreport 10:635-638.

Klucken J, Shin Y, Masliah E, Hyman BT, McLean PJ (2004) Hsp70 Reduces alphaSynuclein Aggregation and Toxicity. J Biol Chem 279:25497-25502.

Kowsky S, Poppelmeyer C, Kramer ER, Falkenburger BH, Kruse A, Klein R, Schulz JB (2007) RET signaling does not modulate MPTP toxicity but is required for regeneration of dopaminergic axon terminals. Proc Natl Acad Sci U S A 104:20049-20054.

Krieglstein K, Suter-Crazzolara C, Fischer WH, Unsicker K (1995) TGF-beta superfamily members promote survival of midbrain dopaminergic neurons and protect them against MPP+ toxicity. Embo J 14:736-742.

Kumar P, Wu H, McBride JL, Jung KE, Kim MH, Davidson BL, Lee SK, Shankar P, Manjunath N (2007) Transvascular delivery of small interfering RNA to the central nervous system. Nature 448:39-43.

Lai Y, Du L, Dunsmore KE, Jenkins LW, Wong HR, Clark RS (2005) Selectively increasing inducible heat shock protein 70 via TAT-protein transduction protects neurons from nitrosative stress and excitotoxicity. J Neurochem 94:360-366.

Langston JW, Ballard P, Tetrud JW, Irwin I (1983) Chronic Parkinsonism in humans due to a product of meperidine-analog synthesis. Science 219:979-980. 
Lee VM, Trojanowski JQ (2006) Mechanisms of Parkinson's disease linked to pathological alpha-synuclein: new targets for drug discovery. Neuron 52:3338.

Lei K, Nimnual A, Zong WX, Kennedy NJ, Flavell RA, Thompson CB, Bar-Sagi D, Davis RJ (2002) The Bax subfamily of Bcl2-related proteins is essential for apoptotic signal transduction by c-Jun $\mathrm{NH}(2)$-terminal kinase. Mol Cell Biol 22:4929-4942.

Letoha T, Kusz E, Papai G, Szabolcs A, Kaszaki J, Varga I, Takacs T, Penke B, Duda E (2006) In vitro and in vivo nuclear factor-kappaB inhibitory effects of the cell-penetrating penetratin peptide. Mol Pharmacol 69:2027-2036. Epub 2006 Feb 2027.

Liebetanz D, Baier PC, Paulus W, Meuer K, Bahr M, Weishaupt JH (2007) A highly sensitive automated complex running wheel test to detect latent motor deficits in the mouse MPTP model of Parkinson's disease. Exp Neurol 205:207-213. Epub 2007 Feb 2007.

Liman J, Ganesan S, Dohm CP, Krajewski S, Reed JC, Bahr M, Wouters FS, Kermer P (2005) Interaction of BAG1 and Hsp70 mediates neuroprotectivity and increases chaperone activity. Mol Cell Biol 25:3715-3725.

Linder JC, Klemfuss H, Groves PM (1987) Acute ultrastructural and behavioral effects of 1-methyl-4-phenyl-1,2,3,6-tetrahydropyridine (MPTP) in mice. Neurosci Lett 82:221-226.

Lindholm P, Voutilainen MH, Lauren J, Peranen J, Leppanen VM, Andressoo JO, Lindahl M, Janhunen S, Kalkkinen N, Timmusk T, Tuominen RK, Saarma M (2007) Novel neurotrophic factor CDNF protects and rescues midbrain dopamine neurons in vivo. Nature 448:73-77.

Lingor P, Unsicker K, Krieglstein K (2000) GDNF and NT-4 protect midbrain dopaminergic neurons from toxic damage by iron and nitric oxide. Exp Neurol 163:55-62.

Lin ZS and Yazulla S (1994) Depletion of retinal dopamine increases brightness perception in goldfish. Vis Neurosci. 11:683-693

Liss B., Haeckel O., Wildmann J., Miki T., Seino S. and Roeper J. (2005) K-ATP channels promote the differential degeneration of dopaminergic midbrain neurons. Nat Neurosci 8:1742-1751. 
Lo EH, Singhal AB, Torchilin VP, Abbott NJ (2001) Drug delivery to damaged brain. Brain Res Brain Res Rev 38:140-148.

Lorenzo HK and Susin SA (2007) Therapeutic potential of AIF-mediated caspaseindependent programmed cell death. Drug Resist Updat. 10:235-255.

MacFarlane M, Williams AC (2004) Apoptosis and disease: a life or death decision. EMBO Rep 5:674-678.

Malik JM, Shevtsova Z, Bahr M, Kugler S (2005) Long-term in vivo inhibition of CNS neurodegeneration by Bcl-XL gene transfer. Mol Ther 11:373-381.

Maxfield FR, McGraw TE (2004) Endocytic recycling. Nat Rev Mol Cell Biol 5:121132.

Mayer MP, Bukau B (2005) Hsp70 chaperones: cellular functions and molecular mechanism. Cell Mol Life Sci 62:670-684.

Mayer RA, Kindt MV, Heikkila RE (1986) Prevention of the nigrostriatal toxicity of 1methyl-4-phenyl-1,2,3,6-tetrahydropyridine by inhibitors of 3,4dihydroxyphenylethylamine transport. J Neurochem 47:1073-1079.

Meade BR, Dowdy SF (2007) Enhancing the cellular uptake of siRNA duplexes following noncovalent packaging with protein transduction domain peptides. Adv Drug Deliv Rev 22:22.

Mosser DD, Caron AW, Bourget L, Denis-Larose C, Massie B (1997) Role of the human heat shock protein hsp70 in protection against stress-induced apoptosis. Mol Cell Biol 17:5317-5327.

Mukhopadhyay A (1997) Inclusion bodies and purification of proteins in biologically active forms. Adv Biochem Eng Biotechnol 56:61-109.

Nagahara H, Vocero-Akbani AM, Snyder EL, Ho A, Latham DG, Lissy NA, BeckerHapak M, Ezhevsky SA, Dowdy SF (1998) Transduction of full-length TAT fusion proteins into mammalian cells: TAT-p27Kip1 induces cell migration. Nat Med 4:1449-1452.

Nagel F, Falkenburger BJ, Tönges L, Kowsky S, Pöppelmexer C, Schulz JB, Bähr M, Dietz GPH, (2008) Tat-Hsp70 protects dopaminergic neurons in midbrain cultures and in the substantia nigra in models of Parkinson's disease. $\mathrm{J}$ Neurochem. in press.

Nakase I, Tadokoro A, Kawabata N, Takeuchi T, Katoh H, Hiramoto K, Negishi M, Nomizu M, Sugiura Y, Futaki S (2007) Interaction of arginine-rich peptides 
with membrane-associated proteoglycans is crucial for induction of actin organization and macropinocytosis. Biochemistry 46:492-501.

Norris EH, Giasson BI, Hodara R, Xu S, Trojanowski JQ, Ischiropoulos H, Lee VM (2005) Reversible inhibition of alpha-synuclein fibrillization by dopaminochrome-mediated conformational alterations. J Biol Chem 280:21212-21219.

O'Neill MJ, Murray TK, Whalley K, Ward MA, Hicks CA, Woodhouse S, Osborne DJ, Skolnick P (2004) Neurotrophic actions of the novel AMPA receptor potentiator, LY404187, in rodent models of Parkinson's disease. Eur $\mathrm{J}$ Pharmacol 486:163-174.

Onteniente B (2004) Natural and synthetic inhibitors of caspases: targets for novel drugs. Curr Drug Targets CNS Neurol Disord 3:333-340.

Pahwa R (2006) Understanding Parkinson's disease: an update on current diagnostic and treatment strategies. J Am Med Dir Assoc 7:4-10.

Park HS, Lee JS, Huh SH, Seo JS, Choi EJ (2001) Hsp72 functions as a natural inhibitory protein of c-Jun N-terminal kinase. Embo J 20:446-456.

Parkinson J (2002) An essay on the shaking palsy. 1817. J Neuropsychiatry Clin Neurosci 14:223-236; discussion 222.

Perez F, Joliot A, Bloch-Gallego E, Zahraoui A, Triller A, Prochiantz A (1992) Antennapedia homeobox as a signal for the cellular internalization and nuclear addressing of a small exogenous peptide. J Cell Sci 102:717-722.

Petak I, Houghton JA (2001) Shared pathways: death receptors and cytotoxic drugs in cancer therapy. Pathol Oncol Res 7:95-106.

Playfer JR (1997) Parkinson's disease. Postgrad Med J 73:257-264.

Porter CC TJ, Stone CA (1963) Effect of 6-hydroxydopamine and some other compounds on the concentration of norepinephrine in the hearts of mice. $\mathrm{J}$ Pharmacol Exp Ther 140:308-316.

Przedborski S, Vila M (2003) The 1-methyl-4-phenyl-1,2,3,6-tetrahydropyridine mouse model: a tool to explore the pathogenesis of Parkinson's disease. Ann N Y Acad Sci 991:189-198.

Przedborski S, Tieu K, Perier C, Vila M (2004) MPTP as a mitochondrial neurotoxic model of Parkinson's disease. J Bioenerg Biomembr 36:375-379.

Qu ZX, Neff NH, Hadjiconstantinou M (1988) MPP+ depletes retinal dopamine and induces D-1 receptor supersensitivity. Eur J Pharmacol 148:453-455. 
Quigney DJ, Gorman AM, Samali A (2003) Heat shock protects PC12 cells against MPP+ toxicity. Brain Res 993:133-139.

Ransom BR, Kunis DM, Irwin I, Langston JW (1987) Astrocytes convert the parkinsonism inducing neurotoxin, MPTP, to its active metabolite, MPP+. Neurosci Lett 75:323-328.

Ravagnan L, Gurbuxani S, Susin SA, Maisse C, Daugas E, Zamzami N, Mak T, Jaattela M, Penninger JM, Garrido C, Kroemer G (2001) Heat-shock protein 70 antagonizes apoptosis-inducing factor. Nat Cell Biol 3:839-843.

Richard JP, Melikov K, Vives E, Ramos C, Verbeure B, Gait MJ, Chernomordik LV, Lebleu B (2003) Cell-penetrating peptides. A reevaluation of the mechanism of cellular uptake. J Biol Chem 278:585-590.

Riederer P, Konradi C, Youdim MB (1990) The role of MAO in dopaminergic transmission. Adv Neurol 53:149-153.

Rizzo MA, Springer GH, Granada B, Piston DW (2004) An improved cyan fluorescent protein variant useful for FRET. Nat Biotechnol 22:445-449.

Ritossa F (1962) A new puffing pattern induced by temperature and DNP in Drosophila. Experimentia 18:571-573.

Roh YJ, Moon C, Kim SY, Park MH, Bae YC, Chun MH, Moon JI (2007) Glutathione depletion induces differential apoptosis in cells of mouse retina, in vivo. Neurosci Lett 417:266-270.

Ross RA, Biedler JL (1985) Presence and regulation of tyrosinase activity in human neuroblastoma cell variants in vitro. Cancer Res 45:1628-1632.

Rossetti ZL, Sotgiu A, Sharp DE, Hadjiconstantinou M, Neff NH (1988) 1-Methyl-4phenyl-1,2,3,6-tetrahydropyridine (MPTP) and free radicals in vitro. Biochem Pharmacol 37:4573-4574.

Rothbard JB, Jessop TC, Lewis RS, Murray BA, Wender PA (2004) Role of membrane potential and hydrogen bonding in the mechanism of translocation of guanidinium-rich peptides into cells. J Am Chem Soc 126:9506-9507.

Ryser HJ (1967) A membrane effect of basic polymers dependent on molecular size. Nature 215:934-936.

Ryser HJ (1968) Uptake of protein by mammalian cells: an underdeveloped area. The penetration of foreign proteins into mammalian cells can be measured and their functions explored. Science 159:390-396. 
Saalik P, Elmquist A, Hansen M, Padari K, Saar K, Viht K, Langel U, Pooga M (2004) Protein cargo delivery properties of cell-penetrating peptides. A comparative study. Bioconjug Chem 15:1246-1253.

Saleh A, Srinivasula SM, Balkir L, Robbins PD, Alnemri ES (2000) Negative regulation of the Apaf-1 apoptosome by Hsp70. Nat Cell Biol 2:476-483.

Saporito MS, Thomas BA, Scott RW (2000) MPTP activates c-Jun NH(2)-terminal kinase (JNK) and its upstream regulatory kinase MKK4 in nigrostriatal neurons in vivo. J Neurochem 75:1200-1208.

Scaffidi C, Fulda S, Srinivasan A, Friesen C, Li F, Tomaselli KJ, Debatin KM, Krammer PH, Peter ME (1998) Two CD95 (APO-1/Fas) signaling pathways. Embo J 17:1675-1687.

Schapira AH (1995) Oxidative stress in Parkinson's disease. Neuropathol Appl Neurobiol 21:3-9.

Schelling HR, (2000) Gesellschaftlicher Wandel des Alterns. 1-16. URI: http://www.mysunrise.ch/users/h.r.schelling/Gesellsch_Wandel/Gesellsch_Wa ndel.pdf

Schober A (2004) Classic toxin-induced animal models of Parkinson's disease: 6OHDA and MPTP. Cell Tissue Res 318:215-224.

Schulz JB (2006) Anti-apoptotic gene therapy in Parkinson's disease. J Neural Transm Suppl:467-476.

Schulz J, Beal. M (1994) Mitochondrial dysfunction in movement disorders. Curr Opin Neurol 7:333-339.

Schulz JB, Falkenburger BH (2004) Neuronal pathology in Parkinson's disease. Cell Tissue Res 318:135-147.

Schulz JB, Weller M, Moskowitz MA (1999) Caspases as treatment targets in stroke and neurodegenerative diseases. Ann Neurol 45:421-429.

Schutze-Redelmeier MP, Gournier H, Garcia-Pons F, Moussa M, Joliot AH, Volovitch M, Prochiantz A, Lemonnier FA (1996) Introduction of exogenous antigens into the MHC class I processing and presentation pathway by Drosophila antennapedia homeodomain primes cytotoxic $\mathrm{T}$ cells in vivo. $\mathrm{J}$ Immunol $157: 650-655$.

Schwarze SR, Hruska KA, Dowdy SF (2000) Protein transduction: unrestricted delivery into all cells? Trends Cell Biol 10:290-295. 
Schwarze SR, Ho A, Vocero-Akbani A, Dowdy SF (1999) In vivo protein transduction: delivery of a biologically active protein into the mouse. Science 285:15691572.

Senoh S, Creveling CR, Udenfriend S, Witkop B (1959) Chemical, enzymatic, and metabolic studies on the mechanism of oxidation of dopamine. J Am Chem Soc 81:6236-6240.

Senoh S, Witkop B (1959) Non-enzymatic conversions of dopamine to norepinephrine and trihydroxyphenetylamines. J Am Chem Soc 81:6222-6231.

Shen HY, He JC, Wang Y, Huang QY, Chen JF (2005) Geldanamycin induces heat shock protein 70 and protects against MPTP-induced dopaminergic neurotoxicity in mice. J Biol Chem 280:39962-39969.

Shevtsova Z, Malik I, Garrido M, Scholl U, Bahr M, Kugler S (2006) Potentiation of in vivo neuroprotection by $\mathrm{BcIX}(\mathrm{L})$ and $\mathrm{GDNF}$ co-expression depends on postlesion time in deafferentiated CNS neurons. Gene Ther 13:1569-1578.

Shimoji M, Zhang L, Mandir AS, Dawson VL, Dawson TM (2005) Absence of inclusion body formation in the MPTP mouse model of Parkinson's disease. Brain Res Mol Brain Res 134:103-108.

Shub DA (1994) Bacterial viruses. Bacterial altruism? Curr Biol 4:555-556.

Soane L, Fiskum G (2005) TAT-mediated endocytotic delivery of the loop deletion Bcl-2 protein protects neurons against cell death. J Neurochem 95:230-243.

Song J, Takeda M, Morimoto RI (2001) Bag1-Hsp70 mediates a physiological stress signalling pathway that regulates Raf-1/ERK and cell growth. Nat Cell Biol 3:276-282.

Song DD, Shults CW, Sisk A, Rockenstein E, Masliah E (2004) Enhanced substantia nigra mitochondrial pathology in human alpha-synuclein transgenic mice after treatment with MPTP. Exp Neurol 186:158-172.

Soubrane C, Mouawad R, Antoine EC, Verola O, Gil-Delgado M, Khayat D (2000) A comparative study of Fas and Fas-ligand expression during melanoma progression. Br J Dermatol 143:307-312.

Stichel CC, Zhu XR, Bader V, Linnartz B, Schmidt S, Lubbert H (2007) Mono- and double-mutant mouse models of Parkinson's disease display severe mitochondrial damage. Hum Mol Genet 16:3377-3393. 
Storch A, Kaftan A, Burkhardt K, Schwarz J (2000) 6-Hydroxydopamine toxicity towards human SH-SY5Y dopaminergic neuroblastoma cells: independent of mitochondrial energy metabolism. J Neural Transm 107:281-293.

Susin SA, Lorenzo HK, Zamzami N, Marzo I, Snow BE, Brothers GM, Mangion J, Jacotot E, Costantini P, Loeffler M, Larochette N, Goodlett DR, Aebersold R, Siderovski DP, Penninger JM, Kroemer G (1999) Molecular characterization of mitochondrial apoptosis-inducing factor. Nature 397:441-446.

Tatton NA, Kish SJ (1997) In situ detection of apoptotic nuclei in the substantia nigra compacta of 1-methyl-4-phenyl-1,2,3,6-tetrahydropyridine-treated mice using terminal deoxynucleotidyl transferase labelling and acridine orange staining. Neuroscience 77:1037-1048.

Tatton WG, Kwan MM, Verrier MC, Seniuk NA, Theriault E (1990) MPTP produces reversible disappearance of tyrosine hydroxylase-containing retinal amacrine cells. Brain Res 527:21-31.

Thomas B, Beal MF (2007) Parkinson's disease. Hum Mol Genet 16:R183-194.

Tiffany-Castiglioni E, Saneto RP, Proctor PH, Perez-Polo JR (1982) Participation of active oxygen species in 6-hydroxydopamine toxicity to a human neuroblastoma cell line. Biochem Pharmacol 31:181-188.

Tipton KF, Singer TP (1993) Advances in our understanding of the mechanisms of the neurotoxicity of MPTP and related compounds. J Neurochem 61:11911206.

Trimmer PA, Smith TS, Jung AB, Bennett JP, Jr. (1996) Dopamine neurons from transgenic mice with a knockout of the p53 gene resist MPTP neurotoxicity. Neurodegeneration 5:233-239.

Truettner JS, Hu B, Alonso OF, Bramlett HM, Kokame K, Dietrich WD (2007) Subcellular stress response after traumatic brain injury. J Neurotrauma 24:599-612.

Tuschl T, Borkhardt A (2002) Small interfering RNAs: a revolutionary tool for the analysis of gene function and gene therapy. Mol Interv 2:158-167

Tyagi M, Rusnati M, Presta M, Giacca M (2001) Internalization of HIV-1 tat requires cell surface heparan sulfate proteoglycans. J Biol Chem 276:3254-3261.

Vendeville A, Rayne F, Bonhoure A, Bettache N, Montcourrier P, Beaumelle B (2004) HIV-1 Tat enters $T$ cells using coated pits before translocating from acidified endosomes and eliciting biological responses. Mol Biol Cell 15:2347-2360. 
Vila M, Jackson-Lewis V, Vukosavic S, Djaldetti R, Liberatore G, Offen D, Korsmeyer SJ, Przedborski S (2001) Bax ablation prevents dopaminergic neurodegeneration in the 1-methyl- 4-phenyl-1,2,3,6-tetrahydropyridine mouse model of Parkinson's disease. Proc Natl Acad Sci U S A 98:2837-2842.

Villani L, Beraudi A, Giuliani A, Poli A (2001) MPTP-induced apoptosis in the retina of goldfish. Neurotox Res 3:255-257.

Viswanath V, Wu Y, Boonplueang R, Chen S, Stevenson FF, Yantiri F, Yang L, Beal MF, Andersen JK (2001) Caspase-9 activation results in downstream caspase-8 activation and bid cleavage in 1-methyl-4-phenyl-1,2,3,6tetrahydropyridine-induced Parkinson's disease. J Neurosci 21:9519-9528.

Vocero-Akbani A, Lissy NA, Dowdy SF (2000) Transduction of full-length Tat fusion proteins directly into mammalian cells: analysis of $\mathrm{T}$ cell receptor activationinduced cell death. Methods Enzymol 322:508-521.

Vocero-Akbani A, Chellaiah MA, Hruska KA, Dowdy SF (2001) Protein transduction: delivery of Tat-GTPase fusion proteins into mammalian cells. Methods Enzymol 332:36-49.

Wadia JS, Stan RV, Dowdy SF (2004) Transducible TAT-HA fusogenic peptide enhances escape of TAT-fusion proteins after lipid raft macropinocytosis. Nat Med 10:310-315.

Weishaupt JH, Diem R, Kermer P, Krajewski S, Reed JC and Bahr M (2003) Contribution of caspase- 8 to apoptosis of axotomized rat retinal ganglion cells in vivo. Neurobiol Dis. 13:124-135.

Wender PA, Mitchell DJ, Pattabiraman K, Pelkey ET, Steinman L, Rothbard JB (2000) The design, synthesis, and evaluation of molecules that enable or enhance cellular uptake: peptoid molecular transporters. Proc Natl Acad Sci U S A 97:13003-13008

Wheeler DS, Dunsmore KE, Wong HR (2003) Intracellular delivery of HSP70 using HIV-1 Tat protein transduction domain. Biochem Biophys Res Commun 301:54-59.

Wong C, Ishibashi T, Tucker G, Hamasaki D (1985) Responses of the pigmented rabbit retina to NMPTP, a chemical inducer of parkinsonism. Exp Eye Res 40:509-519.

Wong HR, Mannix RJ, Rusnak JM, Boota A, Zar H, Watkins SC, Lazo JS, Pitt BR (1996) The heat-shock response attenuates lipopolysaccharide-mediated 
apoptosis in cultured sheep pulmonary artery endothelial cells. Am J Respir Cell Mol Biol 15:745-751.

Wu Y, Blum D, Nissou MF, Benabid AL, Verna JM (1996) Unlike MPP+, apoptosis induced by $6-\mathrm{OHDA}$ in PC12 cells is independent of mitochondrial inhibition. Neurosci Lett 221:69-71.

Xia XG, Harding T, Weller M, Bieneman A, Uney JB, Schulz JB (2001) Gene transfer of the JNK interacting protein-1 protects dopaminergic neurons in the MPTP model of Parkinson's disease. Proc Natl Acad Sci U S A 98:10433-10438.

Yang L, Matthews RT, Schulz JB, Klockgether T, Liao AW, Martinou JC, Penney JB, Jr., Hyman BT, Beal MF (1998) 1-Methyl-4-phenyl-1,2,3,6-tetrahydropyride neurotoxicity is attenuated in mice overexpressing Bcl-2. J Neurosci 18:81458152.

Yang Y, Tikhonov I, Ruckwardt TJ, Djavani M, Zapata JC, Pauza CD, Salvato MS (2003) Monocytes treated with human immunodeficiency virus Tat kill uninfected CD4(+) cells by a tumor necrosis factor-related apoptosis-induced ligand-mediated mechanism. J Virol 77:6700-6708.

Yazulla S. and Studholme K. M. (1997) Differential reinnervation of retinal bipolar cell dendrites and axon terminals by dopamine interplexiform cells following dopamine depletion with 6-OHDA. J Comp Neurol 382:535-545.

Yenari MA, Fink SL, Sun GH, Chang LK, Patel MK, Kunis DM, Onley D, Ho DY, Sapolsky RM and Steinberg GK (1998) Gene therapy with HSP72 is neuroprotective in rat models of stroke and epilepsy. Ann Neurol. 44:584-591.

Yenari MA, Liu J, Zheng Z, Vexler ZS, Lee JE, Giffard RG (2005) Antiapoptotic and anti-inflammatory mechanisms of heat-shock protein protection. Ann N Y Acad Sci 1053:74-83.

Yin W, Cao G, Johnnides MJ, Signore AP, Luo Y, Hickey RW, Chen J (2006) TATmediated delivery of $\mathrm{Bcl}-\mathrm{xL}$ protein is neuroprotective against neonatal hypoxic-ischemic brain injury via inhibition of caspases and AIF. Neurobiol Dis 21:358-371.

Zhong LT, Sarafian T, Kane DJ, Charles AC, Mah SP, Edwards RH, Bredesen DE (1993) bcl-2 inhibits death of central neural cells induced by multiple agents. Proc Natl Acad Sci U S A 90:4533-4537. 
Zhou SH, He DC, Zhang LJ and Chen LD (2006) Prokaryotic expression of fusion protein TAT-EDAG and study on its transduction activity. Sheng Wu Gong Cheng Xue Bao. 22:598-603. 


\section{PUBLICATIONS}

Nagel F. (2004): Estimation of consumption rate of burbot (Lota lota (L.)) in a summer-warm lowland river, the lower Oder River, Germany. Master thesis, University of Rostock, 126 p., Signature: 2004 W 9.

Nagel F., Falkenburger B., Tönges L., Kowsky S., Pöppelmeyer C., Schulz, J.B., Bähr, M. and Dietz G. P. H. (2008): Tat-Hsp70 protects dopaminergic neurons against MPTP induced cell death in primary midbrain cultures and substantia nigra (in press, Journal of Neurochemistry).

Nagel F., Dohm C.P., Bähr M., Wouters F.S. and Dietz G.P.H (2008): Quantitative evaluation of chaperone activity and neuroprotection by different preparations of a cell-penetrating Hsp70 (accepted for publication, Journal of Neuroscience Methods).

Hölker F.; Nagel F. and Wolter C. (2008): In situ estimation of gastric evacuation and consumption rates of burbot (Lota lota (L.)) at high temperatures (in revision, Animal Biology).

Nagel F., Bähr M. and Dietz G. P. H. (2008): Dopaminergic amacrine interneurons in the mouse retina are resistant against various Parkinsonian toxins (submitted, Neuroscience Letters)

Doeppner T.R., Nagel F., Tönges L., Dietz G.P.H., Weise J., Bähr M. and Schwarting S. (2008): Tat-Hsp70-mediated neuroprotective effects on endogenous neurogenesis after focal cerebral ischemia (in preparation for Stroke) 


\section{ABSTRACTS / POSTERS}

Florian Nagel, Lars Tönges, Christoph P. Dohm, Fred S. Wouters, Sundar Ganesan, Mathias Bähr and Gunnar P. H. Dietz (2005): Cell penetrating peptide-enhanced delivery of heat shock protein 70 in in vitro models for neurodegenerative diseases. Proceedings FENS/Hertie Winter School in Kitzbühel, Austria, 11-18.12.2005.

Nagel F., Tönges L., Dohm C. P., Wouters F. S., Ganesan S., Bähr M. and Dietz G. P. H. (2006): Tat-mediated delivery of heat shock protein 70 in models of neurodegenerative diseases. FENS Abstr., vol.3, A057.18, 2006, Vienna, Austria, 0812.07.2006

Florian Nagel, Björn H. Falkenburger, Sebastian Kowsky, Charlotte Pöppelmeyer, Jörg B. Schulz, Mathias Bähr and Gunnar P. H. Dietz (2006): Application of TatHsp70 in the MPTP-mouse model for Parkinson's Disease. $7^{\text {th }}$ Meeting of the German Neuroscience Society in Göttingen, Germany, 29.03-01.04.2007.

Florian Nagel, Björn H. Falkenburger, Christoph P. Dohm, Lars Tönges, Fred S. Wouters, Jörg B. Schulz, Mathias Bähr and Gunnar P. H. Dietz (2007): Cellpermeable heat shock protein 70 is neuroprotective in models of Parkinson's disease. Molecular Mechanisms of Neurodegeneration in Antigua, Antigua and Barbuda, 03-06.12.2007. 


\section{CURRICULUM VITAE}

Personal details

Name: $\quad$ Florian Nagel

Date of Birth: $\quad$ April $9^{\text {th }} 1980$

Nationality: $\quad$ German

Education

1998

High school final examinations

1998 - 1999 Military Service in Bad Segeberg, Germany.

1999 - $2004 \quad$ Undergraduate student at the University of Rostock.

2004

Masters Degree (Diplom) in Biology.

Thesis: Estimation of the consumption rate of burbot (Lota lota

(L.)) in a summer-warm lowland river, the lower Oder River, Germany (grade: 1.1).

2005 - 2008 Ph.D. student at the Göttingen University Medical Center, Department of Neurology.

2008

Ph.D. thesis: Cell penetrating peptide-enhanced delivery of heat shock proteins in models of neurodegeneration. 